\title{
AcrllA22 is a novel anti-CRISPR that impairs SpyCas9 activity by relieving DNA torsion of target plasmids
}

Kevin J. Forsberga,b,*, Danica T. Schmidtke ${ }^{a}$, Rachel Werthera, Deanna Hausman ${ }^{a}$, Barry L. Stoddard $^{\mathrm{a}}$, Brett K. Kaiser ${ }^{\mathrm{a}, \mathrm{c}}$, Harmit S. Malik ${ }^{\mathrm{a}, \mathrm{b}}$

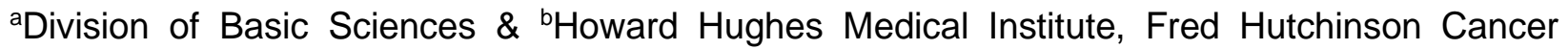
Research Center, Seattle, WA, 98109 USA; 'Department of Biology, Seattle University, 901 12th Avenue, Seattle, WA 98122, USA

Running title: Altering DNA torsion can protect plasmids from Cas9

*Address correspondence to: Kevin J. Forsberg, 1100 Fairview Avenue N. A2-205, Seattle WA 98109; (206) 667-4512; email: kforsber@fredhutch.org 


\section{Abstract}

To overcome CRISPR-Cas defense systems, many phages and mobile genetic elements encode CRISPR-Cas inhibitors called anti-CRISPRs (Acrs). Nearly all mechanistically characterized Acrs directly bind their cognate Cas protein to inactivate CRISPR immunity. Here, we describe AcrllA22, an unconventional Acr found in hypervariable genomic regions of Clostridial bacteria and their prophages from the human gut microbiome. Uncovered in a functional metagenomic selection, AcrllA22 does not bind strongly to SpyCas9 but nonetheless potently inhibits its activity against plasmids. To gain insight into its mechanism, we obtained an X-ray crystal structure of AcrllA22, which revealed homology to PC4-like nucleic-acid binding proteins. This homology helped us deduce that acrllA22 encodes a DNA nickase that relieves torsional stress in supercoiled plasmids, rendering them less susceptible to SpyCas9, which is highly dependent on negative supercoils to form stable R-loops. Modifying DNA topology may provide an additional route to CRISPR-Cas resistance in phages and mobile genetic elements.

Introduction

CRISPR-Cas systems in bacteria and archaea confer sequence-specific immunity against invading phages and other mobile genetic elements (MGEs) ${ }^{1,2}$. In response, MGEs can circumvent CRISPR-Cas systems by evading CRISPR immunity. In its simplest form, evasion requires only a single mutation to a CRISPR target site, which allows a phage or MGE to escape immune recognition ${ }^{3}$. However, CRISPR-Cas systems routinely acquire new spacer sequences to target new sites within phage and MGE genomes ${ }^{1}$. This means that any single-site evasion strategy is likely to be short-lived. Thus, phages also employ forms of CRISPR-Cas evasion that are less easily subverted. For instance, some jumbophages assemble a proteinaceous, nucleuslike compartment around their genomes upon infection, allowing them to overcome diverse bacterial defenses, including CRISPR-Cas and restriction-modification (RM) systems ${ }^{4,5}$. Similarly, other phages decorate their DNA genomes with diverse chemical modifications, which can prevent Cas nucleases from binding their target sequence, such as the glucosylated cytosines used by phage T4 of Escherichia coli ${ }^{\text {. }}$.

MGEs may also overcome CRISPR-Cas systems by inactivating, rather than evading, CRISPR immunity. MGEs encode diverse CRISPR-Cas inhibitors called anti-CRISPRs (Acrs), which allow them to overcome CRISPR-Cas systems and infect otherwise immune hosts ${ }^{7}$. Most known Acrs bind Cas proteins and inhibit Cas activity by either restricting access to target DNA, preventing necessary conformational changes, or inactivating critical CRISPR-Cas components $^{8,9}$. The direct inactivation of Cas proteins by Acrs has proven an effective and widespread strategy for overcoming CRISPR immunity ${ }^{10}$.

Recent genetic, bioinformatic, and metagenomic strategies have identified many Acrs that independently target the same CRISPR-Cas system ${ }^{7-10}$. Yet, most CRISPR-Cas systems are not inhibited by known Acrs ${ }^{10}$. Thus, many undiscovered strategies to inhibit or evade CRISPR-Cas systems probably exist in nature. Indeed, over half of the genes in an average phage genome have no known function ${ }^{11}$. To uncover new counter-immune strategies, we recently devised a high-throughput functional metagenomic selection to find genes that protect a target plasmid from Streptococcus pyogenes Cas9 (SpyCas9), the variant used most frequently for genome editing ${ }^{12}$. Our selection strategy was designed to reveal any gene capable of overcoming SpyCas9 activity in this system, regardless of mechanism. With this approach, we previously described a new 
phage inhibitor of SpyCas9, called AcrllA11, which acts via a novel mechanism and is prevalent across human gut microbiomes ${ }^{12}$.

Here, we describe AcrllA22, which was the second most common Acr candidate recovered from our original functional selection. AcrllA22 encodes a 54 amino acid protein that impairs SpyCas9 activity. We observe that homologs of acrlIA22 are found in hypervariable loci in phage and bacterial genomes. Unlike most other Acrs, AcrllA22 does not bind strongly to SpyCas9 in vitro. Instead, guided by an X-ray crystal structure of AcrlIA22, we show that AcrlIA22 encodes a DNA nickase. By nicking a supercoiled plasmid substrate and relieving its torsional stress, AcrllA22 renders the target less susceptible to SpyCas9 activity. AcrllA22 thus represents a novel mechanism of SpyCas9 evasion, which capitalizes on SpyCas9's uniquely stringent requirement for negative supercoils to form a productive $\mathrm{R}$-loop ${ }^{13-16}$. Such a resistance mechanism could be accessible to diverse MGEs, providing a route to CRISPR-Cas tolerance in many genetic contexts.

\section{Results}

\section{Functional selection reveals a novel anti-CRISPR protein, AcrlIA22}

We recently carried out a functional selection for SpyCas 9 antagonism, recovering clones from metagenomic libraries that could potently inhibit SpyCas ${ }^{12}$. In this two-plasmid setup, we used an inducible SpyCas9 on an expression plasmid to cleave the kanamycin resistance $\left(\operatorname{Kan}^{R}\right)$ gene of a second 'target' plasmid. We then grew cultures in SpyCas9-inducing conditions and measured the proportion of colony forming units (cfus) that remained kanamycin resistant (Figure $1 \mathrm{~A})$. This proportion is a measure of how many clones retained their target plasmid and thus how effectively that plasmid withstood SpyCas9 attack. In our previously published work, we describe AcrllA11, a novel anti-CRISPR from a metagenomic clone named F01A_2 (Genbank ID MK637582.1), which was the most abundant from functional selection of a human fecal microbiome $^{12}$. This functional selection also revealed a second protective clone, F01A_4 (Genbank ID MK637587.1). Together, these two contigs (F01A_2 and F01A_4) accounted for $>96 \%$ of the normalized read coverage and were the most abundant clones recovered from this library.

The F01A_4 contig is $685 \mathrm{bp}$ long, encodes three potential open reading frames (ORFs), and confers complete protection against SpyCas9, with plasmid retention equaling that of an uninduced SpyCas9 control (Figure 1B). To determine the genetic basis for SpyCas9 antagonism in this contig, we introduced an early stop codon into each of the three potential ORFs and analyzed how these mutations affected the contig's ability to protect a target plasmid from SpyCas9. We found that an early stop codon in orf 1 reduced the proportion of $K^{R} n^{R}$ cfus by a factor of $10^{5}$, matching the value observed for an empty vector control (Figure 1B). Furthermore, expression of orf_1 alone was also sufficient for SpyCas9 antagonism (Figure 1C), protecting a target plasmid from SpyCas9 cleavage as well as the potent SpyCas9 inhibitor, AcrllA4. In this assay, orf_ 1 was slightly toxic when singly expressed in E. coli, reducing growth rate by $7 \%$ (Supplemental Figure 1). Combined, our results indicate that orf 1 completely accounts for the SpyCas9 protection phenotype of contig F01A_4.

One trivial mechanism by which orf_ 1 could apparently antagonize SpyCas9 in our functional assay would be to lower its expression. To address this possibility, we carried out two experiments. First, we swapped the spycas 9 gene for gfp in our expression vector and asked whether orf 1 induction impacted fluorescence output. We saw no change in fluorescence upon 
orf_1 induction, indicating that orf_1 neither suppressed transcription from our expression vector nor altered its copy number (Supplemental Figure 2). Second, we used Western blots to test whether orf 1 expression impacted SpyCas9 protein levels through the course of a plasmid protection assay. We used a crRNA that did not target our plasmid backbone to ensure that orf_1 expression remained high and its potential impact on SpyCas9 expression levels would be most evident. We observed that orf_1 expression had no meaningful effect on SpyCas9 expression at any timepoint. Thus, we conclude that orf_1 does not impact SpyCas9's translation or degradation rate (Supplemental Figure 2). Therefore, orf_1 must act via an alternative mechanism to inhibit SpyCas 9 activity. Based on these findings, we conclude that orf 1 encodes a bona fide antiCRISPR protein and hereafter refer to it as acrlIA22.

Next, we investigated whether acrlIA22 could also allow phages to escape from SpyCas9 immunity (Supplemental Figure 3). We measured SpyCas9's ability to protect E. coli from infection by phage $\mathrm{Mu}$, in the presence or absence of acrllA22. As a control, we carried out similar phage infections in the presence or absence of the well-established SpyCas9 inhibitor, acrllA4. As anticipated, SpyCas9 significantly impaired Mu when targeted to the phage's genome but not if a non-targeting CRISPR RNA (crRNA) was used. Consistent with previous findings ${ }^{12}$, phage $\mathrm{Mu}$ could infect targeting and non-targeting strains equally well when we expressed acrIIA4, indicating that SpyCas9 immunity was completely abolished by this acr. However, acrlIA22 could only partially restore the infectivity of phage Mu across multiple experimental conditions (Supplemental Figure 3). We therefore conclude that acrllA22 only weakly protects Mu phage from SpyCas9 whereas it strongly protects plasmids against SpyCas9 cleavage.

\section{AcrllA22 homologs are present in hypervariable regions of bacterial and prophage genomes}

AcrllA22 is 54 amino acids in length and has no sequence homology to any protein of known function, including all previously described Acrs. We examined the distribution of acrllA22 homologs in NCBI's NR and WGS databases but found just seven hits, limiting our ability to make evolutionary inferences about its origins or prevalence. We therefore expanded our search to include IMG/VR, a curated database of cultured and uncultured DNA viruses ${ }^{17}$, and assembly data from a meta-analysis of 9,428 diverse human microbiome samples ${ }^{18}$. With additional homologs from these databases in hand, we found that the majority of acrllA22 homologs exist in either of two genomic contexts: prophage genomes or small, bacterial genomic islands (Figures $2 \mathrm{~A}, 2 \mathrm{~B})$. The original metagenomic DNA fragment from our selection, F01A_4, shared perfect nucleotide identity with one of these genomic islands (Figure 2B).

Because most acrs are found in phage genomes, we first examined the prophages that encoded AcrllA22 homologs. These prophages were clearly related, based on many homologous genes and a similar genome organization (Figure 2A). Despite their similarity, we found these prophages inserted into several different bacterial loci, including one site between the bacterial genes purF and radC (locus \#3, Figure 2A). This prophage insertion site is notable because it is nearly identical to the highly conserved sequences that flanked acrllA22-encoding bacterial genomic islands (Figure 2B). Due to their common genomic loci, we hypothesized that the apparently bacterial acrlIA22 homologs in these genomic islands diverged from a common phage ancestor, encoded by a prophage that previously integrated at this locus. We speculate that the original acrllA22-encoding bacterial genomic island was left behind following the incomplete excision of an ancestral, acrllA22-encoding prophage. Supporting this hypothesis, acrllA22 
homologs are always found at the end of prophage genomes, near their junction with a host bacterial genome (Figure 2A).

To better understand acrllA22's gene neighborhood, we again searched the raw assemblies of over 9,400 human microbiomes for more examples of these genomic islands ${ }^{18}$, but did not include acrIIA22 in our second search criteria. Instead, we focused on the recent evolutionary history of these bacterial genomic islands by only considering contigs with $\geq 98 \%$ nucleotide identity to purF and radC, the conserved genes that flanked the genomic islands. This search yielded 258 contigs. Aligning these sequences revealed that each contig encoded a short, hypervariable region of small ORFs which was flanked by conserved genomic sequences (Figure 2B). In total, we observed 128 unique examples of these hypervariable loci, which displayed considerable gene turnover, resulting in 54 distinct gene arrangements among the 128 unique loci. Despite not including them in our search strategy, acrllA22 homologs were universally conserved in all 128 unique genomic islands whereas no other gene was present in more than two-thirds of the 54 distinct gene arrangements (Figure 2C). Based on this finding, we infer that the arrival of acrlIA22 preceded the diversification seen at this locus and that its homologs have been retained since, despite the considerable gene turnover that has occurred subsequently.

Though most ORFs in these islands were of unknown function, many had close homologs in the genomes of nine representative acrllA22-encoding phage (dashed boxes in Figure 2A, phage icons in Figure $2 \mathrm{C}$ ). This suggests that phages continue to supply the genetic diversity seen at these hypervariable genomic loci. These rapid gene gains and losses probably occur as they do in other genomic islands, via recombination between this locus and related MGEs that infect the same host bacterium without the MGE necessarily integrating into the locus ${ }^{19}$. Taken together, our data suggest that an incomplete prophage excision event left acrllA22 behind in a bacterial genomic locus, which then diversified via gene exchange with additional phage genomes (Figure 2D).

In prophage genomes, acrllA22 homologs were found in hypervariable regions, near the junction with the host bacterial genome (Figure 2A). Both features imply these loci are subject to higher than average rates of recombination. Despite this, we could find no gene consistently present within or outside of these genomic islands that could account for their hypervariable nature (e.g. an integrase, transposase, recombinase, or similar function that is typically associated with genomic islands ${ }^{20}$ ). Instead, acrllA22 was the only gene conserved at this locus. If it could somehow promote recombination, either alone or with other factors, this could account for the high rates of gene exchange observed adjacent to acrllA22 in phage and bacterial genomes (Figures 2A, 2B).

In total, we identified 30 unique acrllA22 homologs, 25 of which were predicted to originate from the unnamed Clostridial genus, CAG-217 (Figure 3A). Because acrs are only beneficial to phages if they inhibit CRISPR-Cas activity, they are typically found only in taxa with a high prevalence of susceptible Cas proteins ${ }^{9}$. If AcrllA22 functions naturally as an Acr, we would predict that Cas9-encoding, type II-A CRISPR-Cas systems like SpyCas9 would be common in CAG-217 bacteria. To test this idea, we examined 779 draft assemblies of CAG-217 genomes and found that 179 of the 181 predicted CRISPR-Cas systems in CAG-217 genomes were Cas9encoding, type II-A systems. This enrichment for Cas9 is particularly striking for a Clostridial genus, as Clostridia rarely encode Cas9. Instead, they typically encode other CRISPR-Cas defenses $^{21}$. Thus, the distribution of CRISPR-Cas systems in CAG-217 genomes supports our hypothesis that acrllA22 functions natively as an acr. 
We also found evidence that Cas9 is active in CAG-217 bacteria. Prophages from CAG-217 encode 78 type II-A Acrs (homologs of AcrllA7, AcrllA17, and AcrlIA21), suggesting they are actively engaged in an arms race with Cas9-based defenses in these bacteria. We even found one example where homologs of acrlIA17 and acrllA22 were located within one kilobase of each other in a prophage genome (Supplemental Figure 4$)^{22}$. Since phages often aggregate acrs in the same genomic locus ${ }^{23}$, this observation independently supports our hypothesis that CAG-217 prophages encode acrlIA22 homologs to inhibit type II-A CRISPR-Cas systems.

We next tested whether the ability to inhibit type II-A CRISPR-Cas systems was a shared property of acrllA22 homologs from CAG-217 bacteria. To do so, we selected acrllA22 homologs that spanned the phylogenetic diversity present among CAG-217 genomes (Figure 3A) and tested their ability to protect a target plasmid from SpyCas9 elimination. These analyses revealed that each acrlIA22 homolog from CAG-217 could antagonize SpyCas9 activity at least partially (Figure 3B). This conservation of anti-SpyCas9 activity among divergent AcrlIA22 homologs (for example, sharing only $56.9 \%$ identity), suggests that they may broadly inhibit Cas9. Broad inhibition has been seen for some other type II-A Acrs ${ }^{12}$ and can occur either by targeting a conserved feature of Cas9 or by inhibiting Cas9 via an indirect mechanism that it cannot easily evade.

\section{AcrllA22 functions via a non-canonical mechanism}

Almost all characterized Acrs inhibit their cognate Cas proteins via direct binding without the involvement of additional co-factors; as a result, they exhibit strong inhibitory activity when tested in vitro (Supplemental Table 1). To determine if this was the case for AcrllA22, we purified it from E. coli and asked whether it could bind and inhibit SpyCas9. To test for binding, we asked whether a tagged AcrllA22 co-precipitated with SpyCas9 when mixed as purified proteins. Unlike AcrllA4, which binds strongly to SpyCas 9 and inhibits its activity in vitro, we could detect little to no binding between AcrllA22 and SpyCas9, regardless of whether a single-guide RNA (sgRNA) was included or not (Supplemental Figure 5). We also observed that AcrllA22 had no impact on SpyCas9's ability to cleave linear, double-stranded DNA (dsDNA), even when AcrllA22 was included at substantial molar excess over SpyCas9 (Supplemental Figure 6). These results suggest that, at least in isolation, AcrllA22 cannot bind and inhibit SpyCas9. Thus, AcrlIA22 lacks the predominant biochemical activities exhibited by previous Acrs that have been mechanistically characterized.

We therefore considered the possibility that AcrllA22 encodes an unconventional antiCRISPR that acts via a non-canonical mechanism. However, AcrllA22 homologs had no sequence homology to other characterized proteins, which would have provided clues about AcrllA22 activity and biochemical mechanisms. Anticipating that structural homology might provide some insight, we solved AcrllA22's structure using X-ray crystallography. We first built a homology model from AcrlIA22's primary sequence with Robetta. We then used this model for molecular replacement to solve its structure at $2.80 \AA ̊$ resolution (PDB:7JTA). The asymmetric unit in AcrlIA22's crystal comprises two monomers stacked end-to-end, with each monomer folding into a four-stranded $\beta$-sheet (Figure 4A, Table 1). A DALI structure-structure search revealed that the AcrllA22 monomer is similar to members of the newly recognized PC4-like structural fold (Figure 4B, Supplemental Table 2). PC4-like proteins have independently evolved in all domains of life, typically adopt a $\beta-\beta-\beta-\beta-\alpha$ topology, and often homodimerize to bind diverse RNA and DNA species using variably positioned $\beta$-sheets ${ }^{24}$. 
Despite crystallizing as a homodimer, AcrllA22 migrated at a size substantially larger than its molecular weight by size exclusion chromatography (SEC) (Figure 4C). This suggested that AcrllA22 may oligomerize in vivo. Structural evidence supported the same conclusion, as AcrllA22 was predicted to form a stable tetramer when analyzed with PISA, a tool for inferring macromolecular assembles from crystalline structure ${ }^{25}$ (Figures 4D, 4E). This putative tetramer has a molecular mass consistent with that observed by SEC and comprises pairs of outwardfacing, concave $\beta$-sheets, as is seen in other PC4-like proteins ${ }^{24}$. Interestingly, many PC4-like proteins bind nucleic acids using similar concave $\beta$-sheets and, in some instances, form higherorder oligomers as a necessary step for binding DNA or RNA ${ }^{24}$. Consistent with this possibility, adjacent $\beta$-sheets along each outward face of the putative AcrllA22 tetramer form a groove that could potentially accommodate a nucleic acid substrate (Figure 4E). Thus, even though AcrllA22 lacks the alpha-helix typically seen in PC4-like proteins, its other structural and functional attributes led us to suspect that AcrllA22 also interacted with nucleic acids.

Our tetramer model predicts that a four amino acid interface at the C-terminus of AcrllA22 is required for adjacent $\beta$-sheets to bind one another and form a grooved, oligomeric structure (Figures 4D, 4F). We predicted that a two-residue, C-terminal truncation of AcrllA22 would disrupt this interface (Figure 4F). To test this prediction, we examined the oligomeric state of this 2-aa AcrllA22 deletion mutant. Consistent with our hypothesis, we found that these AcrllA22 complexes migrated at about half the size of their wild-type counterparts by SEC (Figure 4C), suggesting that this C-terminal interface is required to progress from a two to four-membered oligomer. Moreover, we found that the 2-aa deletion mutant was also impaired for SpyCas9 antagonism in our plasmid protection assay (Figure 4G). Thus, this C-terminal motif is necessary for protection from SpyCas9 and higher-order oligomerization, suggesting that oligomerization may be necessary for AcrllA22's anti-SpyCas9 activity.

\section{AcrllA22 is a DNA nickase that relieves torsion of supercoiled plasmids}

Our structural analyses indicated that AcrlIA22 is a PC4-like nucleic acid-interacting protein. Like AcrllA22, many PC4-like proteins are encoded in phage genomes. Among these is AcrllA22's closest structural relative in the PC4 family: a predicted single-stranded binding (SSB) protein from phage T5 (Figure 4B) ${ }^{26}$. This putative SSB protein has been predicted to directly stimulate recombination during the recombination-dependent replication of phage T5's genome ${ }^{27}$. This prediction, together with our inference from genomic analyses (Figure 2), led us to hypothesize that AcrlIA22 may have similar recombination-stimulating activity. Indeed, other PC4like proteins have been observed experimentally to unwind duplex DNA, a function consistent with their proposed roles in transcription and recombination ${ }^{24,28}$. Therefore, we investigated whether AcrllA22 might interact with duplexed DNA in a manner consistent with its putative recombinogenic properties.

We first asked whether we could detect any biochemical effect of acrllA22 on a doublestranded DNA (dsDNA) target plasmid in vivo. In this experiment, we considered three acrllA22 genotypes: the wild-type sequence, a null mutant with a single base pair change to create an early stop codon, and the 2-aa truncation mutant that we previously showed was defective for oligomerization (Figure 4C) and SpyCas9 antagonism (Figure 4G). We then grew overnight cultures of plasmids expressing each genotype, purified plasmid DNA, and analyzed its topology using gel electrophoresis (Figure 5A). As is typical for plasmid purifications from $E$. coli, the plasmid encoding the null mutant was predominantly recovered in a supercoiled form. In contrast, AcrllA22 expression shifted much of the target plasmid to a slowly migrating form, consistent with 
an open-circle conformation. These findings suggest that AcrllA22 expression could relieve plasmid supercoiling, hinting at a potential DNA nickase activity. We also found that the 2-aa truncation mutant was impaired for this putative nickase activity, consistent with this mutant's compromised oligomerization and anti-Cas9 activities (Figure 4G).

Because acrllA22 expression altered plasmid topology in vivo, we next asked whether purified AcrllA22 had an impact on a plasmid DNA substrate in vitro. By gel electrophoresis, we observed that AcrllA22 shifted a supercoiled plasmid to a slowly migrating form in a time and concentrationdependent manner (Figures 5B, 5C, Supplemental Figure 7). For comparison, we also treated a plasmid with the nickase Nb.BssSI, yielding a band that migrated at the same position as the putatively open-circle product generated via AcrllA22 activity (Figure 5B). Extended incubation times and high concentrations of AcrllA22 resulted in conversion of plasmids to a linearized DNA product, consistent with a nickase-like nuclease activity acting on both strands of DNA (Figure 5B, Supplemental Figure 7). AcrlIA22's nickase activity was strongly stimulated in the presence of $\mathrm{Mn}^{2+}, \mathrm{Co}^{2+}$, and $\mathrm{Mg}^{2+}$, weakly with $\mathrm{Ni}^{2+}$ and $\mathrm{Zn}^{2+}$, but not at all with $\mathrm{Ca}^{2+}$ (Supplemental Figure 8). Consistent with our in vivo observations, we found that the 2-aa deletion mutant was impaired for nickase activity, relative to wildtype AcrllA22 (Figure 5D).

Our in vitro and in vivo findings suggest that AcrllA22 is responsible for the change in plasmid topology observed in bacterial cells. To confirm that the observed gel-shift was the result of AcrllA22 nickase activity and not protein-bound DNA, we purified an AcrllA22-treated plasmid with phenol-chloroform and re-examined it by gel electrophoresis. We observed that the nicked form of the plasmid persisted through purification, establishing AcrlIA22 as a bona-fide nickase (supp figure 8). Therefore, based on both in vitro and in vivo findings, we conclude that that acrllA22 encodes a nickase protein that relieves the torsional stress of supercoiled plasmids.

\section{AcrllA22's nickase activity impairs SpyCas9}

Having established that AcrllA22 is a DNA nickase, we next investigated whether this biochemical activity correlated with its ability to inhibit SpyCas9. If this were the case, it would explain how AcrllA22 protected plasmids from SpyCas9 without directly binding the Cas protein. We therefore tested the consequences of expressing AcrlIA22 on a target plasmid in the presence of SpyCas9. As before, we began by comparing overnight plasmid purifications of a target plasmid expressing AcrlIA22, a null mutant with an early stop codon, or the 2-aa AcrllA22 truncation mutant. However, this time, we also subjected the plasmid to SpyCas9 targeting during bacterial growth. We were unable to recover the negative control target plasmid after overnight growth, implying that this target plasmid was eliminated by SpyCas9 (Figure 6A). The 2-aa truncation mutant was also eliminated by SpyCas9, indicating these residues are important for function. In contrast, SpyCas9 did not eliminate a target plasmid that expressed full-length AcrllA22 (Figure 6A), consistent with AcrlIA22's previously established capacity to protect against SpyCas9 (Figure $1 \mathrm{C})$.

To be effective, a CRISPR-Cas system must eliminate its target at a faster rate than the target can replicate ${ }^{29}$. Our findings raised the possibility that AcrllA22 modifies a target plasmid into a SpyCas9-resistant conformation to win this 'kinetic race' against SpyCas9, potentially shifting the equilibrium to favor plasmid persistence instead of elimination. To test this kinetic race model, we asked whether a plasmid that had been pre-treated with AcrllA22 could resist digestion by SpyCas9 in vitro. Therefore, we purified the open-circle plasmid that resulted from AcrllA22 pretreatment and determined how efficiently it was cleaved by SpyCas9 compared to an unmodified, 
supercoiled plasmid (Figure 6B). SpyCas9 showed a clear preference for cleaving the supercoiled substrate versus the AcrllA22-treated open-circle plasmid (Figure 6C, Supplemental Figure 9). An open-circle plasmid pre-treated with the nickase Nb.Bss.SI was similarly recalcitrant to SpyCas9 digestion. Taken together, our findings suggest that relieving DNA torsion provides the mechanistic explanation for AcrlIA22's ability to inhibit SpyCas9 in vivo.

Our findings also help explain why AcrllA22 is more adept at protecting plasmids than phages from SpyCas9 in our system. Because plasmids are maintained as circular, extrachromosomal elements, they are more likely to undergo torsional change when nicked than phages or transposons, which are often linear or spend significant time integrated into their host's genome. Additionally, linear DNA experiences minimal torsional stress and is therefore less susceptible than supercoiled plasmids to cleavage by SpyCas $9^{15}$. This likely explains why AcrllA22 failed to protect a linear dsDNA substrate from SpyCas9 in vitro (Supplemental Figure 6), as there is very little torsional stress for it to relieve in this substrate. Importantly, in vitro experiments indicate that Cas9 requires a higher degree of negative supercoiling to provide the free energy needed for Rloop formation than type I CRISPR-Cas systems ${ }^{13}$. In vivo observations also show that DNA supercoiling affects the recruitment of SpyCas9 to its target site in bacteria ${ }^{14}$. This suggests that Cas9 may be particularly susceptible to changes in DNA torsion. Thus, factors like the AcrllA22 nickase, which modify DNA torsion, may provide a general means to protect against Cas9.

\section{Discussion}

In this study, we identify and characterize acrllA22, a previously undescribed gene that can antagonize SpyCas9. We show that AcrllA22 homologs have proliferated in genomes of CAG217 bacteria, which have a high prevalence of Cas9 homologs. Using a combination of structural and biochemical studies, we show that AcrllA22 acts by nicking supercoiled DNA to relieve torsional stress on a target plasmid, thereby impairing SpyCas9 activity in vivo and in vitro. Taken together, our data suggest that DNA topology represents a new battleground in the evolutionary arms race between CRISPR-Cas systems and MGEs. Because Cas9 is more susceptible to evasion via changes to DNA topology than other CRISPR-Cas systems ${ }^{13}$, it may be more disadvantaged than other bacterial defense systems in this arms race. Additionally, DNA topology is dynamically regulated in phages, plasmids and other MGEs. This means that topologymodifying factors already exist in diverse MGEs that could have secondary effects on CRISPRCas activity and thus prove useful in the context of a molecular arms race ${ }^{30,31}$. For instance, though not studied in the context of bacterial defense systems, the fitness of phage T4 is improved via the expression of an accessory protein that modifies DNA supercoiling and the propensity of $\mathrm{R}$-loops to form ${ }^{32}$. Other phages, such as those in the T5-like family, incorporate regular nicks into their genome, the function of which has eluded description for over 40 years ${ }^{33}$. Based on our findings, we hypothesize that phages and MGEs targeted by Cas9 exploit factors that modify DNA topology as a tactic to evade host immunity.

Functional selections like ours are biased towards identifying genes that work well in a heterologous context. For example, even though AcrllA22 is encoded on the genome of a genetically intractable bacterium, we could identify it using a functional metagenomic selection for SpyCas9 antagonism in E. coli. Although we have characterized its activities in E. coli and in vitro, it remains formally possible that AcrlIA22 functions differently in its native context. For instance, we cannot rule out the possibility that AcrlIA22 might interact with a Cas9 protein from a CAG217 bacterium. Alternatively, AcrlIA22's anti-Cas9 activity might be related to a native recombinogenic function (Figure 2). As precedent for this idea, CRISPR-Cas evasion was recently 
demonstrated for homologs of the recombination proteins Red $\beta$ and $\lambda$ Exo in Vibrio cholerae ${ }^{34}$. Nevertheless, the heterologous behavior of AcrllA22 in E. coli is clearly sufficient for SpyCas9 antagonism in vivo and its nickase activity can protect plasmids from SpyCas9 in vitro. Furthermore, an AcrllA22 mutant that is partially defective for nickase activity in vitro (Figure 5D) is $\sim 1,000$-fold less effective at protecting a plasmid from SpyCas9 in vivo (Figure 4G). This indicates that modest changes in nickase activity can have major consequences for plasmid survival, which is consistent with our kinetic race model (Figure 6B) and previous observations that non-linear equilibrium dynamics determine whether an MGE withstands CRISPR-Cas immunity ${ }^{29}$.

Our results suggest that proteins that affect DNA torsion may also enable Cas9 antagonism. For example, in addition to AcrllA22, the Nb.BssSI nickase was also capable of protecting a plasmid from SpyCas9 in vitro. Yet, despite the regular occurrence of nickases in nature, functional selections for anti-Cas 9 activity have not previously recovered these enzymes ${ }^{12,35}$. We speculate that AcrllA22 treads a fine balance between activity and toxicity; its nickase activity is high enough to antagonize SpyCas9 in a kinetic race, but not so high that it would be toxic to the host cell (Supplemental Figure 1). Its oligomerization may represent an important mechanism to control nickase activity and suppress host toxicity. Studies of other phage- and bacterial-encoded nickase proteins may provide additional insight into whether AcrllA22 proteins have additional properties that render them to be especially well-suited to antagonize SpyCas9.

Is AcrlIA22 a true anti-CRISPR? AcrlIA22 lacks features that are typical of conventional Acrs, such as the ability to bind Cas proteins or to inhibit CRISPR-Cas activity as a purified protein. However, other Acr proteins also lack these features. For example, the well-characterized SpyCas9 antagonist AcrlIA1 does not inhibit purified SpyCas9, but instead stimulates Cas9 degradation ${ }^{36}$. Similarly, AcrllA7 does not appear to bind SpyCas9 but can nevertheless inhibit it in vitro via an unknown mechanism ${ }^{35}$. Indeed, anti-CRISPR proteins are defined by a common strategy and outcome rather than by a common biochemical mechanism. Our finding that AcrllA22 is encoded by prophages as a single gene that strongly protects plasmids and weakly protects phages from SpyCas9 (Figure 3B, Supplemental Figure 4) makes it much more similar to other $\mathrm{Acrs}^{23}$ and distinct from non-canonical CRISPR-Cas evasion strategies like DNA glucosylation $^{6}$ or homologous recombination ${ }^{34}$.

AcrllA22 does not appear to provide the same potency of Cas9 inhibition as some other characterized Acrs, particularly in protecting phage Mu. However, potent inhibition is not a prerequisite for effective anti-CRISPR activity. Indeed, selection can favor weak anti-CRISPRs over strong ones in mixed phage populations ${ }^{37}$. Even in cases where mechanisms for Cas 9 evasion are weak (Supplemental Figure 3), they may nonetheless confer substantial benefit. For example, slowing down Cas 9 cleavage could increase the time and probability for escape mutants to arise (e.g. Cas9 target-site variants ${ }^{1}$, deletion mutants ${ }^{34}$ ), allow for additional Acr expression ${ }^{38,39}$, or permit further genome replication to overwhelm CRISPR-Cas immunity ${ }^{29}$. This phenomenon weak tolerance giving rise to long-term resistance - is reproducibly observed in cases of strong selective pressure. For instance, in the context of antibiotic resistance, the expression of QNR pentapeptide proteins in many human pathogens can provide low-level drug tolerance, extend survival, and allow time for additional mutations to develop that completely resist quinolone antibiotics $^{40}$.

As the use of functional metagenomics to study phage-bacterial conflicts grows more common, many novel genes and mechanisms for CRISPR-Cas inhibition are likely to be 
400 described ${ }^{12,35}$. Like AcrllA22, which has no homology to any previously described anti-CRISPR 401 and lacks other genetic signatures used for acr discovery (e.g., linkage with helix-turn-helix 402 transcription factors) $)^{41,42}$, these new genes may not exhibit canonical Acr behaviors. It is inevitable 403 that these discoveries will lead a more nuanced understanding of the arms race between 404 CRISPR-Cas systems and MGEs. While they might blur the precise boundaries on what defines 405 an anti-CRISPR, these findings will also reveal undiscovered strategies for molecular antagonism 406 and new battlegrounds in the age-old conflict between bacteria and their phages. 


\section{Methods}

\section{Plasmid protection assay}

All assays were done in Escherichia coli (strain: NEB Turbo). As described previously ${ }^{12}$, SpyCas9 was expressed from a CloDF13-based plasmid marked with a spectinomycin resistance cassette. The SpyCas9 construct programed to eliminate a kanamycin-marked target plasmid was called pSpyCas9_crA (Supplemental Table 4). It eliminated a target vector that inducibly expressed a gene-of-interest via depression of the TetR transcription factor with doxycycline (named generically pZE21_tetR; Supplemental Table 4). IPTG was used in samples with the target vector to ensure high levels of TetR expression (which was driven by the lac promoter) and thus inducible control of our gene of interest. Cultures of each sample were grown overnight at $37 \mathrm{C}$ with shaking at $220 \mathrm{rpm}$ in lysogeny broth (LB; $10 \mathrm{~g} / \mathrm{L}$ casein peptone, $10 \mathrm{~g} / \mathrm{L} \mathrm{NaCl}, 5 \mathrm{~g} / \mathrm{L}$ ultra-filtered yeast powder) containing spectinomycin $50 \mu \mathrm{g} / \mathrm{ml}$, kanamycin $50 \mu \mathrm{g} / \mathrm{ml}$, and $0.5 \mathrm{mM}$ IPTG. These growth conditions kept both SpyCas9 and the gene of interest in uninduced states. The next morning, overnight cultures were diluted 1:50 into LB broth containing spectinomycin 50 $\mu \mathrm{g} / \mathrm{ml}$, kanamycin $50 \mu \mathrm{g} / \mathrm{ml}, 0.5 \mathrm{mM}$ IPTG, and doxycycline $100 \mathrm{ng} / \mathrm{ml}$ to induce the gene of interest. Cultures were grown at $37 \mathrm{C}$ on a roller drum to mid-log phase (for approximately 1.5 hours to OD600 of 0.3-0.6). Once cells reached mid-log phase, they were diluted to OD600 value of 0.01 into two media types: (a) LB containing spectinomycin $50 \mu \mathrm{g} / \mathrm{ml}, 0.5 \mathrm{mM}$ IPTG, and doxycycline $100 \mathrm{ng} / \mathrm{ml}$, and (b) LB containing spectinomycin $50 \mu \mathrm{g} / \mathrm{ml}, 0.5 \mathrm{mM}$ IPTG, doxycycline $100 \mathrm{ng} / \mathrm{ml}$, and $0.2 \%(\mathrm{~L})$ arabinose. These media induced either the gene of interest alone, or both the gene of interest and SpyCas9, respectively. Each sample was grown in triplicate in a 96 well plate in a BioTek Cytation 3 plate reader. After 6 hours of growth at $37^{\circ} \mathrm{C}$ with shaking at 220 rpm, each sample was diluted ten-fold and plated on two types of media: (a) LB spectinomycin $50 \mu \mathrm{g} / \mathrm{ml}+0.5 \mathrm{mM}$ IPTG or (b) LB spectinomycin $50 \mu \mathrm{g} / \mathrm{ml}$, kanamycin $50 \mu \mathrm{g} / \mathrm{ml}, 0.5 \mathrm{mM} \mathrm{IPTG}$. Plates were incubated at $37 \mathrm{C}$ overnight. Then, colonies were counted to determine the fraction of colony forming units (cfus) that maintained kanamycin resistance (and thus the target vector). All figures depicting these data show the log-transformed proportion of $\mathrm{Kan}^{\mathrm{R}} / \mathrm{total}^{\mathrm{c}} \mathrm{cu}$, both with and without SpyCas9 induction. The growth curves in Supplemental Figure 1 match the experiment depicted Figure 1C for the uninduced SpyCas9 samples. For the uninduced orf_1 sample, doxycycline was omitted from media throughout the experiment. Growth rates quoted in text were calculated using the slope of the OD600 growth curves during log phase, following a natural log transformation.

\section{Impact of AcrllA22 on GFP expression}

We swapped spyCas9 for egfp in our CloDF13-based plasmid and co-expressed AcrllA22 to determine if AcrllA22 impacted expression from this construct. We reasoned that if AcrlIA22 influenced CloDF13's copy number or the transcription of spyCas9 it would also impact GFP levels in this construct (pCloDF13_GFP; Supplemental Table 4). To perform this experiment, we co-transformed pCloDF13_GFP and pZE21_tetR encoding acrllA22 into E. coli Turbo. Single colonies were picked into $4 \mathrm{~mL}$ of LB containing spectinomycin $50 \mu \mathrm{g} / \mathrm{ml}$ ('spec50') and kanamycin $50 \mu \mathrm{g} / \mathrm{ml}$ ('kan50') and $0.5 \mathrm{mM}$ IPTG and grown overnight at $37^{\circ} \mathrm{C}$ shaking at $220 \mathrm{rpm}$. The next morning the overnight culture was diluted 1:50 into both LB spec50 Kan50 + 0.5mM IPTG with and without doxycycline (to induce acrllA22) and grown at $37^{\circ} \mathrm{C}$ for about 1.5 hours to mid-log phase (OD600 0.2-0.6). The OD600 was measured, and all samples were diluted to OD600 of 0.01 in two media types: (a) LB spec50 + kan50 + 0.5mM IPTG $+0.2 \%$ arabinose (inducing gfp only) or (b) LB spec50 + kan50 + 0.5mM IPTG + 0.2\% arabinose + 100 $\mathrm{ng} / \mathrm{ml}$ doxycycline (inducing 
gfp and acrllA22). A volume of $200 \mu$ of each sample was then transferred to a 96 -well plate in triplicate and we measured GFP fluorescence every 15 minutes for 24 hours (GFP was excited using $485 \mathrm{~nm}$ light and emission detected via absorbance at $528 \mathrm{~nm}$ ). In parallel, we included control samples that lacked the kanamycin-marked plasmid and varied whether doxycycline was added or not (at $100 \mathrm{ng} / \mathrm{ml}$ ). In these control samples, we noticed that doxycycline slightly diminished GFP expression (sub-toxic levels of the antibiotic may still depress translation). Thus, we normalized GFP fluoresced measurements in our experiment with AcrllA22 to account for this effect in all +doxycycline samples. These fluorescence measurements are depicted in Supplemental Figure 2B.

\section{Western blots to AcrlIA22's impact on SpyCas9 expression}

Overnight cultures of E. coli Turbo that expressed pSpyCa9_crNT and pZE21_tetR encoding a gene of interest (Supplemental Tables 4, 5) were grown in LB spec50 + kan50 + $0.5 \mathrm{mM}$ IPTG. The next morning, these cultures were diluted 1:100 in 4ml of either (a) LB spec50 + kan50 + 0.5mM IPTG or (b) LB spec50 + kan50 + 0.5mM IPTG + $100 \mathrm{ng} / \mathrm{ml}$ doxycycline (to induce the gene of interest). We included samples that expressed either acrllA22 or gfp as a gene of interest. In all SpyCas9 constructs, we used a crRNA that did not target our plasmid backbone (pSpyCa9_crNT) to ensure that acrllA22 expression remained high and its potential impact on SpyCas9 expression levels would be most evident. All samples were grown for two hours at $37^{\circ} \mathrm{C}$ to reach mid-log phase (OD600 0.3 to 0.5 ) and transferred into media that contained $0.2 \%$ arabinose to induce SpyCas9. At transfer, volumes were normalized by OD600 value to ensure an equal number of cells were used (diluted to a final OD600 of 0.05 in the arabinose-containing medium). This second medium did or did not contain $100 \mathrm{ng} / \mathrm{ml}$ doxycycline to control expression of acrllA22 or gfp, as with the initial media. Throughout this experiment, we included a control strain that lacked pZE21_tetR and thus only expressed SpyCas9. Kanamycin and doxycycline were omitted from its growth media. For this control strain, we also toggled the addition of arabinose in the second growth medium to ensure positive and negative controls for SpyCas9 were included in our experiment. After three hours and six hours of SpyCas9 induction, OD600 readings were again taken and these values used to harvest an equal number of cells per sample (at three hours, OD600 values were between 0.76 and 0.93 and $0.75 \mathrm{ml}$ to $0.9 \mathrm{ml}$ volumes harvested; at six hours $0.4 \mathrm{ml}$ was uniformly harvested as all absorbance readings were approximately 1.6).

All samples were centrifuged at $4100 \mathrm{~g}$ to pellet cells, resuspended in $100 \mu$ l of denaturing lysis buffer (12.5 mM Tris-HCl, pH 6.8; 4\% SDS), and passed through a 25 gauge needle several times to disrupt the lysate. Samples were then boiled at $100^{\circ} \mathrm{C}$ for 10 minutes, spun at 13,000 $\mathrm{rpm}$ at $4^{\circ} \mathrm{C}$ for 15 minutes and the supernatants removed and frozen at $-20^{\circ} \mathrm{C}$. The next day, 12 $\mu \mathrm{l}$ of lysate was mixed with $4 \mu \mathrm{l}$ of $4 x$ sample buffer $(200 \mathrm{mM}$ Tris- $\mathrm{HCl}, 8 \%$ SDS, $40 \%$ glycerol, $200 \mathrm{mM}$ DTT, and $0.05 \%$ bromophenol blue) and boiled at $100^{\circ} \mathrm{C}$ for 10 minutes. Then, $10 \mu \mathrm{l}$ sample was loaded onto a BioRad Mini-Protean "any KD Stain Free TGX" gel (cat. \#4569035) and run at $150 \mathrm{~V}$ for 62 minutes. To verify that equivalent amounts of each sample were run, gels were visualized on a BioRad chemidoc for total protein content. Protein was then transferred to a $0.2 \mu \mathrm{M}$ nitrocellulose membrane using the Bio-Rad Trans-Blot Turbo system (25 V, $1.3 \mathrm{~A}$ for 10 $\mathrm{min}$ ). We then washed membranes in PBS/0.1\% Triton-X before incubating them with a mixture of the following two primary antibodies, diluted in in Licor Odyssey Blocking Solution (cat. \#92740000): (i) monoclonal anti-SpyCas9, Diagenode cat. \#C15200229-50, diluted 1:5,000; (ii) polyclonal anti-GAPDH, GeneTex cat. \# GTX100118, diluted 1:5,000. The GAPDH antibody 
served as a second check to ensure equal protein levels were run. Membranes were left shaking overnight at $4^{\circ} \mathrm{C}$, protected from light. Then, membranes were washed four times in PBS/0.1\% Triton-X (ten-minute washes) before they were incubated for 30 minutes at room temperature with a mixture of secondary antibodies conjugated to infrared dyes. Both antibodies were diluted $1: 15,000$ in LiCor Odyssey Blocking Solution. To detect SpyCas9, the following secondary antibody was used: IR800 donkey, anti-mouse IgG, Licor cat\# 926-32212. To detect GAPDH, IR680 goat, anti-rabbit IgG, Licor cat\# 926-68071 was used. Blots were imaged on a Licor Odyssey CLx after three additional washes.

\section{Phage plaquing assay}

Overnight cultures of E. coli Turbo that expressed pSpyCa9_crMu and pZE21_tetR encoding a gene of interest (Supplemental Tables 4, 5) were grown at $37^{\circ} \mathrm{C}$ in LB spec50 + kan50 +0.5 mM IPTG. Genes of interest were either acrllA4, gfp, or acrllA22. The pSpyCas 9 construct targeted phage Mu and was previously demonstrated to confer strong anti-phage immunity in this system $^{12}$. A control strain expressing pZE21-tetR-gfp and SpyCas9_crNT (which encoded a CRISPR RNA that does not target phage Mu) was grown similarly. The next morning, all cultures were diluted 50 -fold into LB spec50 + kan50 + $0.5 \mathrm{mM} \mathrm{IPTG}+5 \mathrm{mM} \mathrm{MgCl} 2$ and grown at $37^{\circ} \mathrm{C}$ for three hours. Then, doxycycline was added to a final concentration of $100 \mathrm{ng} / \mathrm{ml}$ to induce the gene of interest. Two hours later, SpyCas9 was induced by adding a final concentration of $0.2 \%$ $\mathrm{w} / \mathrm{v}$ arabinose. Two hours after that, cultures were used in soft-agar overlays on one of two media types, discordant for arabinose, to either maintain SpyCas9 expression or let it fade as arabinose was diluted in top agar and consumed by the host bacteria (per Supplemental Figure S2). Top and bottom agar media were made with LB spec50 + kan50 + $0.5 \mathrm{mM} \mathrm{IPTG} \mathrm{+} 5 \mathrm{mM} \mathrm{MgCl} 2$. In cases where SpyCas9 expression was maintained, arabinose was also added at a final concentration of $0.02 \%$ to both agar types. Top agar was made using $0.5 \%$ Difco agar and bottom agar used a $1 \%$ agar concentration. For the plaquing assay, $100 \mu \mathrm{l}$ of bacterial culture was mixed with $3 \mathrm{ml}$ of top agar, allowed to solidify, and ten-fold serial dilutions of phage Mu spotted on top using $2.5 \mu \mathrm{l}$ droplets. After the droplets dried, plates were overturned and incubated at $37^{\circ} \mathrm{C}$ overnight before plaques were imaged the subsequent day.

\section{Identification of AcrlIA22 homologs and hypervariable genomic islands}

We searched for AcrllA22 homologs in three databases: NCBI nr, IMG/VR, and a set of assembled contigs from 9,428 diverse human microbiome samples ${ }^{18}$. Accession numbers for the $\mathrm{NCBI}$ homologs are indicated on the phylogenetic tree in Figure 3A. They were retrieved via five rounds of an iterative PSI-BLAST search against NCBI nr performed on October $2^{\text {nd }}, 2017$. In each round of searching, at least $90 \%$ of the query protein (the original AcrllA22 hit) was covered, $88 \%$ of the subject protein was covered, and the minimum amino acid identity of an alignment was $23 \%$ (minimum $47 \%$ positive residues; e-value $\leq 0.001$ ). Only one unique AcrllA22 homolog was identified in IMG/VR (from several different phage genomes) via a blastp search against the July, 2018 IMG/VR proteins database (using default parameters). It is identical to the sequence of AcrllA22b (Figure 3A).

Most unique AcrlIA22 homologs were identified in the assembly data of over 9,400 human microbiomes performed by Pasolli and colleagues ${ }^{18}$. These data are grouped into multiple datasets: (i) the raw assembly data, and (ii) a set of unique species genome bins (SGBs), which was generated by first assigning species-level phylogenetic labels to each assembly and then selecting one representative genome assembly per species. We identified AcrllA22 homologs 
using several queries against both databases. First, we performed a tblastn search against the SGB database using the AcrllA22 sequence as a query, retrieving 141 hits from 137 contigs. A manual inspection of the genome neighborhoods for these hits revealed that most homologs originated from a short, hypervariable genomic island but that some homologs were encoded by prophages. No phage-finding software was used to identify prophages; they were apparent from a manual inspection of the gene annotations that neighbored acrllA22 homologs (see the section entitled "Annotation and phylogenetic assignment of metagenomic assemblies" for details).

To find additional examples of AcrllA22 homologs and of these genomic islands, we then queried the full raw assembly dataset. To do so without biasing for acrllA22-encoding sequences, we used the purF gene that flanked acrllA22-encoding genomic islands as our initial query sequence (specifically, we used the purF gene from contig number 1 in Supplemental Table 3; its sequence is also in Supplemental Table 5). To consider only the recent evolutionary history of this locus, we required all hits have $\geq 98 \%$ nucleotide identity and required all hits to be larger than 15 kilobases in length to ensure sufficient syntenic information. From these contigs, we further filtered for those that had $\geq 98 \%$ nucleotide identity to radC, the gene which flanked the other end of acrllA22-encoding genomic islands (again, we used the variant from contig number 1 in Supplemental Table 3; its sequence is also in Supplemental Table 5). In total, this search yielded 258 contig sequences; nucleotide sequences and annotations for these contigs are provided in Supplementary Dataset 5 . We then searched for acrllA22 homologs in these sequences using tblastn, again observing them in genomic islands and prophage genomes (these prophages were assembled as part of the 258 contigs). In total, this search revealed 320 acrllA22 homologs from 258 contigs. The 258 genomic islands from these sequences were retrieved manually by extracting all nucleotides between the purF and radC genes. These extracted sequences were then clustered at $100 \%$ nucleotide identity with the sequence analysis software geneious to identify 128 unique genomic islands.

Combined, our two searches yielded 461 AcrllA22 sequences from these metagenomic databases that spanned 410 contig sequences. The 461 AcrllA22 homologs broke down into 410 that clustered with the genomic island-like sequences (we specifically searched for genomic islands) and 51 that clustered with prophage-like homologs (we never directly searched for prophages). We then combined these 461 AcrlIA22 sequences with those from NCBI and IMG/VR and clustered the group on $100 \%$ amino acid identity to reveal 30 unique proteins. To achieve this, we used the software cd-hit ${ }^{43}$ with the following parameters: - $d 0$-g 1 -aS 1.0 -c 1.0. These 30 sequences were numbered to match their parent contig (as indicated in Supplemental Table 3 ) and used to create the phylogenetic tree depicted in Figure 3A. For AcrllA22 homologs found outside $\mathrm{NCBI}$, the nucleotide sequences and annotations their parent contigs can be found in Supplementary Datasets 1 and 2. This information can be retrieved for NCBI sequences via their accession numbers (which are shown in Figure 3A). The NCBI gene sequences also used in functional assays (Figure 3B) have been reprinted in Supplemental Table 5, for convenience.

\section{Annotation and phylogenetic assignment of metagenomic assemblies}

Contig sequences from IMG/VR, the Pasolli metagenomic assemblies, and some NCBI entries lacked annotations, making it difficult to make inferences about acrllA22's genomic neighborhood. To facilitate these insights, we annotated all contigs as follows. We used the genefinder MetaGeneMark ${ }^{44}$ to predict open reading frames (ORFs) using default parameters. We then used their amino acid sequences in a profile HMM search with HMMER3 ${ }^{45}$ against TIGRFAM $^{46}$ and Pfam $^{47}$ profile HMM databases. The highest scoring profile was used to annotate 
each ORF. We annotated these contigs to facilitate genomic neighborhood analyses for acrllA22 and not to provide highly accurate functional predictions of their genes. Thus, we erred on the side of promiscuously assigning gene function and our annotations should be treated with the appropriate caution. From these annotated contigs, we immediately observed several examples of acrllA22-encoding prophages (we noticed 35-40 kilobase insertions within some contigs that contained mostly co-linear genes with key phage functions annotated). As a simple means to sample this phage diversity, we manually extracted nine examples of these prophage sequences (their raw sequences and annotated genomes can be found in Supplementary Datasets 3 and 4). Annotations were imported to in the sequence analysis suite Geneious Prime 2020 v1.1 for manual inspection of genome neighborhoods.

We used the genome taxonomy database (GTDB) convention for all sequences discussed in this manuscript ${ }^{48}$. In part, this was because all acrllA22 genomes are found in Clostridial genomes, which are notoriously polyphyletic in NCBI taxonomies (for instance, the NCBI genus appears in GTDB genera and 29 GTDB families) ${ }^{49}$. All SGBs that we retrieved from the Pasolli assemblies were assigned taxonomy as part of that work and were called Clostridium sp. CAG217. Similarly, NCBI assemblies that encoded the most closely acrllA22 homologs to our original hit were assigned to the GTDB genus CAG-217 ${ }^{48,49}$. The raw assembly data from the Pasolli database was not assigned a taxonomic label but was nearly identical in nucleotide composition to the CAG-217 contigs (Figure 2, Supplementary Datasets 1 and 2). Therefore, we also refer to these sequences as originating in CAG-217 genomes but take care to indicate which sequences have been assigned a rigorous taxonomy and which ones for which taxonomy has been inferred in this fashion (Supplemental Table 3).

\section{Comparing genes in genomic islands to phage genomes}

We first examined the annotated genes within each of the 128 unique genomic islands. Manual inspection revealed 54 unique gene arrangements (which differed in gene content and orientation). We then selected one representative from each arrangement and extracted all amino acid sequences from each encoded gene $(n=506)$. Next, we collapsed these 506 proteins into orthologous groups by clustering at $65 \%$ amino acid using cd-hit with the following parameters: d 0 -g 1 -aS 0.95 -c 0.65 . These cluster counts were used to generate the histogram depicted in Figure 2C. To determine which protein families may also be phage encoded, the longest representative from each cluster with at least two sequences was queried against the database of nine CAG-217 phages described in the section entitled "Annotation and phylogenetic assignment of metagenomic assemblies". We used tblastn with default parameters to perform this search, which revealed that some proteins in the CAG-217 genomic islands have homologs in prophage genomes that are out-of-frame with respect to the MetaGeneMark annotations depicted in Figure 2A.

\section{Phylogenetic tree of AcrllA22 homologs}

The 30 unique AcrllA22 homologs we retrieved were used to create the phylogeny depicted in Figure 3A. These sequences were aligned using the sequence alignment tool in the sequence analysis suite Geneious Prime 2020 v1.1. This alignment is provided as Supplementary Dataset 6. From this alignment, the phylogenetic tree in Figure 3A was generated using PhyML with the LG substitution model and 100 bootstraps. Coloration and tip annotations were then added in Adobe Illustrator. 


\section{Identification of CRISPR-Cas systems and Acrs in CAG-217 assemblies}

To determine the type and distribution of CRISPR-Cas systems and Acrs in CAG-217 genomes, we downloaded all assembly data for the 779 SGBs assigned to CAG-217 in Pasolli et. $a l^{18}$ (bin 4303). We then predicted CRISPR-Cas systems for all 779 assemblies in bulk using the command line version of the CRISPR-Cas prediction suite, cctyper ${ }^{50}$. Specifically, we used version 1.2.1 of cctyper with the following options: --prodigal meta --keep_tmp. To identify type IIA Acrs, we first downloaded representative sequences for each of the 21 experimentally confirmed type II-A Acrs from the unified resource for tracking anti-CRISPRs ${ }^{51}$. We then used tblastn to query these proteins against the 779 CAG-217 genome bins and considered any hit with e-value better than 0.001 (which included all hits with $>30 \%$ identity across $50 \%$ of the query). To check if these Acrs were present in acrllA22-encoding phages, we performed an identical tblastn search, but this time used the set of nine acrllA22-encoding prophages as a database.

\section{Recombinant protein overexpression and purification}

The AcrllA22 protein and its mutants were codon optimized for E. coli (Genscript or SynBio Technologies) and the gene construct was cloned into the $\mathrm{pET} 15 \mathrm{HE}^{12}$ plasmid to contain an $\mathrm{N}$ terminal, thrombin-cleavable 6 XHistidine tag. Constructs were transformed and overexpressed in BL21 (DE3) RIL E. coli cells. A $10 \mathrm{~mL}$ overnight culture (grown in LB $+100 \mu \mathrm{g} / \mathrm{mL}$ ampicillin) was diluted 100 -fold into the same media and grown at $37^{\circ} \mathrm{C}$ with shaking to an OD600 of 0.8 , followed by induction with $0.5 \mathrm{mM}$ IPTG. The culture was shaken for an additional 3 hours at $37^{\circ} \mathrm{C}$. Cells were harvested by centrifugation and the pellet stored at $-20^{\circ} \mathrm{C}$ until purification.

Cell pellets were resuspended in $25 \mathrm{mM}$ Tris, $\mathrm{pH}$ 7.5, $300 \mathrm{mM} \mathrm{NaCl}, 20 \mathrm{mM}$ imidazole (Lysis Buffer) and lysed by sonication on ice. The lysate was centrifuged in an SS34 rotor at 18,000 rpm for 25 minutes, followed by filtering through a $5 \mu \mathrm{m}$ syringe filter (Millipore \#SLSV025LS). The clarified lysate was bound using the batch method to Ni-NTA agarose resin (Qiagen) at $4^{\circ} \mathrm{C}$ for 1 hour. The resin was transferred to a gravity column (Biorad), washed with $>50$ column volumes of Lysis Buffer and eluted with $25 \mathrm{mM}$ Tris, pH 7.5, $300 \mathrm{mM} \mathrm{NaCl}, 200 \mathrm{mM}$ imidazole. The protein was diluted with 2 column volumes of $25 \mathrm{mM}$ Tris, $\mathrm{pH} 7.5$ and purified on a HiTrapQ column (GE Healthcare) using a $20 \mathrm{~mL}$ gradient from $150 \mathrm{mM}$ to $1 \mathrm{M} \mathrm{NaCl}$ in $25 \mathrm{mM}$ Tris, $\mathrm{pH}$ 7.5. Peak fractions were pooled, concentrated and buffer exchanged into $200 \mathrm{mM} \mathrm{NaCl}, 25 \mathrm{mM}$ Tris, $\mathrm{pH}$ 7.5 using an Amicon Ultra centrifugal filter with a 3,000 molecular weight cutoff (Millipore, UFC900324), then cleaved in an overnight $4^{\circ} \mathrm{C}$ incubation with biotinylated thrombin (EMD Millipore). Streptavidin agarose slurry (Novagen) was incubated with cleaved protein at $4^{\circ} \mathrm{C}$ for 30 minutes to remove thrombin. The sample was then passed through a $0.22 \mu \mathrm{m}$ centrifugal filter and loaded onto a HiLoad 16/60 Superdex 200 prep grade size exclusion column (Millipore Sigma) equilibrated in $25 \mathrm{mM}$ Tris, $\mathrm{pH} \mathrm{7.5,200} \mathrm{mM} \mathrm{NaCl}$. The peak fractions were confirmed for purity by SDS-PAGE. Figure 4C depicts size exclusion chromatography data generated for thrombin-cleaved AcrllA22 variants generated using a Superdex75 16/60 (GE HealthCare) column with $25 \mathrm{mM}$ Tris, $\mathrm{pH} 7.5,200 \mathrm{mM} \mathrm{NaCl}$. Recombinant AcrllA4 was purified similarly to other Acr proteins as previously described ${ }^{12}$, but with the following deviations. First, the 6XHistidine-tagged AcrllA4 gene was cloned into pET15B rather than pET15HE, which differs by only by a few bases just upstream of the N-terminal thrombin tag. IPTG was used at $0.2 \mathrm{mM}$ and cells were harvested after 18 hours of induction at $18^{\circ} \mathrm{C}$. Thrombin cleavage also occurred at $18^{\circ} \mathrm{C}$. This untagged version was used to help generate Supplemental Figure 5. Peak fractions for all proteins were pooled, concentrated, flash frozen as single-use aliquots in liquid nitrogen, and stored at $-80^{\circ} \mathrm{C}$. 
SpyCas9 was expressed in E. coli from plasmid pMJ806 (addgene \#39312) to contain a TEVcleavable N-terminal 6XHis-MBP tag and was purified as described previously ${ }^{12}$. Briefly, sequential steps of purification consisted of Ni-NTA affinity chromatography, TEV cleavage, Heparin HiTrap chromatography and SEC. The protein was stored in a buffer consisting of 200 $\mathrm{mM} \mathrm{NaCl}, 25 \mathrm{mM}$ Tris (pH 7.5), 5\% glycerol, and $2 \mathrm{mM}$ DTT.

To perform in vitro pulldown experiments, we purified AcrlIA22 and AcrllA4 proteins with a Cterminal twin-strep tag. To achieve this, the Acrs were subcloned into pET15B which was previously engineered to contain a thrombin-cleavable C-terminal twin-strep tag. The protein was expressed as described above and purified according to the manufacturer's guidelines (IBA Inc.). Briefly, cell lysates were resuspended in Buffer W (150 mM NaCl, $100 \mathrm{mM}$ Tris, pH 8.0, 1 mM EDTA) and lysed by sonication. Clarified lysates were then passed over Streptactin-Sepharose resin using a gravity filtration column. The flow through was passed over the resin an additional time. The column was washed with a minimum of 20 column volumes of buffer $\mathrm{W}$, followed by elution in buffer $\mathrm{E}$ (150 mM NaCl, $100 \mathrm{mM}$ Tris, pH $8.0 \mathrm{mM}, 1$ EDTA, $2.5 \mathrm{mM}$ desthiobiotin). The eluted protein was purified over a HiTrap Q column, followed by SEC in $200 \mathrm{mM} \mathrm{NaCl}, 25 \mathrm{mM}$ Tris, 7.5.

\section{X-ray crystallography and structural analyses}

An AcrllA22 crystal was grown using $14 \mathrm{mg} / \mathrm{mL}$ protein via the hanging drop method using 200mM ammonium nitrate, 40\% (+/-)-2-methyl-2,4-pentanediol (MPD, Hampton Research), $10 \mathrm{mM} \mathrm{MgCl} 2$ as a mother liquor. Diffraction data was collected at the Argonne National Laboratory Structural Biology Center synchrotron facility (Beamline 19BM). Data was processed with HKL2000 in space group P4332, then built and refined using COOT ${ }^{52}$ and PHENIX53. The completed 2.80A structure was submitted to the Protein Data Bank with PDB Code 7JTA. We submitted this finished coordinate file to the PDBe PISA server (Protein Data Bank Europe, Protein Interfaces, Surfaces and Assemblies; http://pdbe.org/pisa/) which uses free energy and interface contacts to calculate likely multimeric assemblies ${ }^{25}$. The server calculated tetrameric, dimeric and monomeric structures to be thermodynamically stable in solution. The tetrameric assembly matches the molecular weight expected from the size exclusion column elution peak and is the most likely quaternary structure as calculated by the PISA server. The tetramer gains $-41.8 \mathrm{kcal} / \mathrm{mol}$ free energy by solvation when formed and requires an external driving force of 3.1 $\mathrm{kcal} / \mathrm{mol}$ to disassemble it according to PISA $\Delta \mathrm{G}$ calculations.

\section{sgRNA generation}

The single-guide RNA (sgRNA) for use in in-vitro experiments was generated as described previously ${ }^{12}$. It was transcribed from a double-stranded DNA (dsDNA) template by T7 RNA polymerase using Megashortscript Kit (Thermo Fisher \#AM1354). We made the dsDNA template via one round of thermal cycling $\left(98^{\circ} \mathrm{C}\right.$ for $90 \mathrm{~s}, 55^{\circ} \mathrm{C}$ for $15 \mathrm{~s}, 72^{\circ} \mathrm{C}$ for $\left.60 \mathrm{~s}\right)$ in $50 \mu$ reactions. We used the Phusion PCR polymerase mix (NEB) containing 25 pmol each of the following two oligo sequences (the sequence that binds the protospacer on our pIDTsmart target vector is underlined): 


\section{AAAAAAGCACCGACTCGGTGCCACTTTTTCAAGTTGATAACGGACTAGCCTTAT} TTTAACTTGC.

The dsDNA templates were then purified using an Oligo Clean and Concentrator Kit (ZymoResearch) before quantification via the Nanodrop. Reactions were then treated with DNAse, extracted via phenol-chloroform addition followed by chloroform, ethanol precipitated, resuspended in RNase free water, and frozen at $-20^{\circ} \mathrm{C}$. RNA was quantified by Nanodrop and analyzed for quality on $15 \%$ acrylamide/TBE/UREA gels.

\section{Pulldown assay using strep-tagged AcrllA22 and AcrllA4}

The same buffer was used for pulldowns and to dilute proteins, consisting of $200 \mathrm{mM} \mathrm{NaCl}$, $25 \mathrm{mM}$ Tris $(\mathrm{pH}$ 7.5). As a precursor to these assays, 130 pmol SpyCas9 and sgRNA were incubated together at room temperature for 15 minutes where indicated. SpyCas9, with or without pre-complexed sgRNA, was then incubated with 230 pmol AcrllA4 or 320 pmol AcrlIA22 for 25 minutes at room temperature. Subsequently, $50 \mu \mathrm{l}$ of a $10 \%$ slurry of Streptactin Resin (IBA biosciences \#2-1201-002), pre-equilibrated in binding buffer, was added to the binding reactions and incubated at $4^{\circ} \mathrm{C}$ on a nutator for 45 minutes. Thereafter all incubations and washes were carried out at $4^{\circ} \mathrm{C}$ or on ice. Four total washes of this resin were performed, which included one tube transfer. Washes proceeded via centrifugation at $2000 \mathrm{rpm}$ for one minute, aspiration of the supernatant with a 25-gauge needle, and resuspension of the beads in $100 \mu$ l binding buffer. Strep-tagged proteins were eluted via suspension in $40 \mu \mathrm{l}$ of 1x BXT buffer (100 mM Tris-Cl, 150 $\mathrm{mM} \mathrm{NaCl}, 1 \mathrm{mM}$ EDTA, $50 \mathrm{mM}$ Biotin, $\mathrm{pH}$ 8.0) and incubated for $15 \mathrm{~min}$ at room temperature. After centrifugation, $30 \mu$ of supernatant was removed and mixed with $4 \mathrm{X}$ reducing sample buffer (Thermo Fisher). Proteins then separated by SDS PAGE on BOLT 4-12\% gels in MES buffer (Invitrogen) and visualized by Coomassie staining.

\section{SpyCas9 linear DNA cleavage assay}

All SpyCas9 cleavage reactions using linear DNA were performed in the following cleavage buffer: $20 \mathrm{mM}$ Tris $\mathrm{HCl}$ (pH7.5), $5 \%$ glycerol, $100 \mathrm{mM} \mathrm{KCl,} 5 \mathrm{mM} \mathrm{MgCl} 2,1 \mathrm{mM}$ DTT. In preparation for these reactions, all proteins were diluted in $30 \mathrm{mM} \mathrm{NaCl} / 25 \mathrm{mM}$ Tris, $\mathrm{pH} 7.4$ / $2.7 \mathrm{mM} \mathrm{KCl}$, whereas all DNA and sgRNA reagents were diluted in nuclease-free water. Where indicated, SpyCas9 $(0.36 \mu \mathrm{M})$ was incubated with sgRNA $(0.36 \mu \mathrm{M})$ for 10 minutes at room temperature. Before use, sgRNA was melted at $95^{\circ} \mathrm{C}$ for five minutes and then slowly cooled at $0.1^{\circ} \mathrm{C} / \mathrm{s}$ to promote proper folding. SpyCas9 (either pre-complexed with sgRNA or not, as indicated in Supplemental Figure 6) was then incubated for 10 minutes at room temperature with AcrllA4 $(2.9 \mu \mathrm{M})$ or AcrllA22 at the following concentrations: [23.2, 11.6, 5.8, and $2.9 \mu \mathrm{M}]$. As substrate, the plasmid pIDTsmart was linearized by restriction digest and used at a final concentration of $3.6 \mathrm{nM}$. The reaction was initiated by the addition of this DNA substrate in isolation or in combination with sgRNA $(0.36 \mu \mathrm{M})$ as indicated in Supplemental Figure 6. Reactions were immediately moved to a $37^{\circ} \mathrm{C}$ incubator and the reaction stopped after fifteen minutes via the addition of $0.2 \%$ SDS $/ 100 \mathrm{mM}$ EDTA and incubating at $75^{\circ} \mathrm{C}$ for five minutes. Samples were then run on a $1.5 \%$ TAE agarose gel at $120 \mathrm{~V}$ for 40 minutes. Densitometry was used to calculate the proportion of DNA cleaved by SpyCas9 via band intensities quantified using the BioRad ImageLab software v5.0. 
In all experiments, cultures were first grown overnight at $37^{\circ} \mathrm{C}$ with shaking at $220 \mathrm{rpm}$ in LB with $0.5 \mathrm{mM}$ IPTG, spectinomycin (at $50 \mu \mathrm{g} / \mathrm{mL}$ ), and kanamycin (at $50 \mu \mathrm{g} / \mathrm{mL}$ ). Then, these overnight cultures were diluted 1:50 into LB with $0.5 \mathrm{mM} \mathrm{IPTG,} \mathrm{spectinomycin} \mathrm{(at} 50 \mu \mathrm{g} / \mathrm{mL}$ ), and, where indicated, doxycycline (at $100 \mathrm{ng} / \mathrm{mL}$, to induce acrs). Cultures were grown at $37^{\circ} \mathrm{C}$ with shaking at $220 \mathrm{rpm}$ and, if indicated, $0.2 \%$ (L)-arabinose was added after two hours of growth to induce spyCas 9 expression. The next morning, cultures were centrifuged at $4100 \mathrm{~g}$ and plasmids purified using a miniprep kit (Qiagen). The concentration of dsDNA in each miniprep was measured using the Qubit-4 fluorometer and the associated dsDNA high sensitivity assay kit (Invitrogen). For each sample with a SpyCas9-expressing plasmid, 150ng of DNA was digested with the restriction enzyme Hincll (NEB) per manufacturer's recommendations, except that digests were incubated overnight before being stopped by heating at $65^{\circ} \mathrm{C}$ for 20 minutes. This restriction enzyme will cut once, only in the SpyCas9 plasmid, to linearize it. This allowed us to visualize the SpyCas9 plasmid as a single band, which served two purposes: (i) it allowed us to more easily identify bands from acrllA22-encoding plasmids (which had not been digested), and (ii) it served as an internal control for plasmid DNA that is unaffected by SpyCas9 targeting or AcrllA22 expression (Supplemental Figure 2). Following restriction digest, 30ng of sample was analyzed via gel electrophoresis using a 1\% TAE-agarose gel run at $120 \mathrm{~V}$ for between 45 and 60 minutes. In samples that lacked a SpyCas9-expressing plasmid, 30ng of purified plasmid was directly analyzed by gel electrophoresis, as described previously.

\section{In vitro AcrlIA22 plasmid nicking assay}

Except for the divalent cation experiment, all reactions were performed using NEB buffer 3.1 (100 mM NaCl, 50 mM Tris- $\mathrm{HCl}, \mathrm{pH} 7.9,10 \mathrm{mM} \mathrm{MgCl}$, $100 \mu \mathrm{g} / \mathrm{mL}$ BSA). To determine cation preference, the same reaction buffer was re-created, but $\mathrm{MgCl} 2$ was omitted. All proteins were diluted in $130 \mathrm{mM} \mathrm{NaCl}, 25 \mathrm{mM}$ Tris, $\mathrm{pH}$ 7.4, $2.7 \mathrm{mM} \mathrm{KCl}$. DNA was diluted in nuclease-free water. In the cation preference experiment, $60 \mu \mathrm{M}$ AcrlIA22 and $6 \mathrm{nM}$ of purified pIDTsmart plasmid DNA were used. All other reactions were set up with the AcrllA22 final concentrations indicated in Figure 5 and Supplemental Figure 7. In the cation preference experiment, reactions were started by adding $10 \mathrm{mM}$ of the indicated cation. All other reactions were initiated via the addition of $2 \mathrm{nM}$ pIDTsmart plasmid DNA. In all cases, reactions were immediately transferred to a $37^{\circ} \mathrm{C}$ incubator. At $0.5,1,2,4,6$, or 20 -hour timepoints, a subset of the reaction was removed and run on a $1 \%$ TAE agarose gel at $120 \mathrm{~V}$ for 40 minutes. For the cation preference experiment, only the 2-hour timepoint was considered and the reaction was stopped via the addition of NEB loading buffer and $100 \mathrm{mM}$ EDTA. In this case, DNA was visualized on a $1 \%$ TBE gel run for 60 minutes at $110 \mathrm{~V}$. Densitometry was used to calculate the proportion of DNA in each topological form via band intensities quantified using the BioRad ImageLab software v5.0.

\section{SpyCas 9 cleavage kinetics assay}

Except where indicated in Supplemental Figure 9B, all cleavage reactions were performed in the following cleavage buffer: $20 \mathrm{mM}$ Tris $\mathrm{HCl}(\mathrm{pH} 7.5), 5 \%$ glycerol, $100 \mathrm{mM} \mathrm{KCl}, 5 \mathrm{mM} \mathrm{MgCl}$, $1 \mathrm{mM}$ DTT. In preparation for these reactions, all proteins were diluted in $30 \mathrm{mM} \mathrm{NaCl} / 25 \mathrm{mM}$ Tris, $\mathrm{pH} 7.4$ / 2.7mM KCl, whereas all DNA and sgRNA reagents were diluted in nuclease-free 
water. NEB Buffer 3.1 (100 mM NaCl, 50 mM Tris-HCl, pH 7.9, 10 mM MgCl2, $100 \mu \mathrm{g} / \mathrm{mL}$ BSA) was used as a reaction buffer in Supplemental Figure 9B.

In preparation for these reactions, purified pIDTsmart plasmid was pre-treated with either AcrllA22, the nickase Nb.Bss.SI (NEB), or no enzyme. For the AcrllA22 pre-treatment, $3.1 \mu \mathrm{g}$ of plasmid was incubated with $230 \mu \mathrm{M}$ AcrllA22 and the plasmid nicked as described previously. Plasmid nicking with Nb.Bss.SI proceeded via manufacturer's recommendations (NEB). Both reactions were incubated at $37^{\circ} \mathrm{C}$ for 2 hours. To isolate the nicked plasmid, samples were then run on a $1.5 \%$ agarose gel for 2 hours and the open-circle form of the plasmid was excised and purified using the Zymo Research Gel DNA Recovery Kit. Untreated plasmid was also purified via gel extraction. Plasmid yield was quantified using a Nanodrop.

To determine SpyCas9's substrate preference, we incubated each pre-treated plasmid substrate with SpyCas9 and looked for the appearance of a linearized plasmid as indication of SpyCas9 digestion. In all cases, SpyCas9 was used at a final concentration of $31.2 \mathrm{nM}$. To begin the reaction, DNA substrate and sgRNA were added simultaneously to the reaction mix and the samples moved immediately from ice to $37^{\circ} \mathrm{C}$ and incubated for either 1 or 5 minutes. We noticed that the digestion reaction proceeded too quickly with NEB Buffer 3.1 to detect SpyCas9's substrate preference (i.e., the substrates were all rapidly linearized Supplemental Figure 9B). The cleavage buffer used in most reactions (detailed atop this section) was chosen because it slowed digestion kinetics so that we could detect SpyCas9's substrate preference. Before addition to the reaction, sgRNA was melted at $95^{\circ} \mathrm{C}$ for five minutes and then slowly cooled at $0.1^{\circ} \mathrm{C} / \mathrm{s}$ to promote proper folding. At each timepoint, $5 \mu \mathrm{l}$ of the reaction was removed and the reaction was stopped using $0.2 \%$ SDS $/ 100 \mathrm{mM}$ EDTA, then incubating at $75^{\circ} \mathrm{C}$ for 5 minutes. Samples were run on a $1.5 \%$ TAE gel at $120 \mathrm{~V}$ for 40 minutes.

\section{Acknowledgements}

We thank Kaylee Dillard, Ilya Finkelstein, and Tera Levin for comments on the manuscript. Use of the Advanced Photon Source, an Office of Science User Facility operated for the U.S. Department of Energy (DOE) Office of Science by Argonne National Laboratory, was supported by the U.S. DOE under Contract No. DE-AC02-06CH11357. This work was supported by a Helen Hay Whitney Foundation postdoctoral fellowship awarded to KJF, a Seattle University summer faculty fellowship to BKK, NIH grant R01GM105691 and discretionary funding from the Fred Hutchinson Cancer Research Center to BLS, and grants from the G. Harold and Leila Y. Mathers Foundation and the Howard Hughes Medical Institute to HSM. The funders played no role in study design, data collection and interpretation, or the decision to publish this study. HSM is an Investigator of the Howard Hughes Medical Institute.

\section{Competing Interests}

All authors declare no significant competing financial, professional, or personal interests that might have influenced the performance or presentation of the work described in this manuscript. 


\section{References}

8381 Barrangou, R. et al. CRISPR provides acquired resistance against viruses in

$839 \quad$ prokaryotes. Science 315, 1709-1712, doi:10.1126/science.1138140 (2007).

8402 Marraffini, L. A. \& Sontheimer, E. J. CRISPR interference limits horizontal gene transfer

$841 \quad$ in staphylococci by targeting DNA. Science 322, 1843-1845,

842 doi:10.1126/science.1165771 (2008).

8433 Deveau, H. et al. Phage response to CRISPR-encoded resistance in Streptococcus

844 thermophilus. J Bacteriol 190, 1390-1400, doi:10.1128/JB.01412-07 (2008).

8454 Mendoza, S. D. et al. A bacteriophage nucleus-like compartment shields DNA from

$846 \quad$ CRISPR nucleases. Nature 577, 244-248, doi:10.1038/s41586-019-1786-y (2020).

8475 Malone, L. M. et al. A jumbo phage that forms a nucleus-like structure evades CRISPR-

$848 \quad$ Cas DNA targeting but is vulnerable to type III RNA-based immunity. Nat Microbio/ 5, 48-

849

850 55, doi:10.1038/s41564-019-0612-5 (2020).

6 Bryson, A. L. et al. Covalent Modification of Bacteriophage T4 DNA Inhibits CRISPRCas9. mBio 6, e00648, doi:10.1128/mBio.00648-15 (2015).

851

852 Stanley, S. Y. \& Maxwell, K. L. Phage-Encoded Anti-CRISPR Defenses. Annu Rev Genet 52, 445-464, doi:10.1146/annurev-genet-120417-031321 (2018).

8548 Trasanidou, D. et al. Keeping crispr in check: diverse mechanisms of phage-encoded anti-crisprs. FEMS Microbiol Lett, doi:10.1093/femsle/fnz098 (2019).

9 Davidson, A. R. et al. Anti-CRISPRs: Protein Inhibitors of CRISPR-Cas Systems. Annu Rev Biochem 89, 309-332, doi:10.1146/annurev-biochem-011420-111224 (2020).

85810 Wiegand, T., Karambelkar, S., Bondy-Denomy, J. \& Wiedenheft, B. Structures and Strategies of Anti-CRISPR-Mediated Immune Suppression. Annu Rev Microbiol 74, 21 37, doi:10.1146/annurev-micro-020518-120107 (2020).

861

Hatfull, G. F. Dark Matter of the Biosphere: the Amazing World of Bacteriophage

862 Diversity. J Virol 89, 8107-8110, doi:10.1128/JVI.01340-15 (2015).

86312 Forsberg, K. J. et al. Functional metagenomics-guided discovery of potent Cas9 inhibitors in the human microbiome. eLife 8, e46540, doi:10.7554/eLife.46540 (2019).

865 Szczelkun, M. D. et al. Direct observation of R-loop formation by single RNA-guided Cas9 and Cascade effector complexes. Proc Natl Acad Sci U S A 111, 9798-9803, doi:10.1073/pnas.1402597111 (2014).

867

Farasat, I. \& Salis, H. M. A Biophysical Model of CRISPR/Cas9 Activity for Rational Design of Genome Editing and Gene Regulation. PLoS Comput Biol 12, e1004724, doi:10.1371/journal.pcbi.1004724 (2016). and supercoiling. Proc Natl Acad Sci U S A 117, 5853-5860, doi:10.1073/pnas.1913445117 (2020). Guide Length on Target Selection by a Cytosine-Specific Cas9. ACS Synth Biol 6, 11031113, doi:10.1021/acssynbio.7b00050 (2017).

881

882

Paez-Espino, D. et al. IMG/VR v.2.0: an integrated data management and analysis system for cultivated and environmental viral genomes. Nucleic acids research 47, D678-D686, doi:10.1093/nar/gky1127 (2019).

18 Pasolli, E. et al. Extensive Unexplored Human Microbiome Diversity Revealed by Over 150,000 Genomes from Metagenomes Spanning Age, Geography, and Lifestyle. Cell 176, 649-662 e620, doi:10.1016/j.cell.2019.01.001 (2019). 
$93036 \quad$ Osuna, B. A. et al. Listeria Phages Induce Cas9 Degradation to Protect Lysogenic Genomes. Cell Host Microbe 28, 31-40 e39, doi:10.1016/j.chom.2020.04.001 (2020).

37 Chevallereau, A. et al. Exploitation of the Cooperative Behaviors of Anti-CRISPR Phages. Cell Host Microbe 27, 189-198 e186, doi:10.1016/j.chom.2019.12.004 (2020). Borges, A. L. et al. Bacteriophage Cooperation Suppresses CRISPR-Cas3 and Cas9 Immunity. Cell 174, 917-925 e910, doi:10.1016/j.cell.2018.06.013 (2018). Landsberger, M. et al. Anti-CRISPR Phages Cooperate to Overcome CRISPR-Cas Immunity. Cell 174, 908-916 e912, doi:10.1016/j.cell.2018.05.058 (2018).

41 Pawluk, A., Davidson, A. R. \& Maxwell, K. L. Anti-CRISPR: discovery, mechanism and function. Nat Rev Microbiol, doi:10.1038/nrmicro.2017.120 (2017).

44 Zhu, W., Lomsadze, A. \& Borodovsky, M. Ab initio gene identification in metagenomic sequences. Nucleic Acids Res 38, e132, doi:10.1093/nar/gkq275 (2010).

Borges, A. L., Davidson, A. R. \& Bondy-Denomy, J. The Discovery, Mechanisms, and Evolutionary Impact of Anti-CRISPRs. Annu Rev Virol 4, 37-59, doi:10.1146/annurevvirology-101416-041616 (2017).

43 Li, W. \& Godzik, A. Cd-hit: a fast program for clustering and comparing large sets of protein or nucleotide sequences. Bioinformatics 22, 1658-1659, doi:10.1093/bioinformatics/btl158 (2006).

48 Parks, D. H. et al. A complete domain-to-species taxonomy for Bacteria and Archaea. Nat Biotechnol, doi:10.1038/s41587-020-0501-8 (2020).

49 Parks, D. H. et al. A standardized bacterial taxonomy based on genome phylogeny substantially revises the tree of life. Nat Biotechnol 36, 996-1004, doi:10.1038/nbt.4229 (2018).

50 Russel, J., Pinilla-Redondo, R., Mayo-Muñoz, D., Shah, S. A. \& Sørensen, S. J. CRISPRCasTyper: An automated tool for the identification, annotation and classification of CRISPR-Cas loci. bioRxiv, 2020.2005.2015.097824, doi:10.1101/2020.05.15.097824 (2020).

51 Bondy-Denomy, J. et al. A Unified Resource for Tracking Anti-CRISPR Names. The CRISPR Journal 1, 304-305, doi:10.1089/crispr.2018.0043 (2018).

52 Emsley, P., Lohkamp, B., Scott, W. G. \& Cowtan, K. Features and development of Coot. Acta Crystallogr D Biol Crystallogr 66, 486-501, doi:10.1107/S0907444910007493 (2010).

53 Adams, P. D. et al. PHENIX: a comprehensive Python-based system for macromolecular structure solution. Acta Crystallogr D Biol Crystallogr 66, 213-221, doi:10.1107/S0907444909052925 (2010). 
bioRxiv preprint doi: https://doi.org/10.1101/2020.09.28.317578; this version posted September 29,2020 . The copyright holder for this preprint (which was not certified by peer review) is the author/funder, who has granted bioRxiv a license to display the preprint in perpetuity. It is made available under aCC-BY-NC-ND 4.0 International license.

Table 1. Structural features of AcrllA22.

\begin{tabular}{|c|c|}
\hline Data collection & \\
\hline Space Group & P4332 \\
\hline \multicolumn{2}{|l|}{ Cell Dimensions } \\
\hline$a, b, c(\AA)$ & $128.56,128.56,128.56$ \\
\hline$\alpha, \beta, \gamma\left({ }^{\circ}\right)$ & $90.0,90.0,90.0$ \\
\hline Resolution $(\AA)$ & $50.00-2.80$ \\
\hline $\mathrm{R}_{\text {merge }}$ & $0.106(0.906)$ \\
\hline $1 / \sigma_{1}$ & $17.4(2.6)$ \\
\hline Completeness (\%) & $98.7(100.0)$ \\
\hline Redundancy & $10.4(10.7)$ \\
\hline CC 1/2 & 0.837 \\
\hline \multicolumn{2}{|l|}{ Refinement } \\
\hline No. Reflections & 9334 \\
\hline $\mathrm{R}_{\text {work }}\left(\mathrm{R}_{\text {free }}\right)(\%)$ & $22.2(24.6)$ \\
\hline No. Complex in ASU & 2 \\
\hline \multicolumn{2}{|l|}{ No. atoms } \\
\hline Protein & 810 \\
\hline Heteroatoms & 50 \\
\hline Water & 3 \\
\hline B-factor & 82.82 \\
\hline \multicolumn{2}{|l|}{ R.m.s deviations } \\
\hline Bond lengths $(\AA ̊)$ & 0.003 \\
\hline Bond angles $\left({ }^{0}\right)$ & 0.610 \\
\hline \multicolumn{2}{|l|}{ Ramachandran } \\
\hline Preferred (\%) & 98.15 \\
\hline Allowed (\%) & 1.85 \\
\hline Outliers (\%) & 0 \\
\hline
\end{tabular}




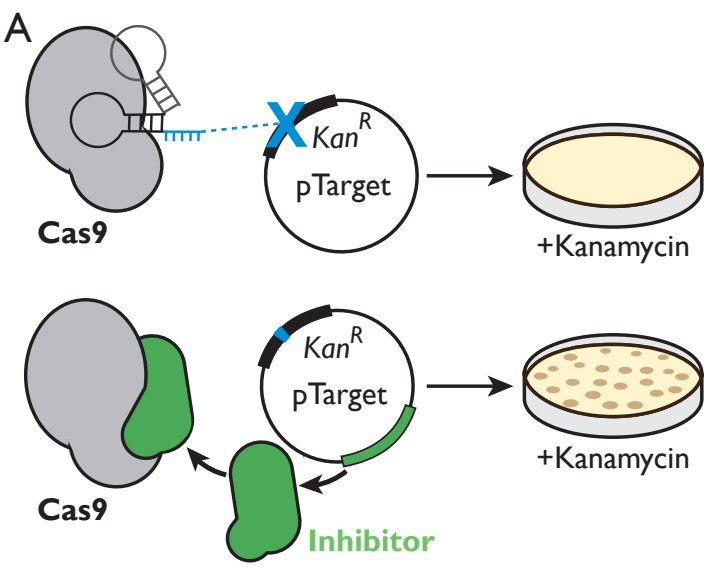

B
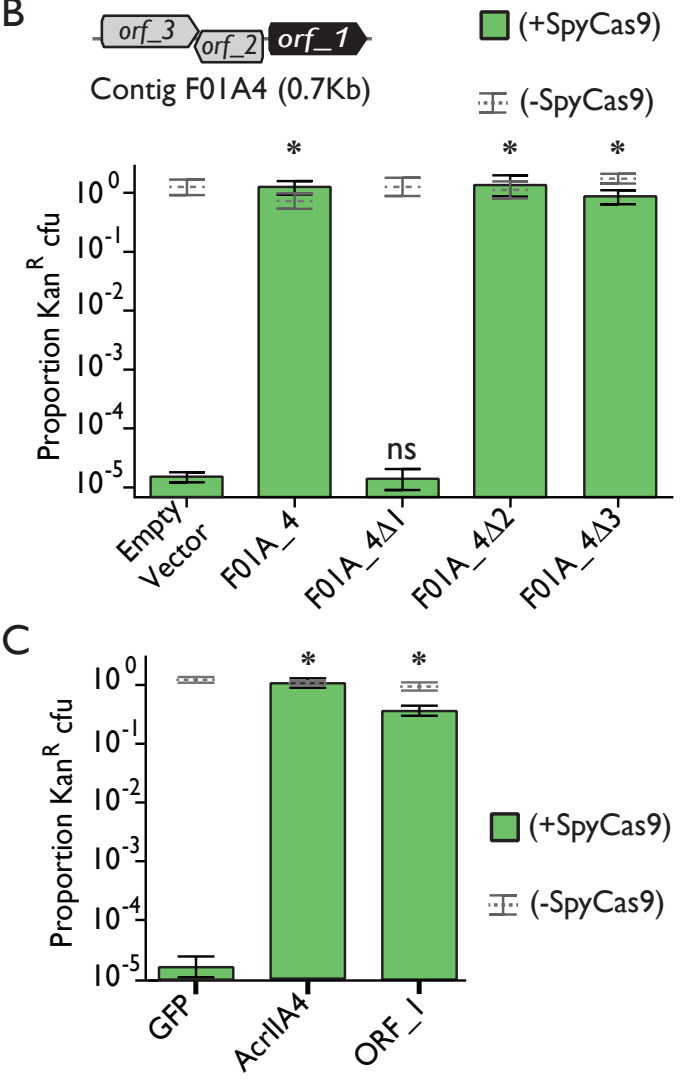

Figure 1. Orf_1 from the metagenomic contig F01A_4 encodes a SpyCas9 inhibitor. (A) The plasmid protection assay used to reveal SpyCas9 inhibition. Plasmids without SpyCas9 inhibitors are cleaved by Cas 9 and do not give rise to $\operatorname{Kan}^{R}$ colonies. Those with inhibitors withstand SpyCas9 attack and yield colonies. (B) An early stop codon in orf_1 ( $\Delta 1$ ), but not orf_2 or orf_3 ( $\Delta 2$ and $\Delta 3$ ), eliminates the ability of contig F01A_4 to protect a plasmid from SpyCas9. Asterisks depict statistically significant differences in plasmid retention between the indicated genotype and an empty vector control in SpyCas9-inducing conditions (Student's t-test, $p<0.002, n=3$ ); ns indicates no significance. All p-values were corrected for multiple hypotheses using Bonferroni's method. (C) Expression of orf_1 is sufficient for SpyCas9 antagonism, protecting a plasmid as well as acrllA4. Asterisks are as in panel B but relate to the GFP negative control rather than an empty vector. 
bioRxiv preprint doi: https://doi.org/10.1101/2020.09.28.317578; this version posted September 29, 2020. The copyright holder for this preprint (which was not certified by peer review) is the author/funder, who has granted bioRxiv a license to display the preprint in perpetuity. It is made available under aCC-BY-NC-ND 4.0 International license.
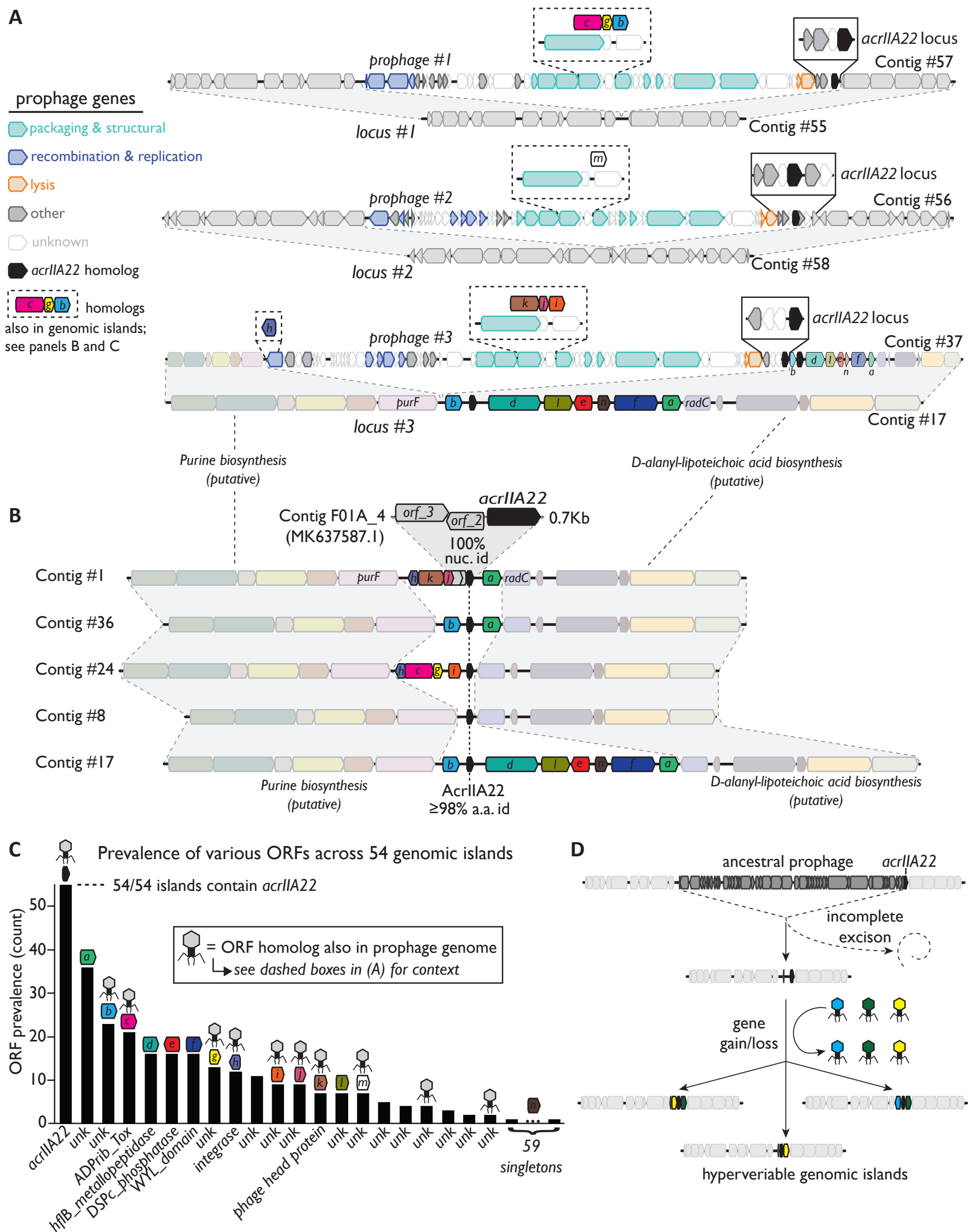

hyperveriable genomic islands

Figure 2. Caption on next page. 
Figure 2. AcrllA22 homologs are found in hypervariable regions of prophage and bacterial genomes. (A) Homologs of acrllA22 are depicted in three related prophage genomes, integrated at three different genomic loci, revealed by a comparison of prophage-bearing contigs (\#57, \#56, \#37) relative to unintegrated contigs (\#55, \#58, \#17 respectively) that are otherwise nearly identical. Prophage genes are colored by functional category, according to the legend at the left of panel A. Genes immediately adjacent to acrllA22 (solid boxes) vary across phages, despite strong relatedness across much of the prophage genomes. Bacterial genes are colored gray, except for in contig \#17, which is also depicted in panel B, below. (B) Homologs of acrllA22 are depicted in diverse genomic islands, including Contig \#1, whose sequence has perfect nucleotide identity to the original metagenomic contig we recovered (F01A_4). All acrllA22 homologs in these loci are closely related but differ in their adjacent genes, which often have homologs in the prophages depicted in panel A (dashed boxes). Genomic regions flanking these hypervariable islands are nearly identical to one another and to prophage integration locus \#3, as shown by homology to contig \#17 from panel A. (C) The prevalence of various protein families (clustered at $65 \%$ amino acid identity) in a set of 54 unique genomic islands is shown. Each of these islands is flanked by the conserved genes purF and radC but contains a different arrangement of encoded genes. Domain-level annotations are indicated below each protein family (unk; unknown function). Gene symbols above each protein family are colored and lettered to indicate their counterparts or homologs in panels $A$ and $B$. The phage capsid icon indicates sequences with homologs in prophage genomes. (D) An evolutionary model for the origin of the acrllA22-encoding hypervariable genomic islands depicted in panel B is shown. We propose that acrllA22 moved via a phage insertion into a bacterial genomic locus, remained following an incomplete prophage excision event, and its neighboring genes subsequently diversified via horizontal exchange with additional phage genomes. Contigs are numbered to indicate their descriptions in Supplemental Table 3, which contains their metadata, taxonomy, and sequence retrieval information. All sequences and annotations may also be found in Supplementary Datasets 1 and 2. 


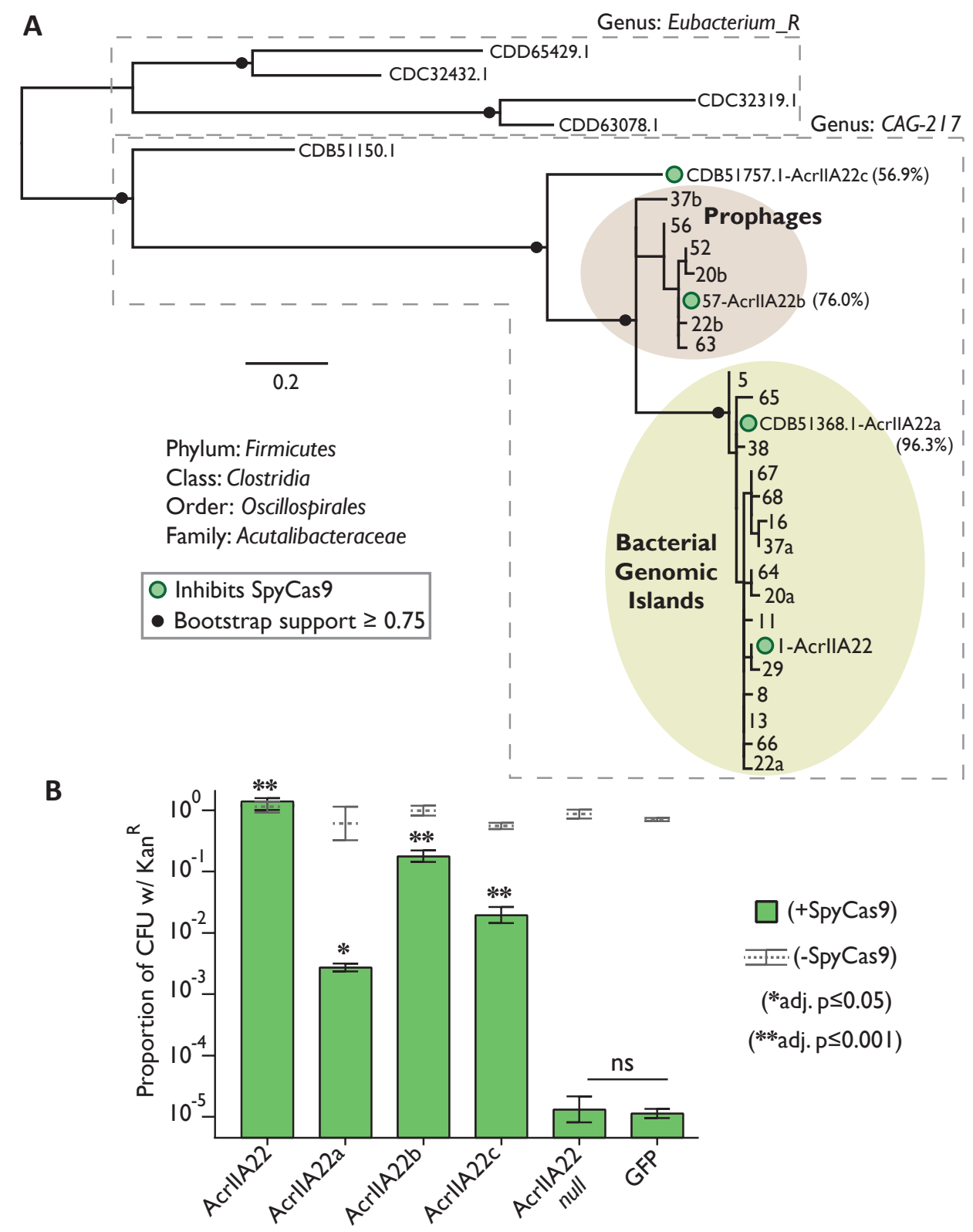

Figure 3. AcrllA22 homologs capable of inhibiting SpyCas9 are common in the unnamed Clostridial genus, CAG-217. Phylogenetic classifications were assigned corresponding to the GTDB naming convention (Methods). (A) A phylogeny of all unique AcrllA22 homologs identified from metagenomic and NCBI databases. Prophage sequences are shaded brown and homologs from hypervariable bacterial genomic islands are shaded yellow. Sequences obtained from NCBI are labeled with protein accession numbers. In other cases, AcrllA22 homologs are numbered to match their contig-of-origin (Supplemental Table 3). In some cases, more than one AcrlIA22 homolog is found on the same contig ('a' or 'b' indicates its presence in a hypervariable genomic island or prophage genome, respectively). Circles at nodes indicate bootstrap support $\geq 0.75$. Dashed boxes separate sequences identified from different bacterial genera. Filled green circles indicate homologs that were tested for their ability to inhibit SpyCas9 in the plasmid protection assay in panel B. (B) Homologs of AcrllA22 in CAG-217 genomes inhibit SpyCas9. Asterisks depict statistically significant differences in plasmid retention under SpyCas9-inducing conditions between the indicated sample and a null mutant with an early stop codon in acrllA22, per the legend at right (ns indicates no significance). All p-values were corrected for multiple hypotheses using Bonferroni's method (Student's t-test, $n=3$ ). 

available under aCC-BY-NC-ND 4.0 International license.

A

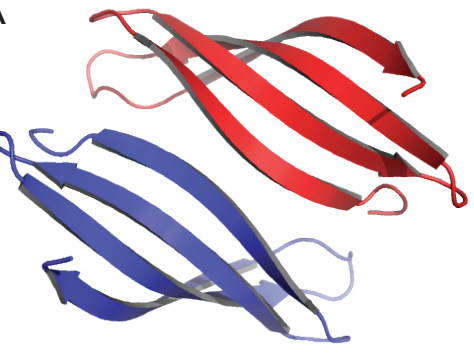

D

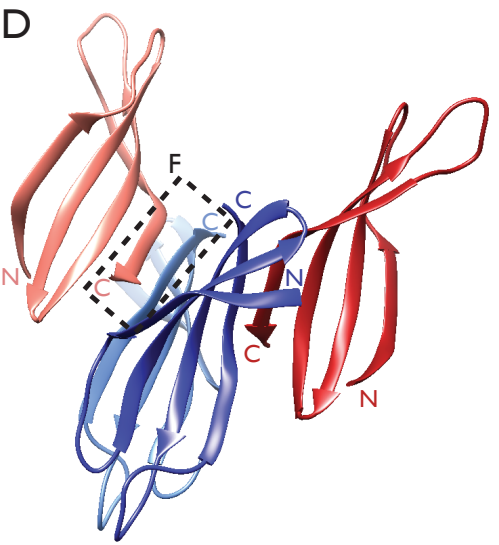

G

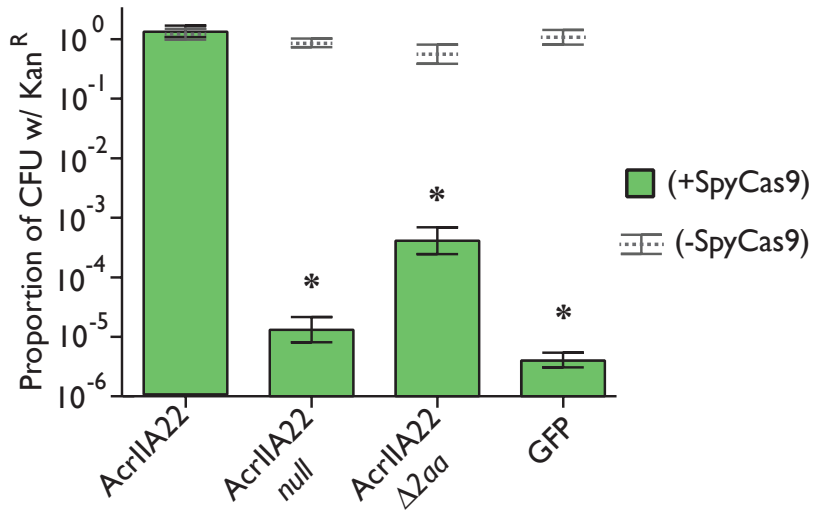

B

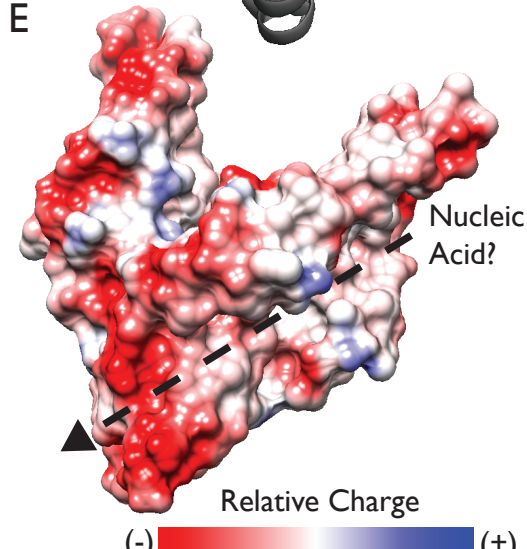

$E$

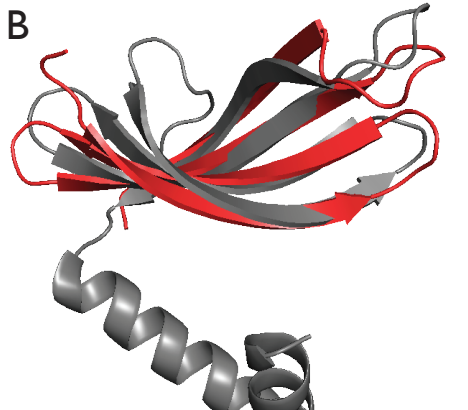

C

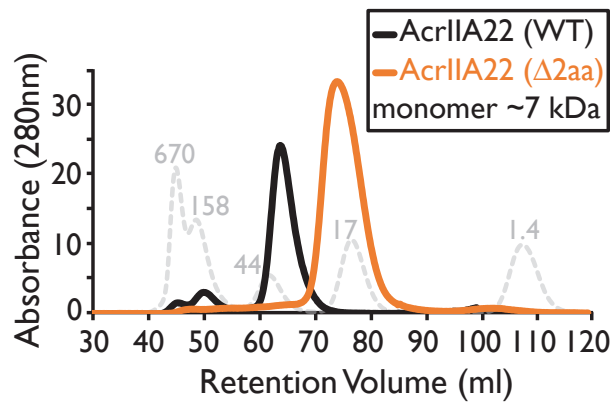

$\mathrm{F}$
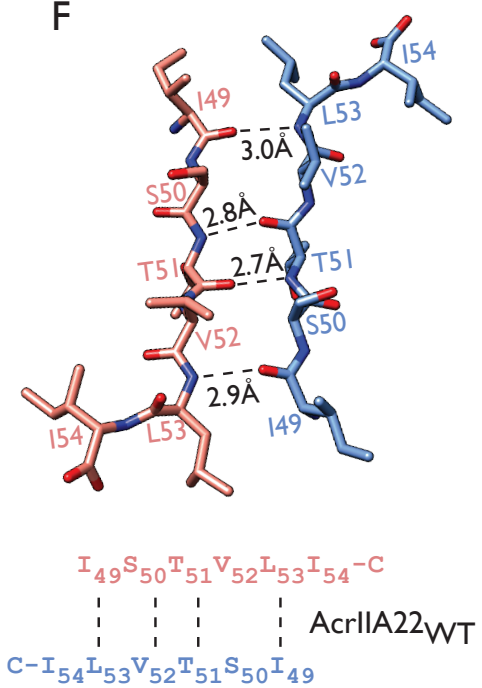

$I_{49} S_{50} T_{51} V_{52}-(\Delta 2)-C$

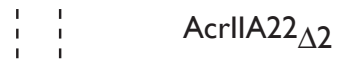

$C-(\Delta 2)-v_{52} T_{51} S_{50} I_{49}$

Figure 4. AcrllA22 is a PC4-like protein that oligomerizes and inhibits SpyCas9. (A) AcrllA22's crystal structure reveals a homodimer of two four-stranded $\beta$-sheets. (B) A monomer of AcrllA22 (PDB:7JTA) is structurally similar to a predicted single-stranded DNA binding protein, which is proposed to promote recombination in phage T5 (PDB:4BG7, Z-score $=6.2$, matched residues $15 \%)$. (C) AcrlIA22 elutes as an oligomer that is 4-5 times the predicted molecular mass of its monomer. The gray, dashed trace depicts protein standards of the indicated molecular weight. The orange trace depicts the elution profile of a two-amino acid C-terminal AcrllA22 truncation mutant. (D) Ribbon diagram of a proposed AcrlIA22 tetramer which requires binding between anti-parallel $\beta$-strands at the C-termini of AcrllA22 monomers to form extended, concave $\beta$ sheets. This putative oligomerization interface is indicated by the dashed box and is detailed in panel F. (E) Space filling model of the tetrameric AcrllA22 structure from panel D, with relative charge depicted, highlighting a groove (dashed line with arrowhead) that may accommodate nucleic acids. (F) A putative oligomerization interface between the C-termini of two AcrllA22 monomers is shown with hydrogen bond distances between the polypeptide backbones indicated. The wild-type sequence and truncation mutant are indicated below. Dashed lines indicate potential hydrogen bonds. This interface occurs twice in the putative tetramer, between red-hued and blue-hued monomers in panel D. (G) The truncation mutant fails to protect a plasmid from SpyCas9 elimination, similar to an early stop codon mutant (null) and a gfp negative control. Asterisks depict statistically significant differences in plasmid retention under SpyCas9-inducing conditions between the indicated sample and the wild-type sequence (adj. $p<0.002$, Student's ttest, $n=3$ ). All $p$-values were corrected for multiple hypotheses using Bonferroni's method. 


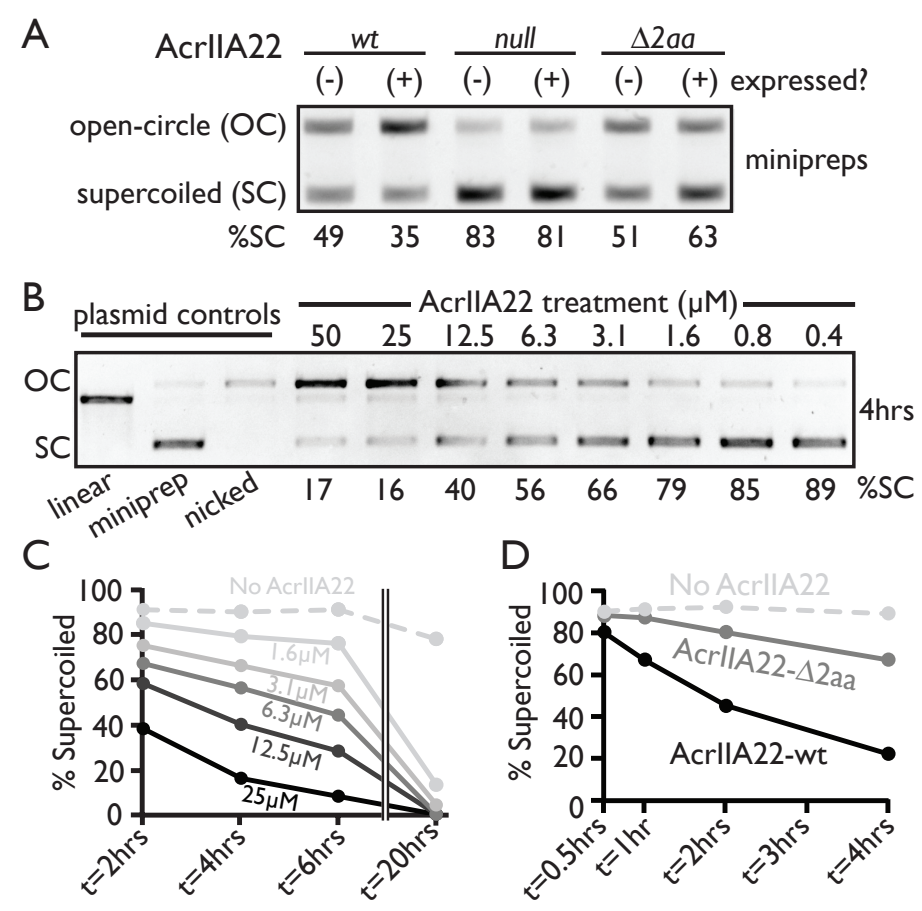

Figure 5. AcrllA22 nicks supercoiled plasmids in vivo and in vitro. (A) Gel electrophoresis of plasmids purified from overnight $E$. coli cultures expressing the indicated genotypes. OC, opencircle plasmid; SC, supercoiled plasmid. \%SC indicates the percentage of DNA in the supercoiled form for each sample. (B) AcrlIA22 nicks supercoiled plasmids in vitro. Supplemental Figure 7 depicts this experiment at additional time points. (C) Quantification of AcrllA22-nicked plasmids in panel B and Supplemental Figure 7. AcrllA22 nicks plasmids in a time and concentrationdependent manner. (D) A nickase assay as in panels $B$ and $C$ shows that the 2-aa truncation mutant is impaired for activity in vitro, relative to wild-type AcrlIA22. In both cases, $25 \mu \mathrm{M}$ protein was used. 
A

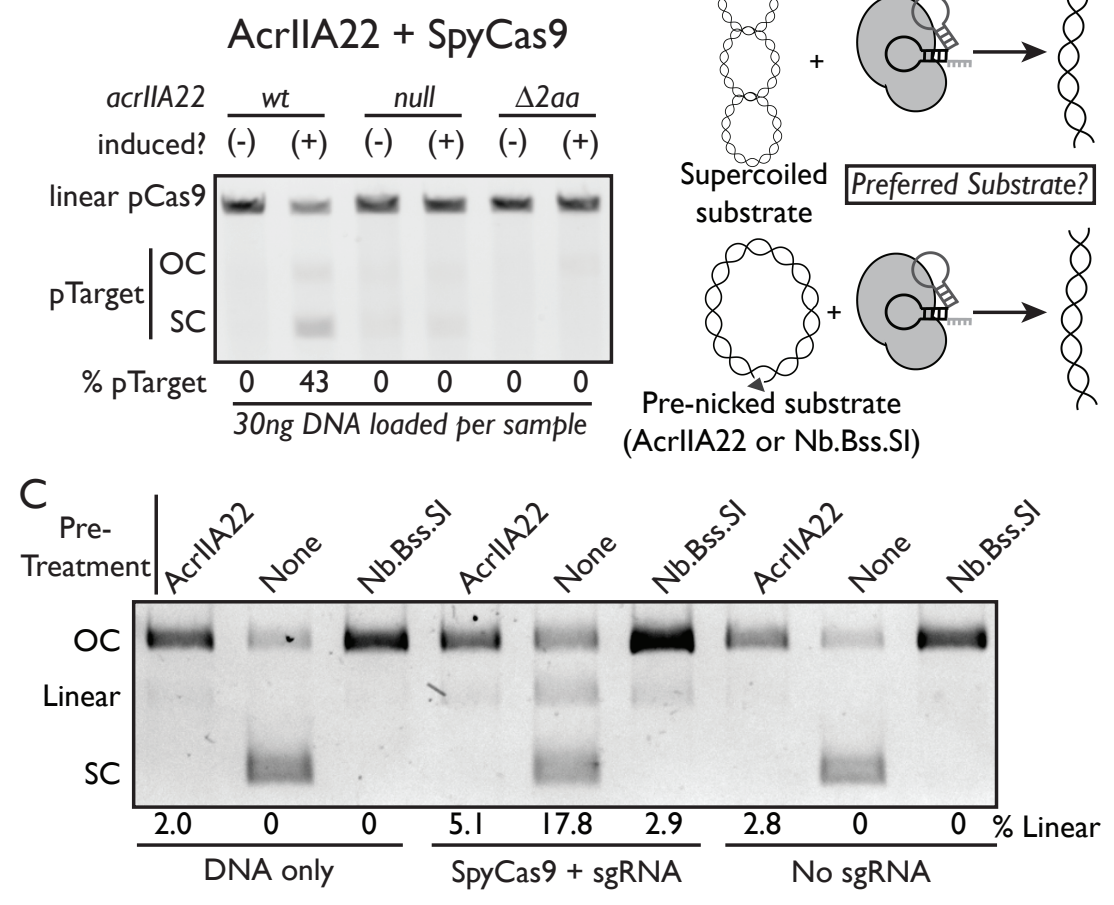

Figure 6. AcrllA22 protects plasmids from SpyCas9 cleavage in vivo and in vitro. (A) Gel electrophoresis of plasmids purified from overnight $E$. coli cultures expressing the indicated acrllA22 genotypes and SpyCas9 from a second plasmid. The acrllA22-encoding plasmids are indicated with the 'pTarget' label. OC, open-circle; SC, supercoiled. The SpyCas9 plasmid was linearized via a unique restriction site before electrophoresis. (B) Experimental design for the data depicted in panel C. The experiment tests whether SpyCas9 preferentially cleaves a supercoiled or open-circle plasmid target in vitro. (C) Nicked plasmids are less susceptible to linearization via SpyCas9 cleavage. Plasmid purifications from overnight cultures were either left unmodified or pre-treated with one of two nickase enzymes, AcrllA22 or Nb.Bss.SI. Linear, open-circle (OC), and supercoiled (SC) plasmid forms are indicated. The percentage of DNA in the linear form is quantified below the gel, where the reaction components are also listed. See Supplemental Figure 9 for these data in different reaction conditions. 


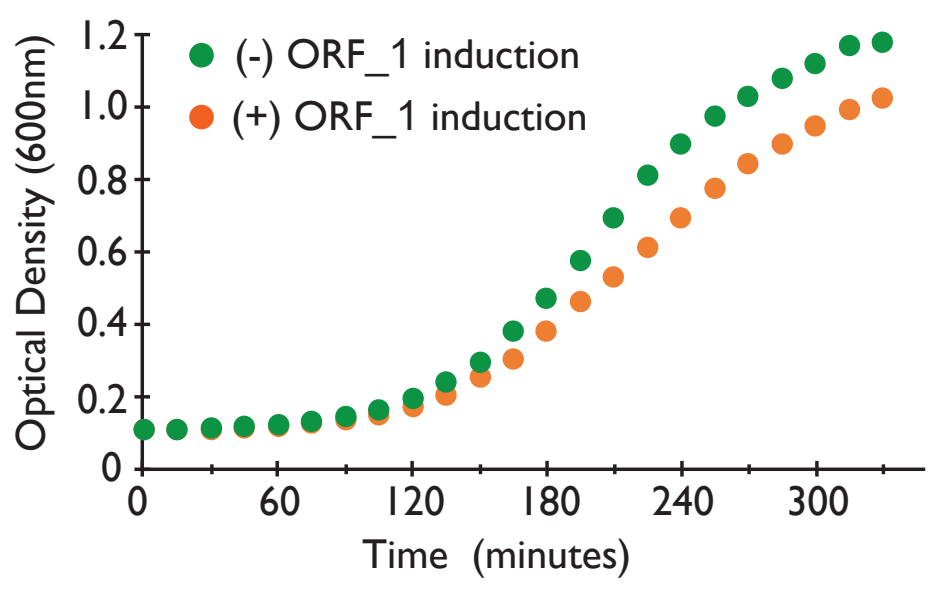

Supplemental Figure 1. Orf_1 confers mild toxicity in E. coli. Growth curves with (orange) and without (green) orf_1 induction. These growth data map directly to the cfu data in Figure 1C, demonstrating that anti-SpyCas 9 activity occurs under conditions with minimal orf_1 toxicity. Samples were removed after six hours of growth to plate for cfus. Growth curves are shown for samples without SpyCas 9 induction to ensure that orf_1 toxicity is not mitigated due to elimination of its plasmid. Points indicate averages from three replicates. Standard deviations at each timepoint are so small that the error bars do not exceed the bounds of the data point. 
A

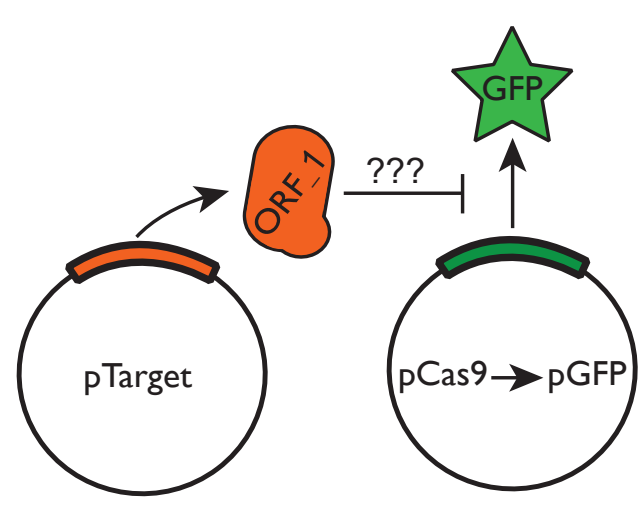

B

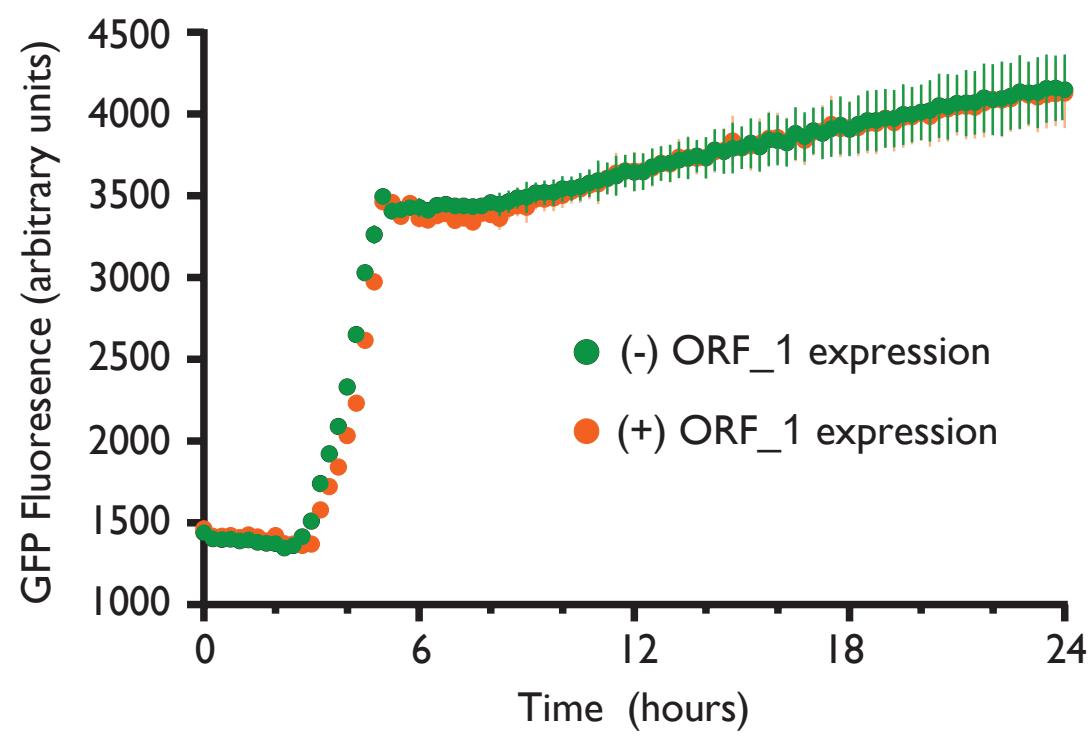

D
C

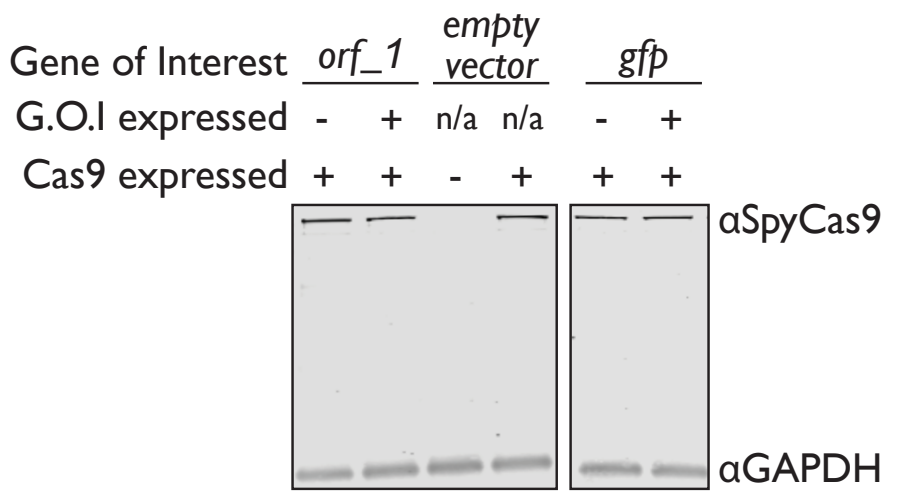

3 hours SpyCas9 expression

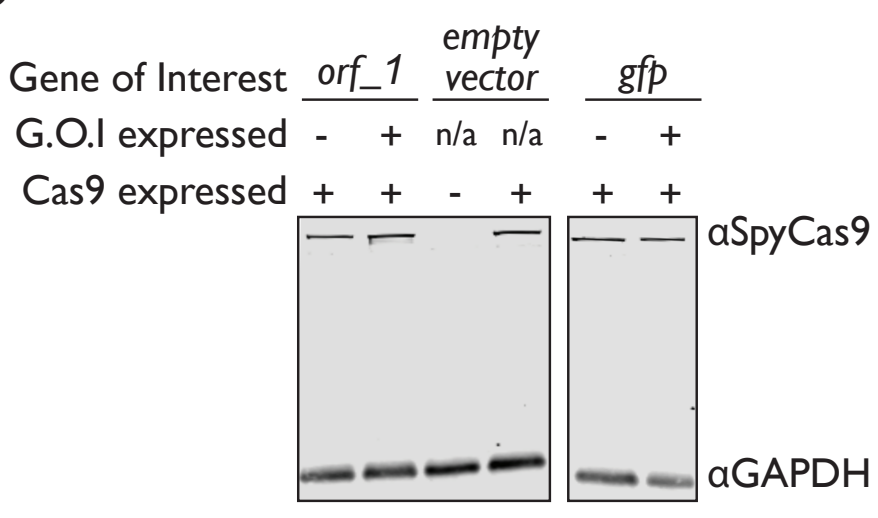

6 hours SpyCas9 expression

Supplemental Figure 2. Orf_1 does not impact SpyCas9 expression. (A) Cartoon depicting the experimental design for (B). If ORF_1 prevented transcription from pCas9 or altered its copy number, we would expect expression of the orf_1 gene to deplete the level of green fluorescence observed from a construct that replaces the spycas9 gene with gfp. (B) Fluorescence measurements for the experiment depicted in panel A, throughout an E. coli growth curve. ORF_1 does not impact GFP expression. Points indicate averages from three replicates, error bars indicate standard deviation. (C) A western blot to detect SpyCas9 expression as a function of ORF_1 or GFP expression in growing E. coli cultures. As an internal control, GAPDH expression was also detected. (D) As in panel C, but samples were collected six hours after SpyCas9 induction, instead of three. 
A

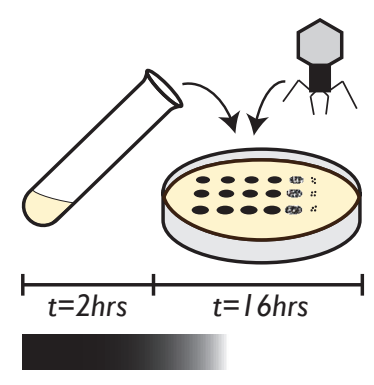

SpyCas9 Pulsed

B

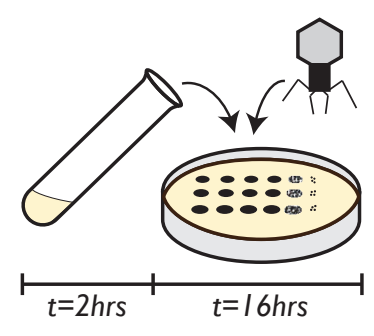

SpyCas9 Constant
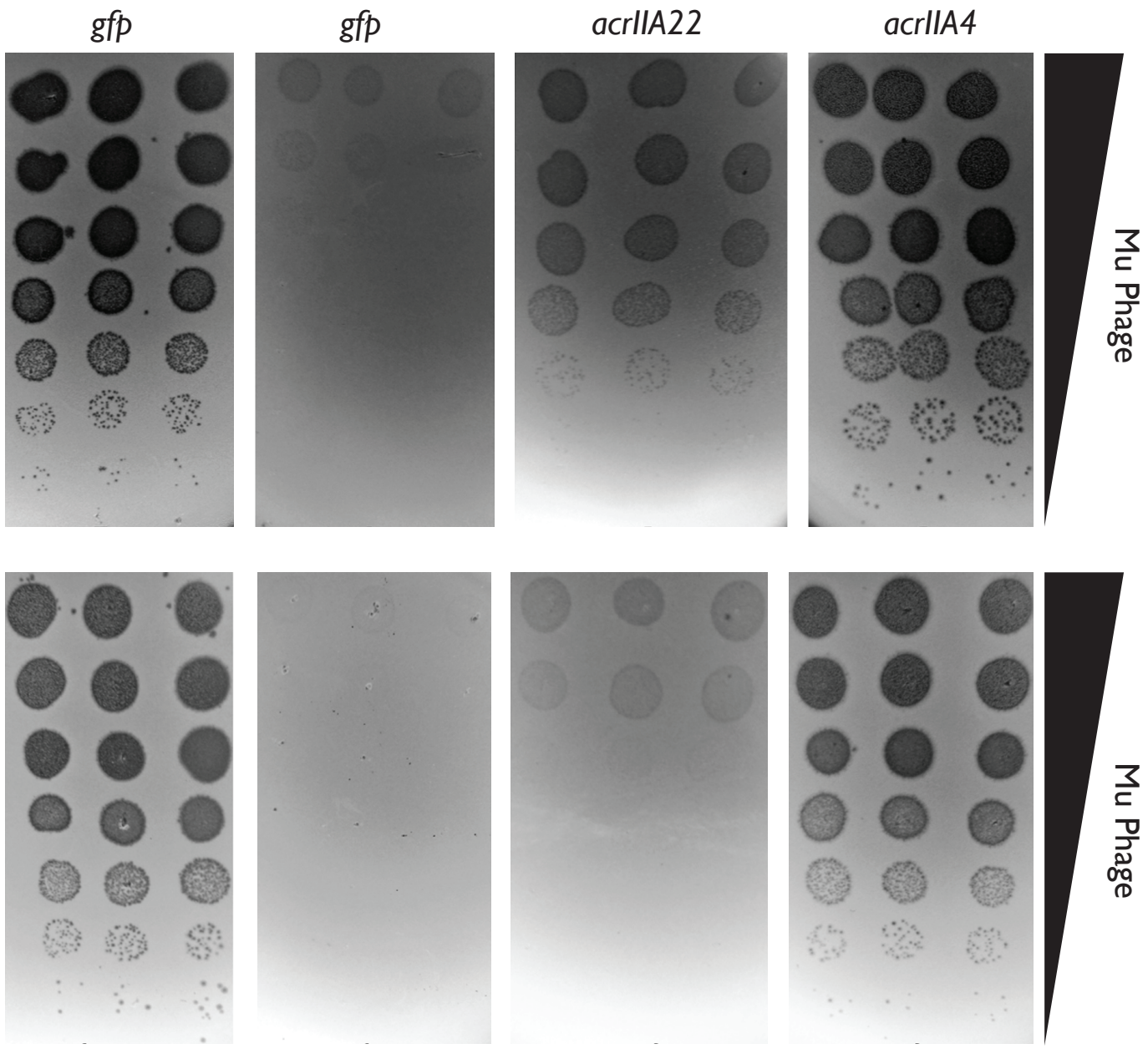

Mu-targeting crRNA

targeting

Supplemental Figure 3. Mu phage fitness, measured by plaquing on E. coli. Plaquing is measured in the presence of $g f p$, acrllA22, or acrllA4 via serial ten-fold dilutions. Bacterial clearing (black) occurs when phage Mu overcomes SpyCas9 immunity and lyses E. coli. In (A) and in (B), SpyCas9 with a Mu-targeting crRNA confers substantial protection against phage Mu relative to a non-targeting (n.t.) control, in both conditions tested. These conditions are depicted at left, with the only difference being whether SpyCas9 was only expressed in liquid growth prior to phage infection (panel $A$ ) or expressed both in liquid media and in solid media throughout infection (panel B). The positive control acrllA4 significantly enhances Mu fitness by inhibiting SpyCas9 in all conditions. In contrast, acrllA22 confers milder protection against SpyCas9. The indicated acr gene or gfp control is expressed from a second plasmid, in trans. 


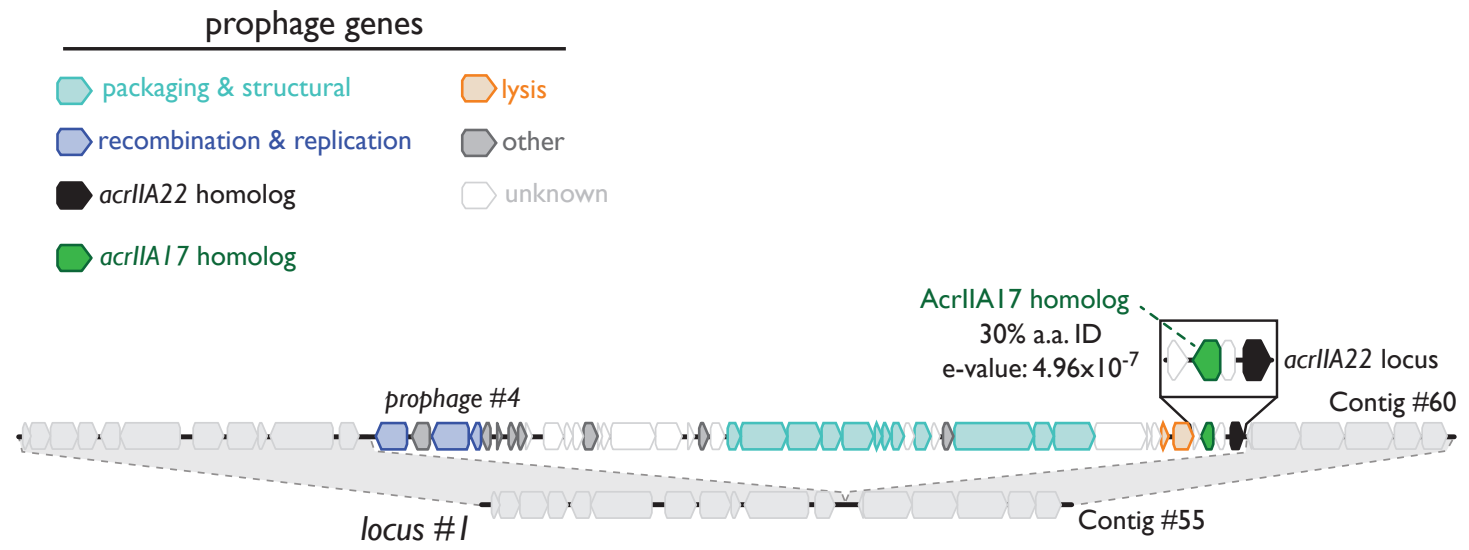

Supplemental Figure 4. An acrllA22-encoding prophage similar to those depicted in Figure 2A. Prophage genes are colored by functional category, per the legend and as in Figure 2. This prophage encodes for a homolog of the previously described SpyCas9 inhibitor acrllA17 within one kilobase of an acrllA22 homolog. Sequence relatedness for the depicted acrllA17 gene and the original discovery by Mahendra et al. is shown. Because phages often encode multiple acrs in the same locus, the co-localization of acrlIA17 with acrlIA22 is consistent with the latter gene functioning natively to inhibit CRISPR-Cas activity. Contigs are numbered to indicate their descriptions in Supplemental Table 3, which contains their metadata, taxonomy, and sequence retrieval information. All sequences and annotations may also be found in Supplementary Datasets 1 and 2. 


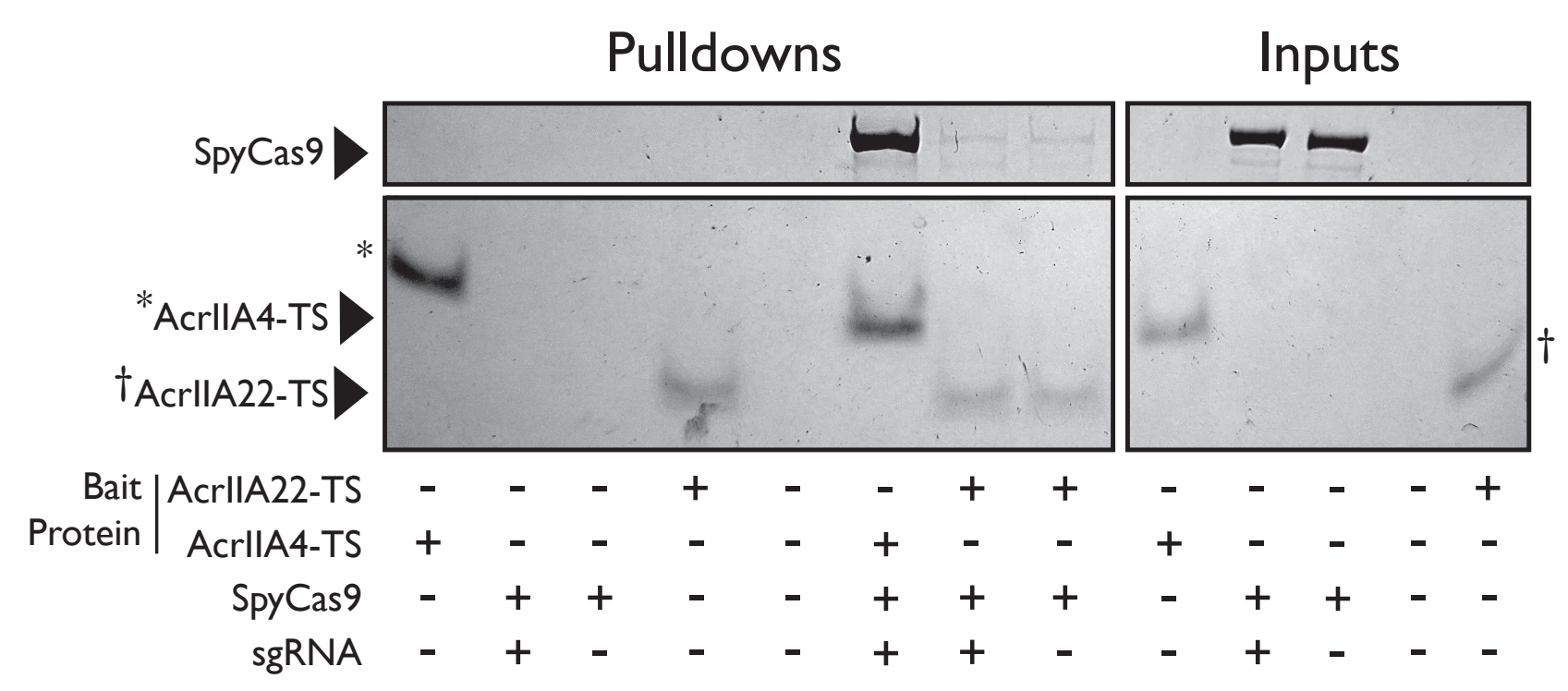

Supplemental Figure 5. AcrllA22 does not strongly bind SpyCas9. SpyCas9 and sgRNA were pre-incubated before mixing with a twin-strep (TS) tagged AcrllA22 or AcrllA4. SpyCas9 without sgRNA was also used. (A) Streptactin pulldowns on AcrllA4 also pulled down SpyCas9 preincubated with sgRNA, as previously reported. Similar pulldowns with AcrllA22 indicate little to no interaction with SpyCas9, regardless of whether sgRNA was used. These images depict total protein content visualized by Coomassie stain. Reaction components are indicated below the gel image. Aterisks $\left({ }^{*}\right)$ and dagger $(\dagger)$ symbols indicate AcrllA4 and AcrllA22 protein bands that run at slightly different positions than expected due to gel smiling. 
A

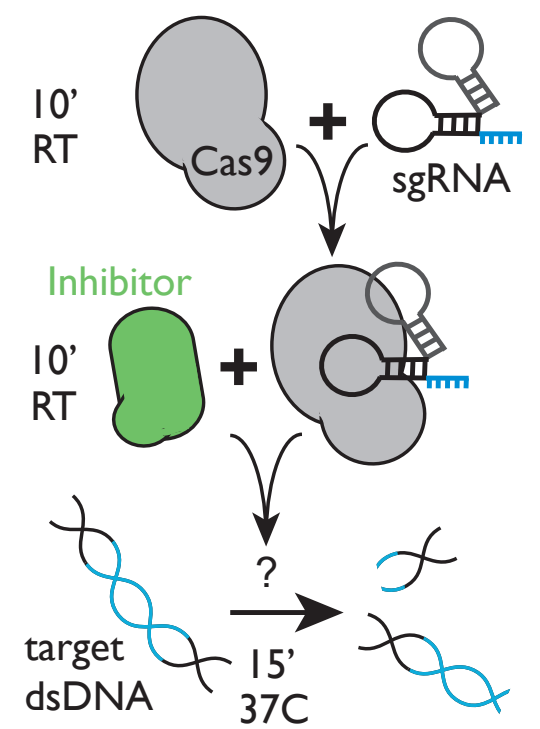

C

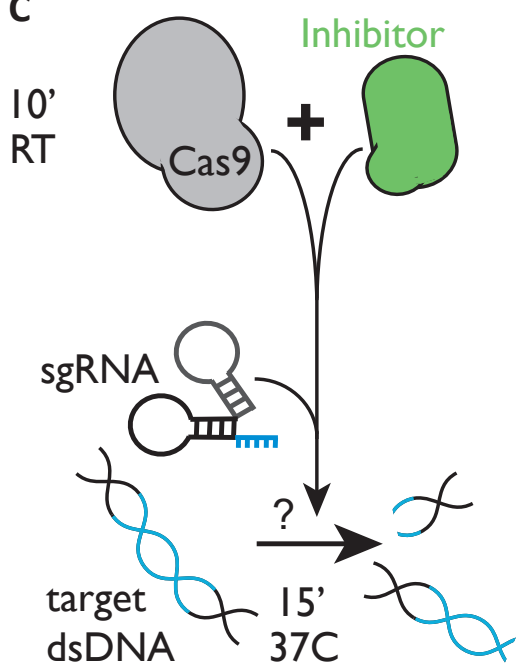

B

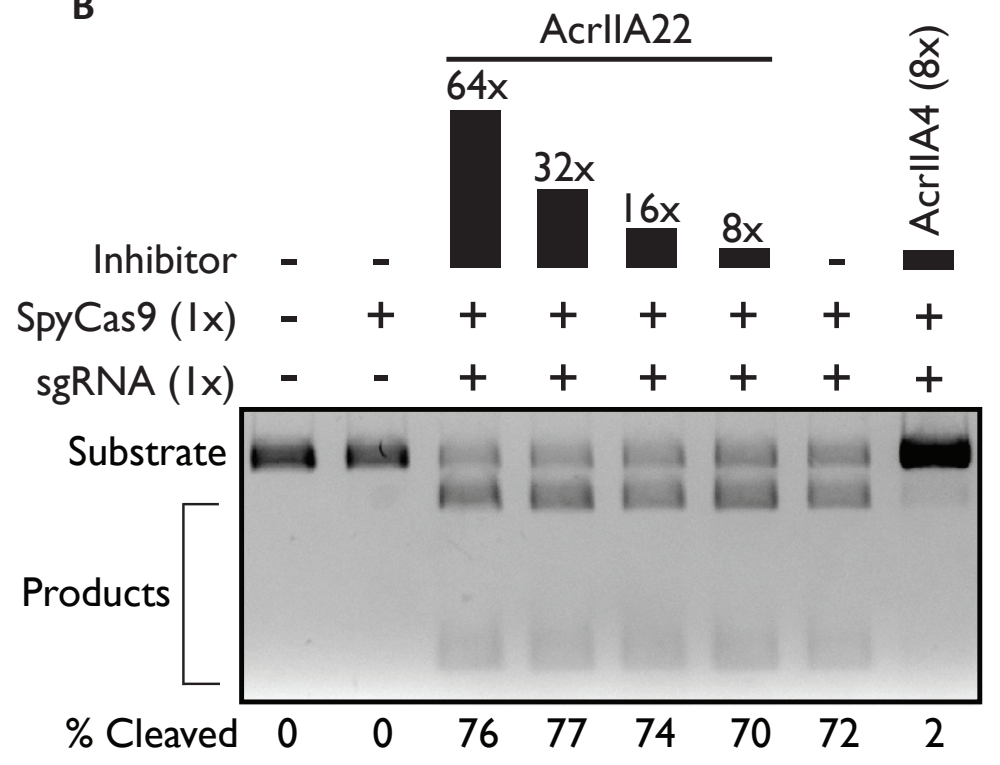

Supplemental Figure 6. AcrlIA22 does not inhibit SpyCas9 from cleaving linear DNA. (A) Cartoon depicting the experiment in (B). SpyCas9 was pre-incubated with sgRNA targeting linear DNA. Then, Acrs candidates were added. Subsequently, cleavage reactions were performed, and the DNA products visualized by gel electrophoresis in panel $B$. (B) Products of the reactions described in panel A for the inhibitors AcrllA22 and AcrllA4. Reaction components are depicted atop the gel image, with molar equivalents relative to SpyCas9 indicated. The percent of DNA substrate cleaved by SpyCas9 is quantified below each lane. (C) As in panel A, except candidate Acrs were incubated with SpyCas9 before sgRNA addition. Reactions were begun via the simultaneous addition of sgRNA and linear dsDNA instead of dsDNA in isolation. (D) The products of the reactions described in panel $C$ for AcrllA22 and AcrllA4 inhibitors. To push these Cas9 digestion reactions toward completion, ratios of Cas9:DNA were ten-fold higher than those shown in Figure 6C and reactions were allowed to progress for three times as long. 


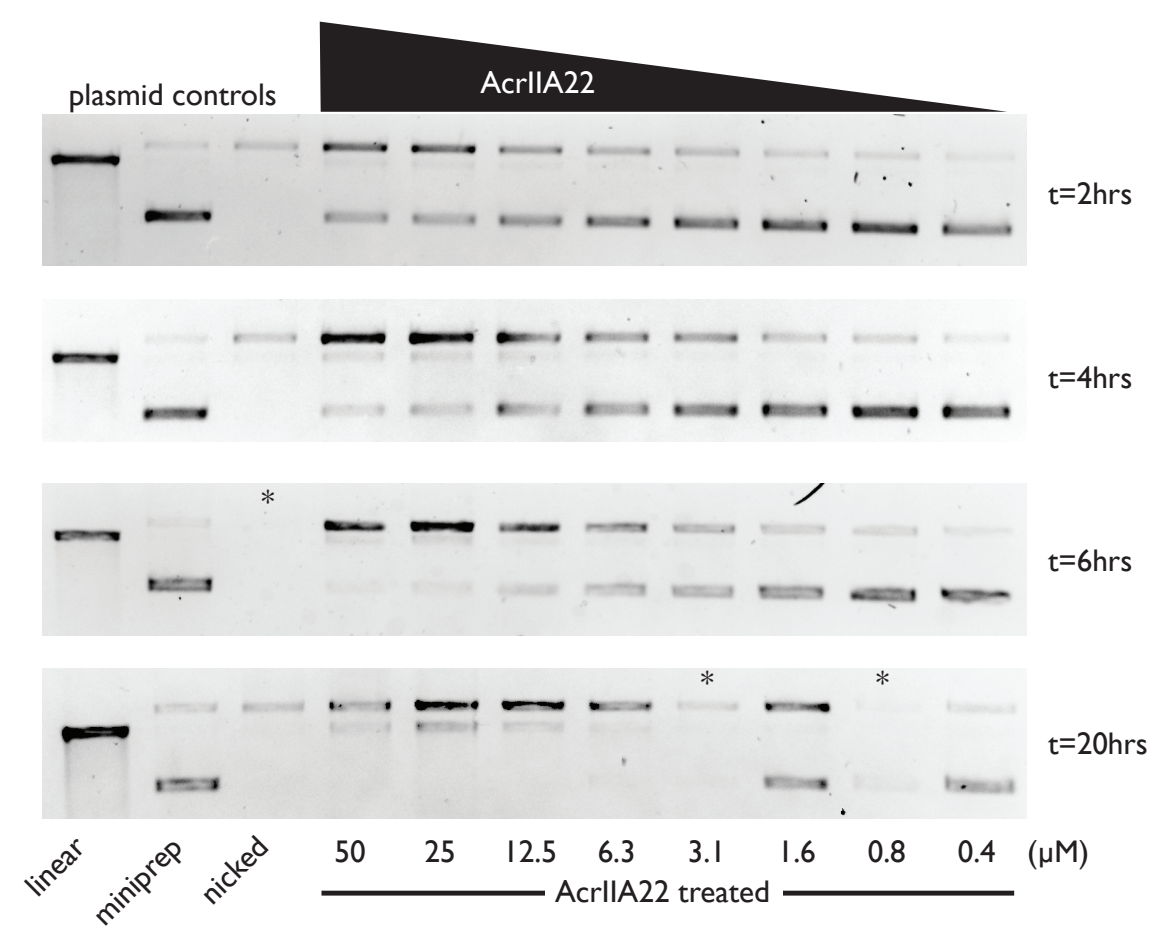

Supplemental Figure 7. AcrllA22 nicks supercoiled plasmids in vitro. Plasmid controls are in the leftmost three lanes. Reaction times are indicated to the right of each gel. AcrllA22 nicks supercoiled plasmids in a concentration and time dependent manner. Extended incubations at high concentrations produce a linearized product. Asterisks $\left(^{*}\right)$ indicate loading errors, where less sample was loaded than other lanes. 

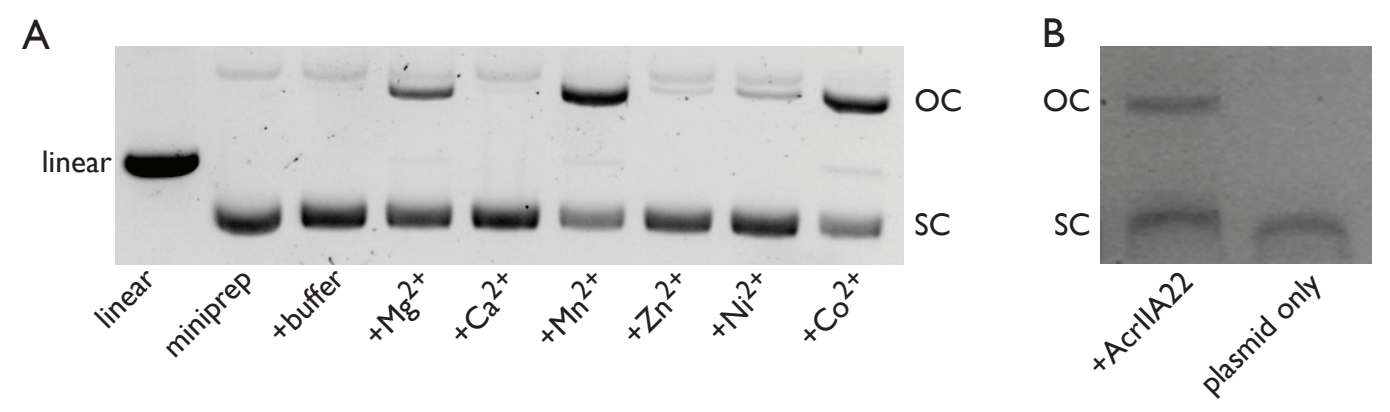

DNA visualized after phenol-chloroform extraction

Supplemental Figure 8. AcrllA22 is a nickase. (A) The impact of different divalent cations on AcrllA22's nickase activity. OC, open-circle plasmid form. SC, supercoiled plasmid. (B) The opencircle plasmid product persists through phenol-chloroform extraction following AcrllA22 treatment. 


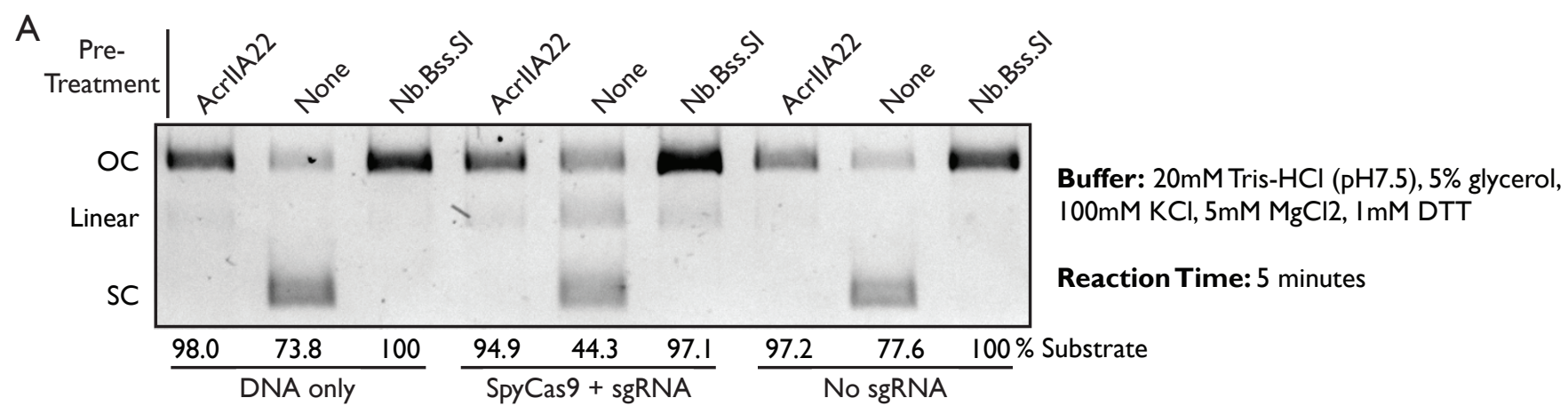

B

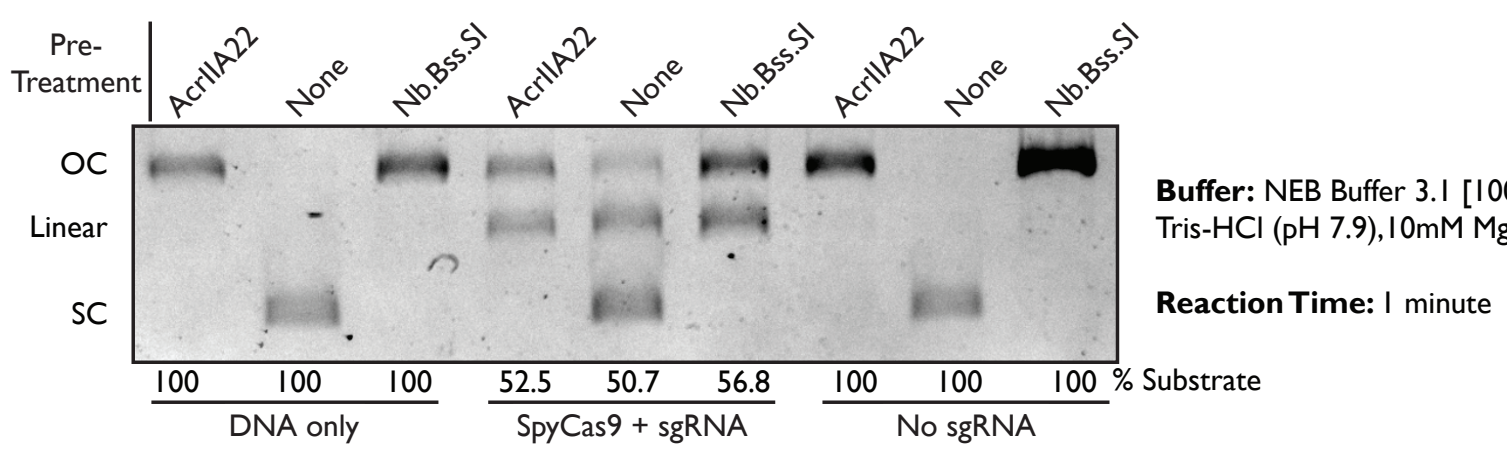

Supplemental Figure 9. Nicked plasmids are less susceptible to linearization via SpyCas9 cleavage. (A) As in Figure 6C, Plasmid purifications from overnight cultures were either left unmodified or pre-treated with one of two nickase enzymes, AcrllA22 or Nb.Bss.SI. Linear, opencircle (OC), and supercoiled (SC) plasmid forms are indicated. The \% substrate value indicates the percentage of DNA in the nicked form for AcrlIA22 or Nb.Bss.SI-treated plasmids or in the supercoiled form for the untreated miniprep. Reaction components are listed below each lane. Buffer conditions and reaction time is listed at right. (B) As in (A), but with different reaction conditions, listed at right. In these conditions, the reaction proceeded too quickly to detect SpyCas9's substrate preference (all substrates were rapidly linearized). 
Supplemental Table 1. Whether anti-CRISPRs are known to bind Cas proteins and inhibit their cleavage activity as purified proteins.

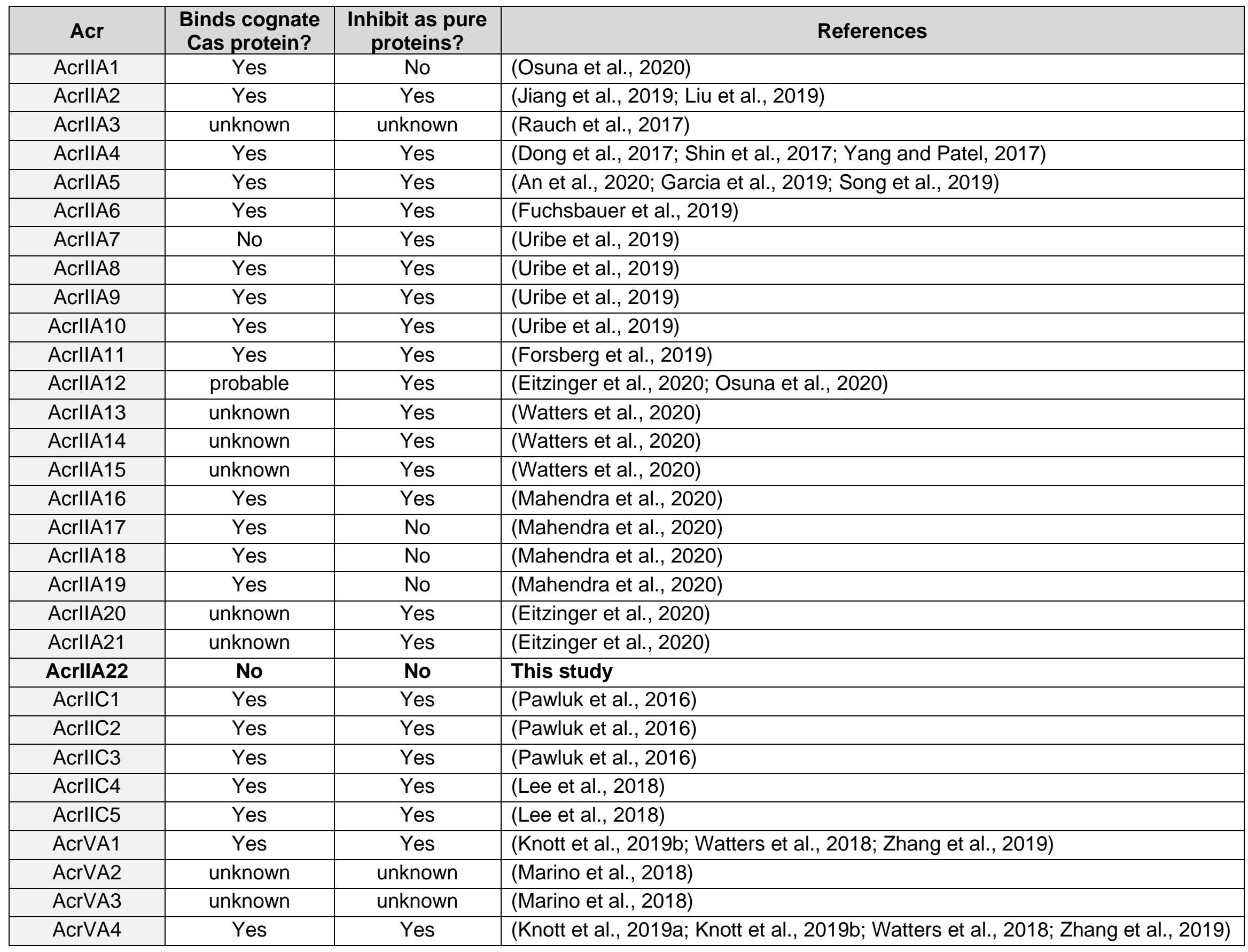




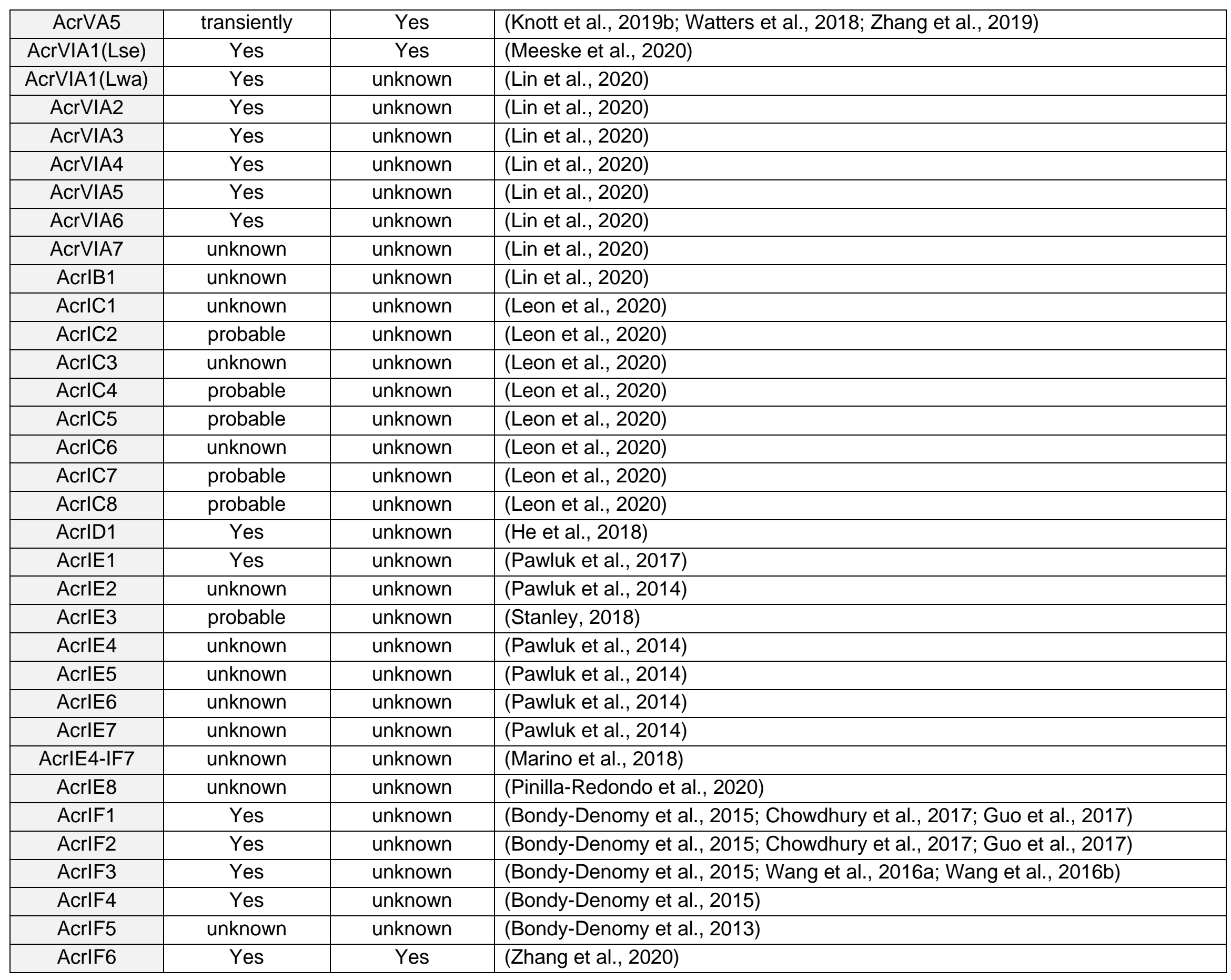




\begin{tabular}{|c|c|c|c|}
\hline AcrlF7 & Yes & unknown & (Hirschi et al., 2020) \\
\hline AcrlF8 & Yes & Yes & (Zhang et al., 2020) \\
\hline AcrlF9 & Yes & Yes & (Hirschi et al., 2020; Zhang et al., 2020) \\
\hline AcrIF10 & Yes & unknown & (Guo et al., 2017) \\
\hline AcrIF12 & unknown & unknown & (Marino et al., 2018) \\
\hline AcrIF13 & unknown & unknown & (Marino et al., 2018) \\
\hline AcrIF16 & unknown & unknown & (Pinilla-Redondo et al., 2020) \\
\hline AcrIF17 & unknown & unknown & (Pinilla-Redondo et al., 2020) \\
\hline AcrlF18 & probable & unknown & (Pinilla-Redondo et al., 2020) \\
\hline AcrIF19 & unknown & unknown & (Pinilla-Redondo et al., 2020) \\
\hline AcrlF20 & unknown & unknown & (Pinilla-Redondo et al., 2020) \\
\hline Acrlll-1 & $\begin{array}{l}\text { No (degrades } \\
\text { CA4 second } \\
\text { messenger) }\end{array}$ & No & (Athukoralage et al., 2020) \\
\hline AcrllIB1 & Yes & unknown & (Bhoobalan-Chitty et al., 2019) \\
\hline
\end{tabular}


Supplemental Table 2. PC4-like proteins with structural homology to AcrlIA22

\begin{tabular}{|c|c|c|c|c|c|c|}
\hline \multicolumn{2}{|r|}{ Structural Homolog } & \multirow{2}{*}{$\begin{array}{c}\text { Function } \\
\text { DNA/RNA Binding } \\
\end{array}$} & \multicolumn{4}{|c|}{ Similarity to AcrllA22 } \\
\hline PDBID & Name & & Zscore & r.m.s.d. & $\mathrm{n}$-align & $\%$ A.A. ID \\
\hline $4 \mathrm{bg} 7$ & PC4 putative transcriptional coactivator p15 & DNA & 6.2 & 2.5 & 54 & 15 \\
\hline $3 k 44$ & D. melanogaster Pur- $\alpha$ & DNA/RNA & 5.9 & 2.6 & 47 & 9 \\
\hline $5 f g p$ & Pur- $\alpha$ repeat I and II from D. melanogaster & DNA/RNA & 5.6 & 2.1 & 48 & 8 \\
\hline $3 n 8 b$ & Pur- $\alpha$ from B. burgdorferi & DNA/RNA & 5 & 2.8 & 48 & 6 \\
\hline 2gje & $\begin{array}{l}\text { Mitochondrial RNA Binding Protein } \\
\text { (Trypanosoma brucei) }\end{array}$ & RNA & 4.9 & 2.5 & 52 & 8 \\
\hline $5 z k l$ & $\begin{array}{l}\text { Protein of unknown function SP_0782, S. } \\
\text { pneumoniae }\end{array}$ & DNA & 4.7 & 3.6 & 52 & 12 \\
\hline $5 f g o$ & D. melanogaster Pur- $\alpha$ repeat III & No info & 4.5 & 2.7 & 44 & 14 \\
\hline $1 \mathrm{pcf}$ & Replication \& transcription cofactor PC4 CTD & DNA & 4.5 & 2.5 & 45 & 7 \\
\hline 2ltt & Putative Uncharacterized Protein YDBC & DNA & 4.5 & 2.8 & 50 & 12 \\
\hline 4bhm & MoSub1-DNA PC4 transcription cofactor & DNA & 3.9 & 2.8 & 45 & 4 \\
\hline $3 \mathrm{~cm} 1$ & $\begin{array}{l}\text { SSGA-like sporulation specific cell division } \\
\text { protein }\end{array}$ & No info & 2.8 & 3.7 & 47 & 13 \\
\hline $113 a$ & Transcription factor PBF-2 (P24, WHY1) & DNA & 2.8 & 5 & 48 & 8 \\
\hline 4 ntq & Anti-toxin Cdil, E. cloacae & No info & 2.7 & 3 & 49 & 12 \\
\hline $3 n 1 k$ & WHY2 transcription factor, S. tuberosum & DNA & 2.6 & 2.8 & 52 & 4 \\
\hline
\end{tabular}

${ }^{*}$ RNA/DNA binding data from (Janowski and Niessing, 2020). 
Supplemental Table 3. All sequences used in this study. Sequence names and databases are indicated. All sequences and annotations are also available as supplemental data. Sequences retrieved from Pasolli et al. refer to the following study: (Pasolli et al., 2019).

\begin{tabular}{|c|c|c|c|c|c|c|c|c|c|}
\hline $\begin{array}{l}\text { Contig } \\
\text { No. }\end{array}$ & Sequence Name & How Used? & $\begin{array}{l}\text { NCBI } \\
\text { Nuc. } \\
\text { ID }\end{array}$ & $\begin{array}{l}\text { Pasolli } \\
\text { et al } \\
\text { SGB? }\end{array}$ & $\begin{array}{l}\text { Pasolli et } \\
\text { al Raw } \\
\text { Assembly? }\end{array}$ & $\begin{array}{c}\text { Pasolli } \\
\text { Reconstructed } \\
\text { Genome Name }\end{array}$ & $\begin{array}{c}\text { SGB } \\
\text { id }\end{array}$ & GTDB Taxonomy & $\begin{array}{l}\text { External Data } \\
\text { Available at: }\end{array}$ \\
\hline 1 & $\begin{array}{l}\text { 4303_LiJ_2014_V1.UC63- } \\
\text { 0_bin.67_NODE_112_leng } \\
\text { th_95405_cov_4.60675 }\end{array}$ & $\begin{array}{l}\text { Figures } 2 \text {, find gene } \\
\text { functions from } 54 \\
\text { unique genomic loci; } \\
\text { Figure } 3 \text { Acr Seq } \\
\end{array}$ & $\mathrm{n} / \mathrm{a}$ & Yes & No & $\begin{array}{l}\text { LiJ_2014_V1. } \\
\text { UC63- } \\
\text { 0__bin. } 67\end{array}$ & 4303 & $\begin{array}{c}d \_ \text {Bacteria; } p \_ \text {Firmicutes_A; } c \text { C_Clostridia; } \\
\text { o__scillospirales; } f \_ \text {Acutalibacteraceae; } \\
\text { g__CAG-217 }\end{array}$ & $\begin{array}{l}\text { http://segatalab.cibio } \\
\text {.unitn.it/data/Pasolli_ } \\
\text { et_al.html }\end{array}$ \\
\hline 2 & $\begin{array}{l}\text { Bengtsson- } \\
\text { PalmeJ_2015_TRAVELRE } \\
\text { S9_NODE_4_length_53858 } \\
0 \text { cov } 9.43148\end{array}$ & $\begin{array}{l}\text { find gene functions } \\
\text { from } 54 \text { unique } \\
\text { genomic loci }\end{array}$ & $\mathrm{n} / \mathrm{a}$ & No & Yes & $\mathrm{n} / \mathrm{a}$ & $\mathrm{n} / \mathrm{a}$ & $\begin{array}{c}\text { d_Bacteria; } p \_ \text {Firmicutes_A; c_Clostridia; } \\
\text { o__Oscillospirales; } f \text { Acutalibacteraceae; } \\
\text { g__CAG-217 (inferred) }\end{array}$ & $\begin{array}{l}\text { http://segatalab.cibio } \\
\text {.unitn.it/data/Pasolli_ } \\
\text { et_al.html }\end{array}$ \\
\hline 3 & $\begin{array}{c}\text { ChengpingW_2017_AS9ra } \\
\text { w_NODE_922_length_2766 } \\
\text { 4_cov_3.49089 }\end{array}$ & $\begin{array}{l}\text { find gene functions } \\
\text { from } 54 \text { unique } \\
\text { genomic loci }\end{array}$ & $\mathrm{n} / \mathrm{a}$ & No & Yes & $\mathrm{n} / \mathrm{a}$ & $\mathrm{n} / \mathrm{a}$ & 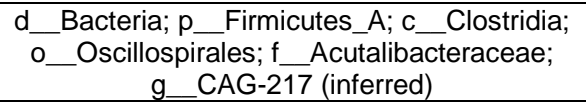 & $\begin{array}{l}\text { http://segatalab.cibio } \\
\text {.unitn.it/data/Pasolli_ } \\
\text { et_al.html }\end{array}$ \\
\hline 4 & $\begin{array}{l}\text { CosteaPI_2017_SID713B0 } \\
\text { 25-11-0- } \\
\text { 0_NODE_4_length_351620 } \\
\text { cov_7.46108 }\end{array}$ & $\begin{array}{l}\text { find gene functions } \\
\text { from } 54 \text { unique } \\
\text { genomic loci }\end{array}$ & $\mathrm{n} / \mathrm{a}$ & No & Yes & $\mathrm{n} / \mathrm{a}$ & $\mathrm{n} / \mathrm{a}$ & $\begin{array}{c}\text { d_Bacteria; } p_{\ldots} \text { Firmicutes_A; } c \text { CClostridia; } \\
\text { o__oscillospirales; } f \text { Acutalibacteraceae; } \\
\text { g_CAG-217 (inferred) }\end{array}$ & $\begin{array}{l}\text { http://segatalab.cibio } \\
\text {.unitn.it/data/Pasolli_ } \\
\text { et_al.html }\end{array}$ \\
\hline 5 & $\begin{array}{l}\text { BritolL_2016_M1.64.ST_N } \\
\text { ODE_47_length_140472_co } \\
\text { v_9.49805 }\end{array}$ & $\begin{array}{l}\text { find gene functions } \\
\text { from } 54 \text { unique } \\
\text { genomic loci; Figure } \\
3 \text { Acr Seq }\end{array}$ & $\mathrm{n} / \mathrm{a}$ & No & Yes & $\mathrm{n} / \mathrm{a}$ & $\mathrm{n} / \mathrm{a}$ & $\begin{array}{c}d \_ \text {Bacteria; } p \_ \text {Firmicutes_A; c_Clostridia; } \\
\text { o__Oscillospirales; } f \text { Acutalibacteraceae; } \\
\text { g__CAG-217 (inferred) }\end{array}$ & $\begin{array}{l}\text { http://segatalab.cibio } \\
\text {.unitn.it/data/Pasolli_ } \\
\text { et_al.html }\end{array}$ \\
\hline 7 & $\begin{array}{l}\text { BritolL_2016_WL.14.ST_N } \\
\text { ODE_13_length_259523_co } \\
\text { v_10.8408 }\end{array}$ & $\begin{array}{l}\text { find gene functions } \\
\text { from } 54 \text { unique } \\
\text { genomic loci }\end{array}$ & $\mathrm{n} / \mathrm{a}$ & No & Yes & $\mathrm{n} / \mathrm{a}$ & $\mathrm{n} / \mathrm{a}$ & $\begin{array}{c}\text { d_Bacteria; } p \ldots \text { Firmicutes_A; } c \text { CClostridia; } \\
\text { o_Oscillospirales; } f \text { Acutalibacteraceae; } \\
\text { g_CAG-217 (inferred) }\end{array}$ & $\begin{array}{l}\text { http://segatalab.cibio } \\
\text { unitn.it/data/Pasolli_ } \\
\text { et_al.html }\end{array}$ \\
\hline 8 & $\begin{array}{c}\text { ChengpingW_2017_AS67r } \\
\text { aw_NODE_2_length_43917 } \\
\text { 7_cov_9.00174 }\end{array}$ & $\begin{array}{l}\text { Figure } 2 \text {, find gene } \\
\text { functions from } 54 \\
\text { unique genomic loci; } \\
\text { Figure } 3 \text { Acr Seq }\end{array}$ & $\mathrm{n} / \mathrm{a}$ & No & Yes & $\mathrm{n} / \mathrm{a}$ & $\mathrm{n} / \mathrm{a}$ & $\begin{array}{c}\text { d_Bacteria; } p \_ \text {Firmicutes_A; c_Clostridia; } \\
\text { o__Oscillospirales; } f \text { Acutalibacteraceae; } \\
\text { g__CAG-217 (inferred) }\end{array}$ & $\begin{array}{l}\text { http://segatalab.cibio } \\
\text {.unitn.it/data/Pasolli_ } \\
\text { et_al.html }\end{array}$ \\
\hline 9 & $\begin{array}{c}\text { CM_madagascar_A90_04 } \\
\text { - } 1 \mathrm{FE} \_ \text {NODE_125_length_8 } \\
1453 \text { cov_9.00904 }\end{array}$ & $\begin{array}{l}\text { find gene functions } \\
\text { from } 54 \text { unique } \\
\text { genomic loci }\end{array}$ & $\mathrm{n} / \mathrm{a}$ & No & Yes & $\mathrm{n} / \mathrm{a}$ & $\mathrm{n} / \mathrm{a}$ & $\begin{array}{c}\text { d_Bacteria; } p_{\ldots} \text { Firmicutes_A; c_Clostridia; } \\
\text { o__scillospirales; } f \text { Acutalibacteraceae; } \\
\text { g_CAG-217 (inferred) }\end{array}$ & $\begin{array}{l}\text { http://segatalab.cibio } \\
\text { unitn.it/data/Pasolli_ } \\
\text { et_al.html }\end{array}$ \\
\hline 10 & $\begin{array}{l}\text { CM_madagascar_V12_01 } \\
\text { 2FE_NODE_5_length_202 } \\
\text { 628_cov_9.50435 }\end{array}$ & $\begin{array}{l}\text { find gene functions } \\
\text { from } 54 \text { unique } \\
\text { genomic loci }\end{array}$ & $\mathrm{n} / \mathrm{a}$ & No & Yes & $\mathrm{n} / \mathrm{a}$ & $\mathrm{n} / \mathrm{a}$ & 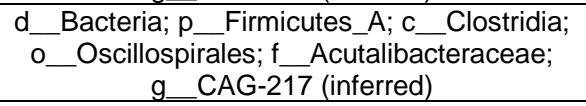 & $\begin{array}{l}\text { http://segatalab.cibio } \\
\text {.unitn.it/data/Pasolli_ } \\
\text { et_al.html }\end{array}$ \\
\hline 11 & $\begin{array}{c}\text { CosteaPI_2017_SID713A0 } \\
\text { 46-11-0- } \\
\text { 0_NODE_322_length_6900 } \\
\text { 0_cov_4.32987 }\end{array}$ & $\begin{array}{l}\text { find gene functions } \\
\text { from } 54 \text { unique } \\
\text { genomic loci; Figure } \\
3 \text { Acr Seq } \\
\end{array}$ & $\mathrm{n} / \mathrm{a}$ & No & Yes & $\mathrm{n} / \mathrm{a}$ & $\mathrm{n} / \mathrm{a}$ & $\begin{array}{c}\text { d_Bacteria; } p \_ \text {Firmicutes_A; c_Clostridia; } \\
\text { o__Oscillospirales; } f \text { Acutalibacteraceae; } \\
\text { g__CAG-217 (inferred) }\end{array}$ & $\begin{array}{l}\text { http://segatalab.cibio } \\
\text {.unitn.it/data/Pasolli_ } \\
\text { et_al.html }\end{array}$ \\
\hline 12 & $\begin{array}{c}\text { CosteaPI_2017_SID713A0 } \\
\text { 45-11-0- } \\
\text { 0_NODE_78_length_64886 } \\
\text { Cov_3.97493 }\end{array}$ & $\begin{array}{l}\text { find gene functions } \\
\text { from } 54 \text { unique } \\
\text { genomic loci }\end{array}$ & $\mathrm{n} / \mathrm{a}$ & No & Yes & $\mathrm{n} / \mathrm{a}$ & $\mathrm{n} / \mathrm{a}$ & $\begin{array}{c}\text { d_Bacteria; } p \_ \text {Firmicutes_A; c_Clostridia; } \\
\text { o__oscillospirales; } f \text { Acutalibacteraceae; } \\
\text { g_CAG-217 (inferred) }\end{array}$ & $\begin{array}{l}\text { http://segatalab.cibio } \\
\text {.unitn.it/data/Pasolli_ } \\
\text { et_al.html }\end{array}$ \\
\hline 13 & $\begin{array}{c}\text { CosteaPI_2017_SID713A0 } \\
\text { 04-11-0- } \\
\text { 0_NODE_1_length_647860 } \\
\text { Cov_14.1013 }\end{array}$ & $\begin{array}{l}\text { find gene functions } \\
\text { from } 54 \text { unique } \\
\text { genomic loci; Figure } \\
3 \text { Acr Seq } \\
\end{array}$ & $\mathrm{n} / \mathrm{a}$ & No & Yes & $\mathrm{n} / \mathrm{a}$ & $\mathrm{n} / \mathrm{a}$ & $\begin{array}{c}\text { d_Bacteria; } p \_ \text {Firmicutes_A; c_Clostridia; } \\
\text { o__Oscillospirales; } f \text { Acutalibacteraceae; } \\
\text { g__CAG-217 (inferred) }\end{array}$ & $\begin{array}{l}\text { http://segatalab.cibio } \\
\text {.unitn.it/data/Pasolli_ } \\
\text { et_al.html }\end{array}$ \\
\hline 14 & $\begin{array}{l}\text { CosteaPI_2017_peacemak } \\
\text { er-11-60- }\end{array}$ & $\begin{array}{l}\text { find gene functions } \\
\text { from } 54 \text { unique } \\
\text { genomic loci }\end{array}$ & $\mathrm{n} / \mathrm{a}$ & No & Yes & $\mathrm{n} / \mathrm{a}$ & $\mathrm{n} / \mathrm{a}$ & $\begin{array}{c}\text { d_Bacteria; } p_{\text {__Firmicutes_A; }} \text { C_CClostridia; } \\
\text { o__scillospirales; } f \text { Acutalibacteraceae; } \\
\text { g_CAG-217 (inferred) }\end{array}$ & $\begin{array}{l}\text { http://segatalab.cibio } \\
\text { unitn.it/data/Pasolli_ } \\
\text { et_al.html }\end{array}$ \\
\hline
\end{tabular}




\begin{tabular}{|c|c|c|c|c|c|c|c|c|c|}
\hline & $\begin{array}{c}\text { 0_NODE_48_length_49378 } \\
\text { cov_15.5445 }\end{array}$ & & & & & & & & \\
\hline 15 & $\begin{array}{l}\text { CosteaPI_2017_SID713A0 } \\
\text { 63-11-90- } \\
\text { 0_NODE_2082_length_169 } \\
\text { 60_cov_2.98527 }\end{array}$ & $\begin{array}{l}\text { find gene functions } \\
\text { from } 54 \text { unique } \\
\text { genomic loci }\end{array}$ & $\mathrm{n} / \mathrm{a}$ & No & Yes & $\mathrm{n} / \mathrm{a}$ & $\mathrm{n} / \mathrm{a}$ & $\begin{array}{c}d \_ \text {Bacteria; } p \_ \text {Firmicutes_A; } c \text { _Clostridia; } \\
\text { o__oscillospirales; } f \_ \text {Acutalibacteraceae; } \\
\text { g_CAG-217 (inferred) }\end{array}$ & $\begin{array}{l}\text { http://segatalab.cibio } \\
\text {.unitn.it/data/Pasolli_ } \\
\text { et_al.html }\end{array}$ \\
\hline 16 & $\begin{array}{l}\text { CosteaPI_2017_SID713A0 } \\
\text { 88-11-0- } \\
\text { 0_NODE_89_length_11329 } \\
\text { 7_cov_5.77445 }\end{array}$ & $\begin{array}{l}\text { find gene functions } \\
\text { from } 54 \text { unique } \\
\text { genomic loci; Figure } \\
3 \text { Acr Seq } \\
\end{array}$ & $\mathrm{n} / \mathrm{a}$ & No & Yes & $\mathrm{n} / \mathrm{a}$ & $\mathrm{n} / \mathrm{a}$ & $\begin{array}{c}d \_ \text {Bacteria; } p \_ \text {Firmicutes_A; } c \text { _Clostridia; } \\
\text { o__oscillospirales; } f \text { Acutalibacteraceae; } \\
\text { g__CAG-217 (inferred) }\end{array}$ & $\begin{array}{l}\text { http://segatalab.cibio } \\
\text {.unitn.it/data/Pasolli_ } \\
\text { et_al.html }\end{array}$ \\
\hline 17 & $\begin{array}{l}\text { CosteaPI_2017_SID713A0 } \\
\text { 62-11-0- } \\
\text { 0_NODE_38_length_19219 } \\
\text { 6_cov_4.03099 }\end{array}$ & $\begin{array}{l}\text { Figure 2, find gene } \\
\text { functions from } 54 \\
\text { unique genomic loci }\end{array}$ & $\mathrm{n} / \mathrm{a}$ & No & Yes & $\mathrm{n} / \mathrm{a}$ & $\mathrm{n} / \mathrm{a}$ & $\begin{array}{c}d \_ \text {Bacteria; } p \_ \text {Firmicutes_A; } c \text { _Clostridia; } \\
\text { o__Oscillospirales; } f \text { Acutalibacteraceae; } \\
\text { g__CAG-217 (inferred) }\end{array}$ & $\begin{array}{l}\text { http://segatalab.cibio } \\
\text {.unitn.it/data/Pasolli_ } \\
\text { et_al.html }\end{array}$ \\
\hline 18 & $\begin{array}{l}\text { CosteaPI_2017_SID713B0 } \\
51-11-0- \\
\text { 0_NODE_14_length_29861 } \\
\text { 9_cov_7.20988 }\end{array}$ & $\begin{array}{l}\text { find gene functions } \\
\text { from } 54 \text { unique } \\
\text { genomic loci }\end{array}$ & $\mathrm{n} / \mathrm{a}$ & No & Yes & $\mathrm{n} / \mathrm{a}$ & $\mathrm{n} / \mathrm{a}$ & $\begin{array}{c}d \_ \text {Bacteria; } p \_ \text {Firmicutes_A; c_Clostridia; } \\
\text { o__oscillospirales; } f \text { Acutalibacteraceae; } \\
\text { g_CAG-217 (inferred) }\end{array}$ & $\begin{array}{l}\text { http://segatalab.cibio } \\
\text {.unitn.it/data/Pasolli_ } \\
\text { et_al.html }\end{array}$ \\
\hline 19 & $\begin{array}{c}\text { FengQ_2015_SID31872_N } \\
\text { ODE_2_length_392843_cov } \\
5.93617\end{array}$ & $\begin{array}{l}\text { find gene functions } \\
\text { from } 54 \text { unique } \\
\text { genomic loci }\end{array}$ & $\mathrm{n} / \mathrm{a}$ & No & Yes & $\mathrm{n} / \mathrm{a}$ & $\mathrm{n} / \mathrm{a}$ & $\begin{array}{c}d_{\text {__Bacteria; }} p_{\text {_C_Firmicutes_A; }} \text { C_CCClostridia; } \\
\text { o_Oscillospirales; } f \text { Acutalibacteraceae; } \\
\text { g_CAG-217 (inferred) }\end{array}$ & $\begin{array}{c}\text { http://segatalab.cibio } \\
\text {.unitn.it/data/Pasolli_ } \\
\text { et_al.html } \\
\end{array}$ \\
\hline 20 & $\begin{array}{l}\text { FengQ_2015_SID530258_- } \\
\text { NODE_5_length_350476_c } \\
\text { ov_17.595 }\end{array}$ & $\begin{array}{l}\text { find gene functions } \\
\text { from } 54 \text { unique } \\
\text { genomic loci; Figure } \\
3 \text { Acr Seq }\end{array}$ & $\mathrm{n} / \mathrm{a}$ & No & Yes & $\mathrm{n} / \mathrm{a}$ & $\mathrm{n} / \mathrm{a}$ & $\begin{array}{c}\mathrm{d} \text { _Bacteria; } p \_ \text {Firmicutes_A; c_Clostridia; } \\
\text { o__oscillospirales; } f \text { Acutalibacteraceae; } \\
\text { g_CAG-217 (inferred) }\end{array}$ & $\begin{array}{l}\text { http://segatalab.cibio } \\
\text {.unitn.it/data/Pasolli__ } \\
\text { et_al.html }\end{array}$ \\
\hline 21 & $\begin{array}{c}\text { FengQ_2015_SID530373_ } \\
\text { NODE_21_length_272157_ } \\
\text { cov_9.73468 }\end{array}$ & $\begin{array}{l}\text { find gene functions } \\
\text { from } 54 \text { unique } \\
\text { genomic loci }\end{array}$ & $\mathrm{n} / \mathrm{a}$ & No & Yes & $\mathrm{n} / \mathrm{a}$ & $\mathrm{n} / \mathrm{a}$ & $\begin{array}{c}d \text { B_Bacteria; } p \ldots \text { Firmicutes_A; } c \text { c_Clostridia; } \\
\text { o__Oscillospirales; } f \text { Acutalibacteraceae; } \\
\text { g_CAG-217 (inferred) }\end{array}$ & $\begin{array}{l}\text { http://segatalab.cibio } \\
\text {.unitn.it/data/Pasolli_ } \\
\text { et_al.html }\end{array}$ \\
\hline 22 & $\begin{array}{l}\text { HeQ_2017__SZAXPI02956 } \\
\text { 52_NODE_1_length_50275 } \\
\text { 2_cov_8.09488 }\end{array}$ & $\begin{array}{l}\text { find gene functions } \\
\text { from } 54 \text { unique } \\
\text { genomic loci; Figure } \\
3 \text { Acr Seq } \\
\end{array}$ & $\mathrm{n} / \mathrm{a}$ & No & Yes & $\mathrm{n} / \mathrm{a}$ & $\mathrm{n} / \mathrm{a}$ & $\begin{array}{c}\text { d_Bacteria; } p \_ \text {Firmicutes_A; c_Clostridia; } \\
\text { o__Oscillospirales; } f \text { Acutalibacteraceae; } \\
\text { g__CAG-217 (inferred) }\end{array}$ & $\begin{array}{l}\text { http://segatalab.cibio } \\
\text {.unitn.it/data/Pasolli_ } \\
\text { et_al.html }\end{array}$ \\
\hline 23 & $\begin{array}{l}\text { HeQ_2017_SZAXPI02957 } \\
\text { 5- } \\
90 \_ \text {NODE_229_length_949 } \\
18 \text { cov 3.79903 }\end{array}$ & $\begin{array}{l}\text { find gene functions } \\
\text { from } 54 \text { unique } \\
\text { genomic loci }\end{array}$ & $\mathrm{n} / \mathrm{a}$ & No & Yes & $\mathrm{n} / \mathrm{a}$ & $\mathrm{n} / \mathrm{a}$ & $\begin{array}{c}d \_ \text {Bacteria; } p \_ \text {Firmicutes_A; c_Clostridia; } \\
\text { o__oscillospirales; } f \text { Acutalibacteraceae; } \\
\text { g__CAG-217 (inferred) }\end{array}$ & $\begin{array}{l}\text { http://segatalab.cibio } \\
\text {.unitn.it/data/Pasolli__ } \\
\text { et_al.html }\end{array}$ \\
\hline 24 & $\begin{array}{l}\text { KarlssonFH_2013_S463_ } \\
\text { NODE_1_length_570037_c } \\
\text { ov_16.3973 }\end{array}$ & $\begin{array}{l}\text { Figure } 2 \text {, find gene } \\
\text { functions from } 54 \\
\text { unique genomic loci }\end{array}$ & $\mathrm{n} / \mathrm{a}$ & No & Yes & $\mathrm{n} / \mathrm{a}$ & $\mathrm{n} / \mathrm{a}$ & 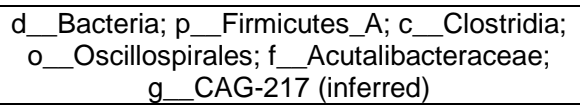 & $\begin{array}{l}\text { http://segatalab.cibio } \\
\text {.unitn.it/data/Pasolli_ } \\
\text { et_al.html }\end{array}$ \\
\hline 25 & $\begin{array}{c}\text { LiJ_2014_O2.UC12- } \\
\text { 1_NODE_323_length_4999 } \\
\text { 5_cov_5.04395 }\end{array}$ & $\begin{array}{l}\text { find gene functions } \\
\text { from } 54 \text { unique } \\
\text { genomic loci }\end{array}$ & $\mathrm{n} / \mathrm{a}$ & No & Yes & $\mathrm{n} / \mathrm{a}$ & $\mathrm{n} / \mathrm{a}$ & 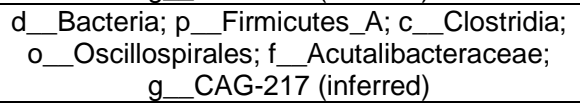 & $\begin{array}{l}\text { http://segatalab.cibio } \\
\text {.unitn.it/data/Pasolli_ } \\
\text { et_al.html }\end{array}$ \\
\hline 26 & $\begin{array}{c}\text { LiJ_2014_V1.FI02_NODE } \\
\text { 274_length_84286_cov_3.4 } \\
\text { 9253 }\end{array}$ & $\begin{array}{l}\text { find gene functions } \\
\text { from } 54 \text { unique } \\
\text { genomic loci }\end{array}$ & $\mathrm{n} / \mathrm{a}$ & No & Yes & $\mathrm{n} / \mathrm{a}$ & $\mathrm{n} / \mathrm{a}$ & 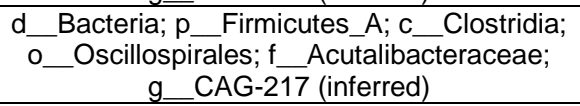 & $\begin{array}{l}\text { http://segatalab.cibio } \\
\text {.unitn.it/data/Pasolli_ } \\
\text { et_al.html }\end{array}$ \\
\hline 28 & $\begin{array}{c}\text { LiJ_2017_H2M514909_NO } \\
\text { DE_68_length_69076_cov_ } \\
\text { 10.283 }\end{array}$ & $\begin{array}{l}\text { find gene functions } \\
\text { from } 54 \text { unique } \\
\text { genomic loci }\end{array}$ & $\mathrm{n} / \mathrm{a}$ & No & Yes & $\mathrm{n} / \mathrm{a}$ & $\mathrm{n} / \mathrm{a}$ & 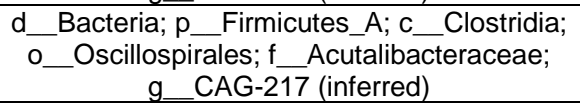 & $\begin{array}{l}\text { http://segatalab.cibio } \\
\text {.unitn.it/data/Pasolli_ } \\
\text { et_al.html }\end{array}$ \\
\hline 29 & $\begin{array}{c}\text { LiuW_2016_SRR3992969 } \\
\text { NODE_1149_length_1899 } \\
\text { 9_cov_8.45033 }\end{array}$ & $\begin{array}{l}\text { find gene functions } \\
\text { from } 54 \text { unique } \\
\text { genomic loci; Figure } \\
3 \text { Acr Seq } \\
\end{array}$ & $\mathrm{n} / \mathrm{a}$ & No & Yes & $\mathrm{n} / \mathrm{a}$ & $\mathrm{n} / \mathrm{a}$ & $\begin{array}{c}d \_ \text {Bacteria; } p \_ \text {Firmicutes_A; c_Clostridia; } \\
\text { o__oscillospirales; } f \text { Acutalibacteraceae; } \\
\text { g_CAG-217 (inferred) }\end{array}$ & $\begin{array}{l}\text { http://segatalab.cibio } \\
\text {.unitn.it/data/Pasolli_ } \\
\text { et_al.html }\end{array}$ \\
\hline
\end{tabular}




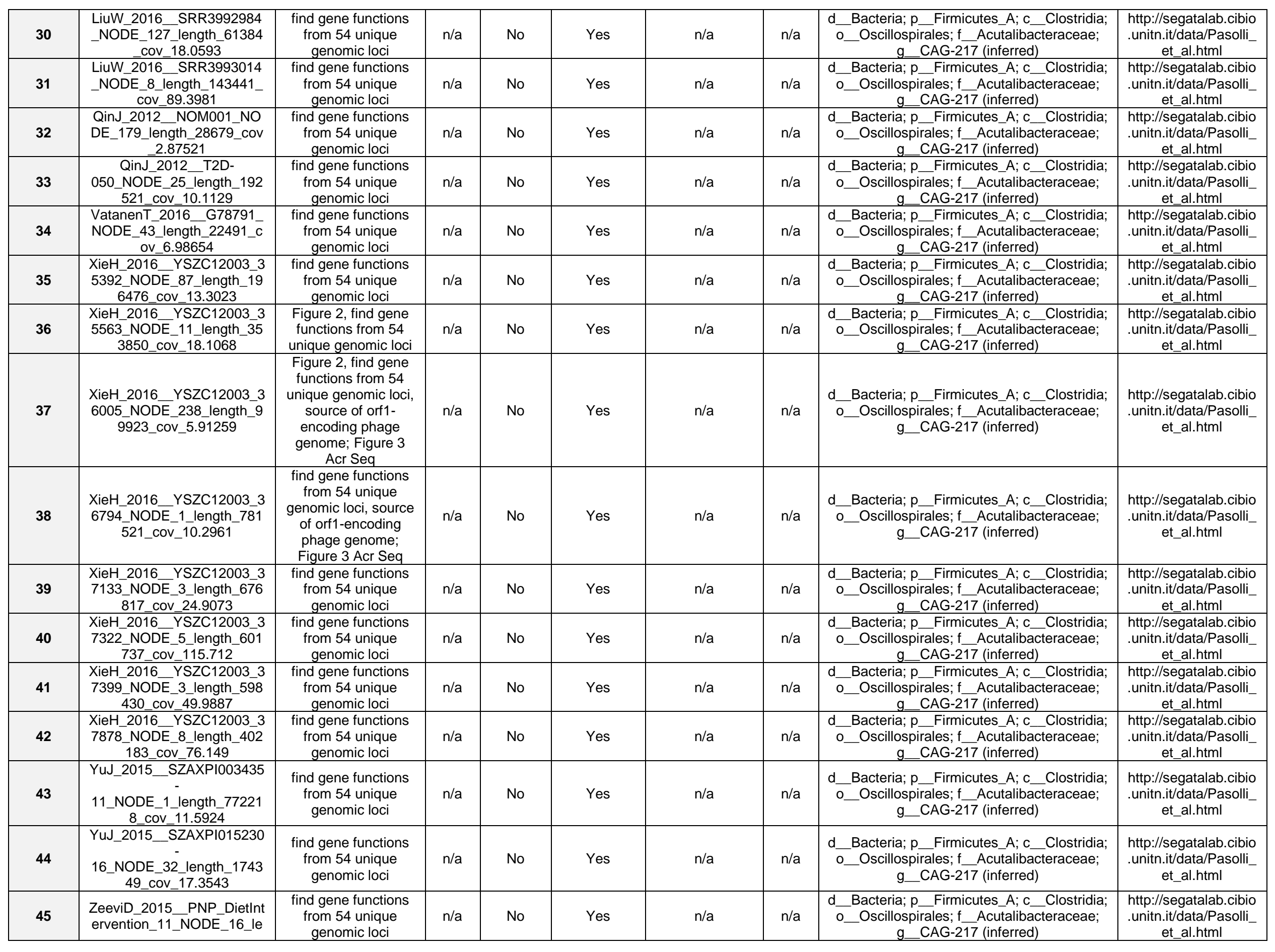




\begin{tabular}{|c|c|c|c|c|c|c|c|c|c|}
\hline & $\begin{array}{c}\text { ngth_97163_cov_10.0000_I } \\
\text { D_22997 }\end{array}$ & & & & & & & & \\
\hline 46 & $\begin{array}{l}\text { ZeeviD_2015_PNP_Main } \\
\text { 234_NODE_10_length_202 } \\
\text { 229_cov_13.9987_ID_1807 } \\
29\end{array}$ & $\begin{array}{l}\text { find gene functions } \\
\text { from } 54 \text { unique } \\
\text { genomic loci }\end{array}$ & $n / a$ & No & Yes & $\mathrm{n} / \mathrm{a}$ & $\mathrm{n} / \mathrm{a}$ & $\begin{array}{c}d \_ \text {Bacteria; } p \_ \text {Firmicutes_A; c_Clostridia; } \\
\text { o__oscillospirales; } f \text { Acutalibacteraceae; } \\
\text { g_CAG-217 (inferred) }\end{array}$ & $\begin{array}{l}\text { http://segatalab.cibio } \\
\text {.unitn.it/data/Pasolli_ } \\
\text { et_al.html }\end{array}$ \\
\hline 47 & $\begin{array}{l}\text { ZeeviD_2015_PNP_Main } \\
\text { 294_NODE_20_length_208 } \\
\text { 110_cov_20.9981_ID_1060 } \\
95\end{array}$ & $\begin{array}{l}\text { find gene functions } \\
\text { from } 54 \text { unique } \\
\text { genomic loci }\end{array}$ & $\mathrm{n} / \mathrm{a}$ & No & Yes & $\mathrm{n} / \mathrm{a}$ & $\mathrm{n} / \mathrm{a}$ & $\begin{array}{c}\text { d_Bacteria; } p \_ \text {Firmicutes_A; c_Clostridia; } \\
\text { o__Oscillospirales; } f \text { Acutalibacteraceae; } \\
\text { g__CAG-217 (inferred) }\end{array}$ & $\begin{array}{l}\text { http://segatalab.cibio } \\
\text {.unitn.it/data/Pasolli_ } \\
\text { et_al.html }\end{array}$ \\
\hline 48 & $\begin{array}{l}\text { ZeeviD_2015_PNP_Main } \\
\text { 390_NODE_33_length_137 } \\
\text { 723_cov_10.9985_ID_4647 } \\
5\end{array}$ & $\begin{array}{l}\text { find gene functions } \\
\text { from } 54 \text { unique } \\
\text { genomic loci }\end{array}$ & $\mathrm{n} / \mathrm{a}$ & No & Yes & $\mathrm{n} / \mathrm{a}$ & $\mathrm{n} / \mathrm{a}$ & $\begin{array}{c}d \_ \text {Bacteria; } p \_ \text {Firmicutes_A; c_Clostridia; } \\
\text { o__oscillospirales; } f \_ \text {Acutalibacteraceae; } \\
\text { g_CAG-217 (inferred) }\end{array}$ & $\begin{array}{l}\text { http://segatalab.cibio } \\
\text {.unitn.it/data/Pasolli__ } \\
\text { et_al.html }\end{array}$ \\
\hline 49 & 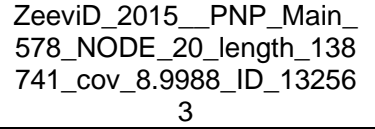 & $\begin{array}{l}\text { find gene functions } \\
\text { from } 54 \text { unique } \\
\text { genomic loci }\end{array}$ & $\mathrm{n} / \mathrm{a}$ & No & Yes & $\mathrm{n} / \mathrm{a}$ & $\mathrm{n} / \mathrm{a}$ & $\begin{array}{c}d \_ \text {Bacteria; } p \_ \text {Firmicutes_A; c_Clostridia; } \\
\text { o__oscillospirales; } f \text { Acutalibacteraceae; } \\
\text { g_CAG-217 (inferred) }\end{array}$ & $\begin{array}{l}\text { http://segatalab.cibio } \\
\text {.unitn.it/data/Pasolli_ } \\
\text { et_al.html }\end{array}$ \\
\hline 50 & $\begin{array}{l}\text { ZeeviD_2015_PNP_Main } \\
\text { 741_NODE_13_length_214 } \\
417 \_ \text {cov_12.0572_ID_9167 } \\
9\end{array}$ & $\begin{array}{l}\text { find gene functions } \\
\text { from } 54 \text { unique } \\
\text { genomic loci }\end{array}$ & $\mathrm{n} / \mathrm{a}$ & No & Yes & $\mathrm{n} / \mathrm{a}$ & $\mathrm{n} / \mathrm{a}$ & $\begin{array}{c}d \_ \text {Bacteria; } p \_ \text {Firmicutes_A; c_Clostridia; } \\
\text { o__oscillospirales; } f \text { Acutalibacteraceae; } \\
\text { g_CAG-217 (inferred) }\end{array}$ & $\begin{array}{l}\text { http://segatalab.cibio } \\
\text {.unitn.it/data/Pasolli_ } \\
\text { et_al.html }\end{array}$ \\
\hline 51 & $\begin{array}{l}\text { ZellerG_2014_CCIS03857 } \\
\text { 607ST-4- } \\
\text { 0_NODE_542_length_3529 } \\
\text { 1_cov_2.7674 }\end{array}$ & $\begin{array}{l}\text { find gene functions } \\
\text { from } 54 \text { unique } \\
\text { genomic loci }\end{array}$ & $\mathrm{n} / \mathrm{a}$ & No & Yes & $\mathrm{n} / \mathrm{a}$ & $\mathrm{n} / \mathrm{a}$ & $\begin{array}{c}d \_ \text {Bacteria; } p \_ \text {Firmicutes_A; c_Clostridia; } \\
\text { o__oscillospirales; } f \_ \text {Acutalibacteraceae; } \\
\text { g_CAG-217 (inferred) }\end{array}$ & $\begin{array}{l}\text { http://segatalab.cibio } \\
\text {.unitn.it/data/Pasolli__ } \\
\text { et_al.html }\end{array}$ \\
\hline 52 & $\begin{array}{l}\text { ZellerG_2014_CCIS22958 } \\
\text { 137ST-20- } \\
\text { 0_NODE_40_length_18149 } \\
\text { 3_cov_7.91373 }\end{array}$ & $\begin{array}{l}\text { find gene functions } \\
\text { from } 54 \text { unique } \\
\text { genomic loci, source } \\
\text { of orf1-encoding } \\
\text { phage genome; } \\
\text { Figure } 3 \text { Acr Seq }\end{array}$ & $\mathrm{n} / \mathrm{a}$ & No & Yes & $\mathrm{n} / \mathrm{a}$ & $\mathrm{n} / \mathrm{a}$ & $\begin{array}{c}d \_ \text {Bacteria; } p \_ \text {Firmicutes_A; } c \text { _Clostridia; } \\
\text { o__Oscillospirales; } f \text { Acutalibacteraceae; } \\
\text { g_CAG-217 (inferred) }\end{array}$ & $\begin{array}{l}\text { http://segatalab.cibio } \\
\text { unitn.it/data/Pasolli_ } \\
\text { et_al.html }\end{array}$ \\
\hline 53 & $\begin{array}{c}\text { XieH_2016_YSZC12003_3 } \\
\text { 5635_NODE_109_length_1 } \\
\text { 56568_cov_5.12141 }\end{array}$ & $\begin{array}{l}\text { find gene functions } \\
\text { from } 54 \text { unique } \\
\text { genomic loci }\end{array}$ & $\mathrm{n} / \mathrm{a}$ & No & Yes & $\mathrm{n} / \mathrm{a}$ & $\mathrm{n} / \mathrm{a}$ & $\begin{array}{c}d \text { _Bacteria; } p \_ \text {Firmicutes_A; c_Clostridia; } \\
\text { o__Oscillospirales; } f \text { Acutalibacteraceae; } \\
\text { g_CAG-217 (inferred) }\end{array}$ & $\begin{array}{l}\text { http://segatalab.cibio } \\
\text {.unitn.it/data/Pasolli_ } \\
\text { et_al.html }\end{array}$ \\
\hline 54 & $\begin{array}{l}\text { ZeeviD_2015_PNP_Main } \\
\text { 85_NODE_182_length_529 } \\
\text { 97_cov_7.0000_ID_133080 }\end{array}$ & $\begin{array}{l}\text { find gene functions } \\
\text { from } 54 \text { unique } \\
\text { genomic loci }\end{array}$ & $\mathrm{n} / \mathrm{a}$ & No & Yes & $\mathrm{n} / \mathrm{a}$ & $\mathrm{n} / \mathrm{a}$ & $\begin{array}{c}d \text { B_Bacteria; } p \text { Firmicutes_A; c_CClostridia; } \\
\text { o__Oscillospirales; } f \text { Acutalibacteraceae; } \\
\text { g_CAG-217 (inferred) }\end{array}$ & $\begin{array}{l}\text { http://segatalab.cibio } \\
\text {.unitn.it/data/Pasolli_ } \\
\text { et_al.html }\end{array}$ \\
\hline 55 & $\begin{array}{l}4303 \_H e Q \text { 2017__SZAXPI } \\
029570- \\
85 \text { bin.1_NODE_2 length } \\
\text { 608092_cov_26.3259 }\end{array}$ & Figure 2 & $\mathrm{n} / \mathrm{a}$ & Yes & No & $\begin{array}{l}\mathrm{HeQ} 2017 \_\mathrm{S} \\
\text { ZAXPI029570- } \\
\text { 85_bin.1 }\end{array}$ & 4303 & $\begin{array}{c}d \_ \text {Bacteria; } p \_ \text {Firmicutes_A; } c \text { _Clostridia; } \\
\text { o__oscillospirales; } f \text { Acutalibacteraceae; } \\
\text { g__CAG-217 }\end{array}$ & $\begin{array}{l}\text { http://segatalab.cibio } \\
\text {.unitn.it/data/Pasolli_ } \\
\text { et_al.html }\end{array}$ \\
\hline 56 & $\begin{array}{l}\text { 4303_CosteaPI_2017_SID } \\
\text { 713B074-11-90- } \\
0 \text { bin.57_NODE_18_lengt } \\
\text { h_238289_cov_5.37382 }\end{array}$ & $\begin{array}{c}\text { Figure 2, source of } \\
\text { orf1-encoding phage } \\
\text { genome; Figure } 3 \\
\text { Acr Seq } \\
\end{array}$ & $\mathrm{n} / \mathrm{a}$ & Yes & No & $\begin{array}{c}\text { CosteaPI_2017 } \\
\text { SID713B074 } \\
-11-90- \\
0 \quad \text { bin. } 57 \\
\end{array}$ & 4303 & $\begin{array}{c}d \_ \text {Bacteria; } p \_ \text {Firmicutes_A; } c \text { _Clostridia; } \\
\text { o__oscillospirales; } f \_ \text {Acutalibacteraceae; } \\
\text { g__CAG-217 }\end{array}$ & $\begin{array}{l}\text { http://segatalab.cibio } \\
\text {.unitn.it/data/Pasolli_ } \\
\text { et_al.html }\end{array}$ \\
\hline 57 & $\begin{array}{l}\text { Clostridiales_bacterium_isol } \\
\text { ate_CIM:MAG_317_1 } \\
\text { contig_8085 }\end{array}$ & $\begin{array}{l}\text { Figure 2, source of } \\
\text { orf1-encoding phage } \\
\text { genome }\end{array}$ & $\begin{array}{c}\text { QAL } \\
\text { M010 } \\
0000 \\
2.1\end{array}$ & No & No & $\mathrm{n} / \mathrm{a}$ & $\mathrm{n} / \mathrm{a}$ & $\begin{array}{c}d \_ \text {Bacteria; } p \_ \text {Firmicutes_A; c_Clostridia; } \\
\text { o__oscillospirales; } f \text { Acutalibacteraceae; } \\
\text { g_CAG-217 (inferred) }\end{array}$ & NCBI Genbank \\
\hline 58 & $\begin{array}{l}\text { TPA_asm:_Ruminococcace } \\
\text { ae_bacterium_isolate_UBA8 } \\
\text { 277_contig_226 }\end{array}$ & $\begin{array}{c}\text { Figure 2; Figure } 3 \\
\text { Acr Seq }\end{array}$ & $\begin{array}{c}\text { DPD } \\
\text { R010 } \\
0001 \\
0.1\end{array}$ & No & No & $\mathrm{n} / \mathrm{a}$ & $\mathrm{n} / \mathrm{a}$ & $\begin{array}{c}d \_ \text {Bacteria; } p \_ \text {Firmicutes_A; c_Clostridia; } \\
\text { o__oscillospirales; } f \text { Acutalibacteraceae; } \\
\text { g_CAG-217 (inferred) }\end{array}$ & NCBI Genbank \\
\hline 59 & $\begin{array}{l}\text { KarlssonFH_2013_S424_- } \\
\text { NODE_2_length_526279_c } \\
\text { ov_9.22761 }\end{array}$ & $\begin{array}{l}\text { source of orf1- } \\
\text { encoding phage } \\
\text { genome }\end{array}$ & $\mathrm{n} / \mathrm{a}$ & No & Yes & $\mathrm{n} / \mathrm{a}$ & $\mathrm{n} / \mathrm{a}$ & $\begin{array}{c}d_{\text {__Bacteria; }} p_{\text {_CF Firmicutes_A; }} \text { c_CClostridia; } \\
\text { o_Oscillospirales; } f \text { Acutalibacteraceae; } \\
\text { g_CAG-217 (inferred) }\end{array}$ & $\begin{array}{l}\text { http://segatalab.cibio } \\
\text {.unitn.it/data/Pasolli_ } \\
\text { et_al.html }\end{array}$ \\
\hline
\end{tabular}




\begin{tabular}{|c|c|c|c|c|c|c|c|c|c|}
\hline 60 & $\begin{array}{l}\text { XieH_2016_YSZC12003_3 } \\
\text { 6696_NODE_1_length_776 } \\
\text { 477_cov_39.8546 }\end{array}$ & $\begin{array}{c}\text { source of orf1- } \\
\text { encoding phage } \\
\text { genome, AcrllA17 } \\
\text { encoding phage } \\
\text { (figure S8) }\end{array}$ & $\mathrm{n} / \mathrm{a}$ & No & Yes & $\mathrm{n} / \mathrm{a}$ & $\mathrm{n} / \mathrm{a}$ & $\begin{array}{c}d \_ \text {Bacteria; } p \_ \text {Firmicutes_A; c_Clostridia; } \\
\text { o__Oscillospirales; } f \text { Acutalibacteraceae; } \\
\text { g_CAG-217 (inferred) }\end{array}$ & $\begin{array}{l}\text { http://segatalab.cibio } \\
\text {.unitn.it/data/Pasolli_ } \\
\text { et_al.html }\end{array}$ \\
\hline 61 & $\begin{array}{c}\text { XieH_2016_YSZC12003_3 } \\
\text { 7308R1_NODE_3_length_7 } \\
\text { 17276_cov_26.9646 }\end{array}$ & $\begin{array}{l}\text { source of orf1- } \\
\text { encoding phage } \\
\text { genome }\end{array}$ & $\mathrm{n} / \mathrm{a}$ & No & Yes & $\mathrm{n} / \mathrm{a}$ & $\mathrm{n} / \mathrm{a}$ & $\begin{array}{c}d_{\text {__Bacteria; }} p_{\text {B_Firmicutes_A; }} \text { c_CClostridia; } \\
\text { o_Oscillospirales; } f \text { Acutalibacteraceae; } \\
\text { g_CAG-217 (inferred) }\end{array}$ & $\begin{array}{l}\text { http://segatalab.cibio } \\
\text {.unitn.it/data/Pasolli_ } \\
\text { et_al.html }\end{array}$ \\
\hline 62 & $\begin{array}{c}\text { ZellerG_2014_CCIS88007 } \\
\text { 743ST-4- } \\
\text { 0_NODE_31_length_21091 } \\
0 \text { cov } 8.07406\end{array}$ & $\begin{array}{l}\text { source of orf1- } \\
\text { encoding phage } \\
\text { genome }\end{array}$ & $\mathrm{n} / \mathrm{a}$ & No & Yes & $\mathrm{n} / \mathrm{a}$ & $\mathrm{n} / \mathrm{a}$ & $\begin{array}{c}\mathrm{d} \text { __Bacteria; } p_{\ldots} \text { Firmicutes_A; c_Clostridia; } \\
\text { o__Oscillospirales; } f \text { Acutalibacteraceae; } \\
\text { g__CAG-217 (inferred) }\end{array}$ & $\begin{array}{l}\text { http://segatalab.cibio } \\
\text {.unitn.it/data/Pasolli_ } \\
\text { et_al.html }\end{array}$ \\
\hline 63 & $\begin{array}{l}\text { 4303_QinN_2014_LD- } \\
22 \text { bin.75_NODE_22_leng } \\
\text { th_329763_cov_10.7401 }\end{array}$ & Figure 3 Acr Seq & $\mathrm{n} / \mathrm{a}$ & Yes & No & $\begin{array}{l}\text { QinN_2014_L } \\
\text { D-22_bin.75 }\end{array}$ & 4303 & 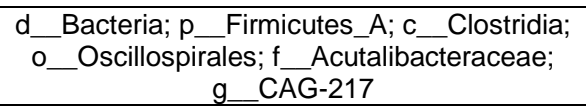 & $\begin{array}{l}\text { http://segatalab.cibio } \\
\text {.unitn.it/data/Pasolli_ } \\
\text { et_al.html }\end{array}$ \\
\hline 64 & $\begin{array}{c}\text { ZellerG_2014_CCMD2596 } \\
\text { 3797ST-21- } \\
\text { 0_NODE_9_length_356111 } \\
\text { _cov_10.1715 }\end{array}$ & Figure 3 Acr Seq & $\mathrm{n} / \mathrm{a}$ & No & Yes & $\mathrm{n} / \mathrm{a}$ & $\mathrm{n} / \mathrm{a}$ & $\begin{array}{c}d \_ \text {Bacteria; } p \_ \text {Firmicutes_A; } c \text { Clostridia; } \\
\text { o_Oscillospirales; } f \text { Acutalibacteraceae; } \\
\text { g_CAG-217 (inferred) }\end{array}$ & $\begin{array}{l}\text { http://segatalab.cibio } \\
\text {.unitn.it/data/Pasolli_ } \\
\text { et_al.html }\end{array}$ \\
\hline 65 & $\begin{array}{l}\text { ZellerG_2014_CCIS41222 } \\
\text { 843ST-4- } \\
\text { 0_NODE_17_length_26713 } \\
3 \text { cov } 14.7383\end{array}$ & Figure 3 Acr Seq & $\mathrm{n} / \mathrm{a}$ & No & Yes & $\mathrm{n} / \mathrm{a}$ & $\mathrm{n} / \mathrm{a}$ & $\begin{array}{c}d \_ \text {Bacteria; } p \_ \text {Firmicutes_A; } c \text { CClostridia; } \\
\text { o__Oscillospirales; } f \text { Acutalibacteraceae; } \\
\text { g__CAG-217 (inferred) }\end{array}$ & $\begin{array}{l}\text { http://segatalab.cibio } \\
\text {.unitn.it/data/Pasolli_ } \\
\text { et_al.html }\end{array}$ \\
\hline 66 & $\begin{array}{l}\text { FengQ_2015_SID530168_- } \\
\text { NODE_20_length_224404_ } \\
\text { cov_6.02914 }\end{array}$ & Figure 3 Acr Seq & $\mathrm{n} / \mathrm{a}$ & No & Yes & $\mathrm{n} / \mathrm{a}$ & $\mathrm{n} / \mathrm{a}$ & $\begin{array}{c}\mathrm{d} \text { _Bacteria; } \mathrm{p} \text { _Firmicutes_A; c_Clostridia; } \\
\text { o__oscillospirales; } f \text { Acutalibacteraceae; } \\
\text { g_CAG-217 (inferred) }\end{array}$ & $\begin{array}{l}\text { http://segatalab.cibio } \\
\text {.unitn.it/data/Pasolli_ } \\
\text { et_al.html }\end{array}$ \\
\hline 67 & $\begin{array}{c}\text { FengQ_2015_SID530041_ } \\
\text { NODE_7_length_421742_c } \\
\text { ov_9.32571 }\end{array}$ & Figure 3 Acr Seq & $\mathrm{n} / \mathrm{a}$ & No & Yes & $\mathrm{n} / \mathrm{a}$ & $\mathrm{n} / \mathrm{a}$ & 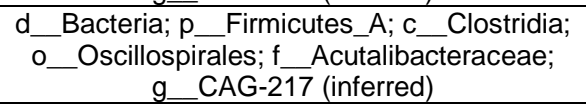 & $\begin{array}{l}\text { http://segatalab.cibio } \\
\text {.unitn.it/data/Pasolli_ } \\
\text { et_al.html }\end{array}$ \\
\hline 68 & $\begin{array}{l}\text { FengQ_2015_SID31223_N } \\
\text { ODE_13_length_228767_co } \\
\text { V } 7.50553\end{array}$ & Figure 3 Acr Seq & $\mathrm{n} / \mathrm{a}$ & No & Yes & $\mathrm{n} / \mathrm{a}$ & $\mathrm{n} / \mathrm{a}$ & $\begin{array}{c}\mathrm{d} \text { B Bacteria; } p \text { Firmicutes_A; c_Clostridia; } \\
\text { o__Oscillospirales; } f \text { Acutalibacteraceae; } \\
\text { g_CAG-217 (inferred) }\end{array}$ & $\begin{array}{l}\text { http://segatalab.cibio } \\
\text {.unitn.it/data/Pasolli_ } \\
\text { et al.html }\end{array}$ \\
\hline
\end{tabular}


Supplemental Table 4. Plasmids used in this study. Supplemental Table S5 indicates genes expressed from pZE21_tetR.

\begin{tabular}{|c|c|c|c|c|}
\hline Plasmid & $\begin{array}{l}\text { crRNA promoter, } \\
\text { sequence }\left(5^{\prime}-3^{\prime}\right)\end{array}$ & Notes & Refs & Purpose \\
\hline pZE21_tetR & $\mathrm{n} / \mathrm{a}$ & $\begin{array}{l}\text { Contains tetR behind pLac promoter for inducible } \\
\text { expression of candidate Acrs. Targeted by } \\
\text { crRNA_A; PAM = AGG. }\end{array}$ & (Forsberg et al., 2019) & $\begin{array}{l}\text { Expressing genes to test } \\
\text { in vivo anti-CRISPR } \\
\text { activity }\end{array}$ \\
\hline pSpyCas9_crA & $\begin{array}{l}\text { pJ23100, } \\
\text { GTTCATTCAGGG } \\
\text { CACCGGAC }\end{array}$ & $\begin{array}{l}\text { Arabinose-inducible SpyCas9 with pZE21 } \\
\text { targeting pZE21_tetR }\end{array}$ & (Forsberg et al., 2019) & $\begin{array}{l}\text { Target pZE21_tetR for } \\
\text { elimination with SpyCas9 }\end{array}$ \\
\hline pSpyCas9_crMu & $\begin{array}{l}\text { pJ23100, } \\
\text { GTAATACTTGTC } \\
\text { CCGCAAAG }\end{array}$ & $\begin{array}{l}\text { Mu-targeting spacer for phage Mu immunity } \\
\text { testing. Otherwise identical to pSpyCas9_crA }\end{array}$ & (Forsberg et al., 2019) & $\begin{array}{l}\text { Phage Mu immunity } \\
\text { testing }\end{array}$ \\
\hline pSpyCa9_crNT & $\begin{array}{l}\text { pJ23100, } \\
\text { GAACGAAAAGCT } \\
\text { GCGCCGGG }\end{array}$ & $\begin{array}{l}\text { non-targeting spacer used as control. Otherwise } \\
\text { identical to pSpyCas9_crA }\end{array}$ & (Forsberg et al., 2019) & $\begin{array}{l}\text { Phage Mu immunity } \\
\text { testing, Western blots }\end{array}$ \\
\hline pCloDF13_GFP & $\begin{array}{l}\text { pJ23100, } \\
\text { GAACGAAAAGCT } \\
\text { GCGCCGGG }\end{array}$ & eGFP gene replaces spyCas9 in pSpyCas9_crA & & $\begin{array}{l}\text { Measure generic protein } \\
\text { expression from } \\
\text { pSpyCas9 expression } \\
\text { vector }\end{array}$ \\
\hline pIDTsmart & $\mathrm{n} / \mathrm{a}$ & $\begin{array}{l}\text { Plasmid used for in-vitro SpyCas9 digestion. } \\
\text { Sequence available at: } \\
\text { https://www.idtdna.com/pages/products/genes- } \\
\text { and-gene-fragments/custom-gene-synthesis }\end{array}$ & & $\begin{array}{l}\text { Plasmid template for in- } \\
\text { vitro nuclease reactions }\end{array}$ \\
\hline
\end{tabular}


Supplemental Table 5. Gene sequences used in this study.

\begin{tabular}{|c|c|c|}
\hline Gene Name & Sequence & Notes \\
\hline acrllA22wt & $\begin{array}{l}\text { ATGGTAGTAGAAGAGACGCGGGATTTAGCCGAAACTGCGGATTGTGTAGTGATCGAAGCCATTTTAGTGGATGACGG } \\
\text { ATTGCGTTACAGACAGCTTTCTGTCGGCATCAAAGACGAAACGGCGACATTATTCGTATCGTCCCTATTTCAACCGTT } \\
\text { CTGATCTAG }\end{array}$ & $\begin{array}{l}\text { The italicized six base pairs were } \\
\text { deleted in the } \Delta 2 \text { aa truncation mutant }\end{array}$ \\
\hline acrllA22-null & $\begin{array}{l}\text { ATGGTAGTAGAAGAGACGCGGGATTTAGCCGAAACTGCGGATTGTGTAGTGATCGAAGCCATTTAAGTGGATGACGG } \\
\text { ATTGCGTTACAGACAGCTTTCTGTCGGCATCAAAGACGAAAACGGCGACATTATTCGTATCGTCCC̄TATTTCAACCGTT } \\
\text { CTGATCTAG }\end{array}$ & $\begin{array}{l}\text { Mutation to introduce early stop } \\
\text { codon in bold, underline }\end{array}$ \\
\hline acrllA22a & $\begin{array}{l}\text { ATGGTCATAGAAGAGACGCGGGATTTAGCTGAAACTGCGGATTGTGTAGTGATCGAAGCCATTTTAGTGGATGACGGA } \\
\text { TTGCGTTACAAACAGCTTTCCGTCGGCATCAAAGACGAAAACGGTGACATTATTCGTATCGTCCCTATTTCAACCGTTC } \\
\text { TGATCTAG }\end{array}$ & $\begin{array}{l}\text { Same amino acid sequence as NCBI } \\
\text { protein CDB51368.1 }\end{array}$ \\
\hline$a c r l l A 22 b$ & $\begin{array}{l}\text { ATGATTGTGGAAGATACCAAAGATTTGGTTGAAACTGCGGACTATGTGATCATCGAAGCTGTTTTAGTGGGATGATGGAT } \\
\text { TGCGTTACAAACAACTTTCTGTTGGCATTAAAGCCAAAAATGGTGACATTATCCGCATAATTCCAATATCGACAATGCT } \\
\text { GATGTAA }\end{array}$ & \\
\hline acrllA22c & $\begin{array}{l}\text { ATGAAAATGATTGTGGAAGATACGAAAGATCTGGTAGAAACGGACGATTATGTAATCATTGAAGCGACTTTGTCAGAG } \\
\text { GGCGATTTGTTGTTGTGCAAATTGCCGTGGGCATTCGCAACGAAGTGGGCGACATTGTTCGTATTATTCCCATTTCC } \\
\text { ACCAACCCAATCTAA }\end{array}$ & $\begin{array}{l}\text { Same amino acid sequence as NCBI } \\
\text { protein CDB51757.1 }\end{array}$ \\
\hline purF & 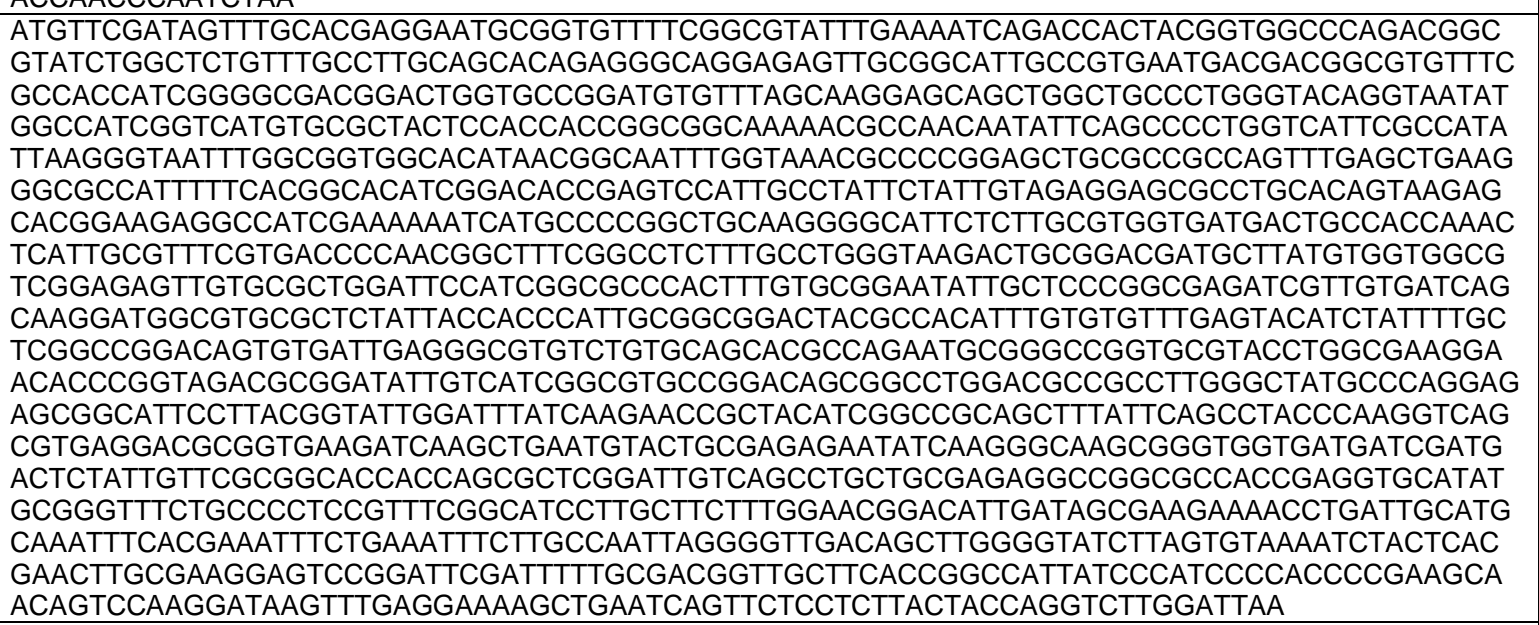 & $\begin{array}{l}\text { Flanks acrlIA22-encoding bacterial } \\
\text { genomic islands. Used as bait to } \\
\text { retrieve additional examples of this } \\
\text { locus for genomic and evolutionary } \\
\text { analyses. }\end{array}$ \\
\hline radC & $\begin{array}{l}\text { ATGCGTGCCGCTTATCTGCAAGGCGGCGGCGACGCTATGCCGGACCACCAGTTGCTGGAATTGCTGCTGTCCATCAG } \\
\text { CATTCCCCGCAGAGATGTAAAGCCCATTGCCTATGCGCTCATTAACCGCTTCGGCTCGCTGGAGCAGGTGTTTGCCG } \\
\text { CCGGCGCAGCAGATCTGCAACAAGTGCCGGGCGTCGGCGAACAGACCGCCGTACAGATTCTGCTGGTACGGGATCT } \\
\text { GAACCGGCGGATCCATCAAAATCAAAACAAACCGGTCAAGCACCTGACAGATGCCACCCAGTCCTGCGCCTACTTTC } \\
\text { CAATCTGTTACGGGACAAAACCGCCGAGCAGGTGACTTGTCACCCTGGACGGCAGTGCCAAATCCTGCAACCC } \\
\text { ACGCCGTAGCAGCGGCAGCGTCACCTGGCTCTGTGGATCAGCGCACTTTGATGGACATATTCTGCGAGACAAC } \\
\text { GCCAACGCTGTTATGCTGGCACACAACCATCCCGGCGGCAAGGCCCAGCCCTCTGCGCAGGATCTGGATTCACCAT } \\
\text { TCGTCTGCTTTCCATTCTGCGTTCCATTCATGTGCAGCTGCTGGATCATATTATCGTCAGTCCTACCGACACCTACTCC } \\
\text { ATGCGCAGCGACCCGGAGTACGGCAGCTTCTTCACCGTCAAATAA }\end{array}$ & $\begin{array}{l}\text { Flanks acrllA22-encoding bacterial } \\
\text { genomic islands. Used as bait to } \\
\text { retrieve additional examples of this } \\
\text { locus for genomic and evolutionary } \\
\text { analyses. }\end{array}$ \\
\hline acrllA4 & $\begin{array}{l}\text { ATGAATATTAACGATTTGATCCGTGAGATTAAGAATAAGGATTATACTGTCAAATTGTCCGGGACAGATTCCAATTCTAT } \\
\text { TACACAATTAATCATCCGTGTGAATAACGATGGTAATGAGTATGTCATCTCTGAATCAGAAAACGAGAGCATCGTAGAA } \\
\text { AAGTTCATCAGTGCCTTCAAGAACGGGTGGAACCAAGAGTATGAAGATGAGGAGGATTTTACAATGATATGCAGACA } \\
\text { ATTACGCTTAAATCAGAATTGAATTAA }\end{array}$ & Discovered by (Rauch et al., 2017) \\
\hline
\end{tabular}




\section{References for Supplemental Tables.}

An, S.Y., Ka, D., Kim, I., Kim, E.-H., Kim, N.-K., Bae, E., and Suh, J.-Y. (2020). Intrinsic disorder is essential for Cas9 inhibition of anti-CRISPR AcrllA5. Nucleic Acids Research 48, 7584-7594.

Athukoralage, J.S., McMahon, S.A., Zhang, C., Gruschow, S., Graham, S., Krupovic, M., Whitaker, R.J., Gloster, T.M., and White, M.F. (2020). An anti-CRISPR viral ring nuclease subverts type III CRISPR immunity. Nature 577, 572-575.

Bhoobalan-Chitty, Y., Johansen, T.B., Di Cianni, N., and Peng, X. (2019). Inhibition of Type III CRISPR-Cas Immunity by an Archaeal VirusEncoded Anti-CRISPR Protein. Cell 179, 448-458 e411.

Bondy-Denomy, J., Garcia, B., Strum, S., Du, M., Rollins, M.F., Hidalgo-Reyes, Y., Wiedenheft, B., Maxwell, K.L., and Davidson, A.R. (2015). Multiple mechanisms for CRISPR-Cas inhibition by anti-CRISPR proteins. Nature 526, 136-139.

Bondy-Denomy, J., Pawluk, A., Maxwell, K.L., and Davidson, A.R. (2013). Bacteriophage genes that inactivate the CRISPR/Cas bacterial immune system. Nature 493, 429-432.

Chowdhury, S., Carter, J., Rollins, M.F., Golden, S.M., Jackson, R.N., Hoffmann, C., Nosaka, L., Bondy-Denomy, J., Maxwell, K.L., Davidson, A.R., et al. (2017). Structure Reveals Mechanisms of Viral Suppressors that Intercept a CRISPR RNA-Guided Surveillance Complex. Cell 169, 47-57 e11.

Dong, Guo, M., Wang, S., Zhu, Y., Wang, S., Xiong, Z., Yang, J., Xu, Z., and Huang, Z. (2017). Structural basis of CRISPR-SpyCas9 inhibition by an anti-CRISPR protein. Nature 546, 436-439.

Eitzinger, S., Asif, A., Watters, K.E., lavarone, A.T., Knott, G.J., Doudna, J.A., and Minhas, F. (2020). Machine learning predicts new anti-CRISPR proteins. Nucleic Acids Res 48, 4698-4708.

Forsberg, K.J., Bhatt, I.V., Schmidtke, D.T., Javanmardi, K., Dillard, K.E., Stoddard, B.L., Finkelstein, I.J., Kaiser, B.K., and Malik, H.S. (2019). Functional metagenomics-guided discovery of potent Cas9 inhibitors in the human microbiome. Elife 8.

Fuchsbauer, O., Swuec, P., Zimberger, C., Amigues, B., Levesque, S., Agudelo, D., Duringer, A., Chaves-Sanjuan, A., Spinelli, S., Rousseau, G.M., et al. (2019). Cas9 Allosteric Inhibition by the Anti-CRISPR Protein AcrllA6. Mol Cell 76, 922-937 e927.

Garcia, B., Lee, J., Edraki, A., Hidalgo-Reyes, Y., Erwood, S., Mir, A., Trost, C.N., Seroussi, U., Stanley, S.Y., Cohn, R.D., et al. (2019). AntiCRISPR AcrllA5 Potently Inhibits All Cas9 Homologs Used for Genome Editing. Cell Rep 29, 1739-1746 e1735.

Guo, T.W., Bartesaghi, A., Yang, H., Falconieri, V., Rao, P., Merk, A., Eng, E.T., Raczkowski, A.M., Fox, T., Earl, L.A., et al. (2017). Cryo-EM Structures Reveal Mechanism and Inhibition of DNA Targeting by a CRISPR-Cas Surveillance Complex. Cell 171, 414-426 e412.

He, F., Bhoobalan-Chitty, Y., Van, L.B., Kjeldsen, A.L., Dedola, M., Makarova, K.S., Koonin, E.V., Brodersen, D.E., and Peng, X. (2018). AntiCRISPR proteins encoded by archaeal lytic viruses inhibit subtype I-D immunity. Nat Microbiol 3, 461-469.

Hirschi, M., Lu, W.T., Santiago-Frangos, A., Wilkinson, R., Golden, S.M., Davidson, A.R., Lander, G.C., and Wiedenheft, B. (2020). AcrlF9 tethers non-sequence specific dsDNA to the CRISPR RNA-guided surveillance complex. Nat Commun 11, 2730.

Janowski, R., and Niessing, D. (2020). The large family of PC4-like domains - similar folds and functions throughout all kingdoms of life. RNA Biol 17, 1228-1238.

Jiang, F., Liu, J.J., Osuna, B.A., Xu, M., Berry, J.D., Rauch, B.J., Nogales, E., Bondy-Denomy, J., and Doudna, J.A. (2019). TemperatureResponsive Competitive Inhibition of CRISPR-Cas9. Mol Cell 73, 601-610 e605.

Knott, G.J., Cress, B.F., Liu, J.J., Thornton, B.W., Lew, R.J., Al-Shayeb, B., Rosenberg, D.J., Hammel, M., Adler, B.A., Lobba, M.J., et al. (2019a). Structural basis for AcrVA4 inhibition of specific CRISPR-Cas12a. Elife 8. 
Knott, G.J., Thornton, B.W., Lobba, M.J., Liu, J.J., Al-Shayeb, B., Watters, K.E., and Doudna, J.A. (2019b). Broad-spectrum enzymatic inhibition of CRISPR-Cas12a. Nat Struct Mol Biol 26, 315-321.

Lee, J., Mir, A., Edraki, A., Garcia, B., Amrani, N., Lou, H.E., Gainetdinov, I., Pawluk, A., Ibraheim, R., Gao, X.D., et al. (2018). Potent Cas9 Inhibition in Bacterial and Human Cells by AcrlIC4 and AcrllC5 Anti-CRISPR Proteins. mBio 9.

Leon, L.M., Park, A.E., Borges, A.L., Zhang, J.Y., and Bondy-Denomy, J. (2020). Mobile element warfare via CRISPR and anti-CRISPR in \&lt;em\&gt;Pseudomonas aeruginosa\&lt;/em\&gt. bioRxiv, 2020.2006.2015.151498.

Lin, P., Qin, S., Pu, Q., Wang, Z., Wu, Q., Gao, P., Schettler, J., Guo, K., Li, R., Li, G., et al. (2020). CRISPR-Cas13 Inhibitors Block RNA Editing in Bacteria and Mammalian Cells. Mol Cell 78, 850-861 e855.

Liu, L., Yin, M., Wang, M., and Wang, Y. (2019). Phage AcrllA2 DNA Mimicry: Structural Basis of the CRISPR and Anti-CRISPR Arms Race. Mol Cell 73, 611-620 e613.

Mahendra, C., Christie, K.A., Osuna, B.A., Pinilla-Redondo, R., Kleinstiver, B.P., and Bondy-Denomy, J. (2020). Broad-spectrum anti-CRISPR proteins facilitate horizontal gene transfer. Nat Microbiol 5, 620-629.

Marino, N.D., Zhang, J.Y., Borges, A.L., Sousa, A.A., Leon, L.M., Rauch, B.J., Walton, R.T., Berry, J.D., Joung, J.K., Kleinstiver, B.P., et al. (2018). Discovery of widespread Type I and Type V CRISPR-Cas inhibitors. Science.

Meeske, A.J., Jia, N., Cassel, A.K., Kozlova, A., Liao, J., Wiedmann, M., Patel, D.J., and Marraffini, L.A. (2020). A phage-encoded anti-CRISPR enables complete evasion of type VI-A CRISPR-Cas immunity. Science 369, 54-59.

Osuna, B.A., Karambelkar, S., Mahendra, C., Christie, K.A., Garcia, B., Davidson, A.R., Kleinstiver, B.P., Kilcher, S., and Bondy-Denomy, J. (2020). Listeria Phages Induce Cas9 Degradation to Protect Lysogenic Genomes. Cell Host Microbe 28, 31-40 e39.

Pasolli, E., Asnicar, F., Manara, S., Zolfo, M., Karcher, N., Armanini, F., Beghini, F., Manghi, P., Tett, A., Ghensi, P., et al. (2019). Extensive Unexplored Human Microbiome Diversity Revealed by Over 150,000 Genomes from Metagenomes Spanning Age, Geography, and Lifestyle. Cell 176, 649-662 e620.

Pawluk, A., Amrani, N., Zhang, Y., Garcia, B., Hidalgo-Reyes, Y., Lee, J., Edraki, A., Shah, M., Sontheimer, E.J., Maxwell, K.L., et al. (2016). Naturally Occurring Off-Switches for CRISPR-Cas9. Cell 167, 1829-1838 e1829.

Pawluk, A., Bondy-Denomy, J., Cheung, V.H., Maxwell, K.L., and Davidson, A.R. (2014). A new group of phage anti-CRISPR genes inhibits the type I-E CRISPR-Cas system of Pseudomonas aeruginosa. MBio 5, e00896.

Pawluk, A., Shah, M., Mejdani, M., Calmettes, C., Moraes, T.F., Davidson, A.R., and Maxwell, K.L. (2017). Disabling a Type I-E CRISPR-Cas Nuclease with a Bacteriophage-Encoded Anti-CRISPR Protein. MBio 8.

Pinilla-Redondo, R., Shehreen, S., Marino, N.D., Fagerlund, R.D., Brown, C.M., Sørensen, S.J., Fineran, P.C., and Bondy-Denomy, J. (2020). Discovery of multiple anti-CRISPRs uncovers anti-defense gene clustering in mobile genetic elements. bioRxiv, 2020.2005.2022.110304.

Rauch, B.J., Silvis, M.R., Hultquist, J.F., Waters, C.S., McGregor, M.J., Krogan, N.J., and Bondy-Denomy, J. (2017). Inhibition of CRISPR-Cas9 with Bacteriophage Proteins. Cell 168, 150-158 e110.

Shin, J., Jiang, F., Liu, J.-J., Bray, N.L., Rauch, B.J., Baik, S.H., Nogales, E., Bondy-Denomy, J., Corn, J.E., and Doudna, J.A. (2017). Disabling Cas9 by an anti-CRISPR DNA mimic. Science Advances 3.

Song, G., Zhang, F., Zhang, X., Gao, X., Zhu, X., Fan, D., and Tian, Y. (2019). AcrllA5 Inhibits a Broad Range of Cas9 Orthologs by Preventing DNA Target Cleavage. Cell Rep 29, $2579-2589$ e2574.

Stanley, S.Y. (2018). An Investigation of Bacteriophage Anti-CRISPR and Anti-CRISPR Associated Proteins. In Department of Molecular Genetics (http://hdl.handle.net/1807/97883: University of Toronto), pp. 120. 
Uribe, R.V., van der Helm, E., Misiakou, M.A., Lee, S.W., Kol, S., and Sommer, M.O.A. (2019). Discovery and Characterization of Cas9 Inhibitors Disseminated across Seven Bacterial Phyla. Cell Host Microbe 25, 233-241 e235.

Wang, J., Ma, J., Cheng, Z., Meng, X., You, L., Wang, M., Zhang, X., and Wang, Y. (2016a). A CRISPR evolutionary arms race: structural insights into viral anti-CRISPR/Cas responses. Cell Res 26, 1165-1168.

Wang, X., Yao, D., Xu, J.G., Li, A.R., Xu, J., Fu, P., Zhou, Y., and Zhu, Y. (2016b). Structural basis of Cas3 inhibition by the bacteriophage protein AcrF3. Nat Struct Mol Biol 23, 868-870.

Watters, K.E., Fellmann, C., Bai, H.B., Ren, S.M., and Doudna, J.A. (2018). Systematic discovery of natural CRISPR-Cas12a inhibitors. Science. Watters, K.E., Shivram, H., Fellmann, C., Lew, R.J., McMahon, B., and Doudna, J.A. (2020). Potent CRISPR-Cas9 inhibitors from Staphylococcus genomes. Proc Natl Acad Sci U S A 117, 6531-6539.

Yang, H., and Patel, D.J. (2017). Inhibition Mechanism of an Anti-CRISPR Suppressor AcrllA4 Targeting SpyCas9. Mol Cell 67, $117-127$ e115.

Zhang, H., Li, Z., Daczkowski, C.M., Gabel, C., Mesecar, A.D., and Chang, L. (2019). Structural Basis for the Inhibition of CRISPR-Cas12a by AntiCRISPR Proteins. Cell Host Microbe 25, 815-826 e814.

Zhang, K., Wang, S., Li, S., Zhu, Y., Pintilie, G.D., Mou, T.C., Schmid, M.F., Huang, Z., and Chiu, W. (2020). Inhibition mechanisms of AcrF9, AcrF8, and AcrF6 against type I-F CRISPR-Cas complex revealed by cryo-EM. Proc Natl Acad Sci U S A 117, 7176-7182. 